\title{
EFFECTIVENESS OF AN ON-BODY LIFTING AID AT REDUCING LOW-BACK PHYSICAL DEMANDS DURING AN AUTOMOTIVE ASSEMBLY TASK: \\ ASSESSMENT OF EMG RESPONSE AND USER ACCEPTABILITY
}

\author{
by
}

\section{RYAN BEVAN GRAHAM}

A thesis submitted to the School of Kinesiology and Health Studies

in conformity with the requirements for

the degree of Master of Science

\author{
Queen's University \\ Kingston, Ontario, Canada
}

July, 2008

Copyright $\odot$ Ryan Bevan Graham, 2008 


\begin{abstract}
The purposes of the present work were: 1) to develop a computerized model that could predict the personal lift-assist device (PLAD) spring excursion and control spring stiffness for various individuals based on their anthropometry and working posture and 2) to test the PLAD's (Version 6) effectiveness and user acceptability during static forward bending in an automotive assembly plant. Study 1 required 30 subjects to carry out a protocol that simulated unloaded stoop, squat, and freestyle lifting. Trunk inclination and knee angles were determined via 3 Fastrak $^{\mathrm{TM}}$ sensors, whereas a displacement transducer attached in-line with the PLAD determined excursion when the trunk or knees flexed. A model was created to determine spring excursion, and it was successfully validated with 10 additional subjects. A computerized model applying the excursion model and mathematical equations was also developed to calculate the required spring stiffness for offsetting a proportion of the $\mathrm{L}_{4} / \mathrm{L}_{5}$ bending moment for each individual in various postures. Study 2 investigated the effectiveness and user acceptability of the PLAD at an automotive manufacturing facility, using operators who performed an assembly process requiring forward bending and static holds. Surface EMG data were collected at six sites on the low back and abdomen, and a tri-axial accelerometer was mounted on each subject's sternum to measure trunk inclination. A $20 \%$ reduction in the $\mathrm{L}_{4} / \mathrm{L}_{5}$ bending moment was provided to each wearer using the aforementioned computerized model. The PLAD was able to significantly reduce low back muscular activity, predictedcompression, and ratings of perceived exertion, without significantly changing abdominal activity or trunk inclination. Workers had positive opinions about the device, and $80 \%$ said they would wear the device everyday on-line. Additionally, the computerized model
\end{abstract}


developed in Study 1 was effective, as worker low back muscular activity was reduced by approximately $20 \%$ when wearing the PLAD. With slight alterations, the PLAD appears to be beneficial in reducing low back forces and discomfort in many tasks that place excessive biomechanical loading on the low back. 


\section{ACKNOWLEDGEMENTS}

Firstly, I would like to thank the Natural Sciences and Engineering Research Council (NSERC) and the Workplace Safety and Insurance Board of Ontario (WSIB) for their financial contributions to my research studies. I would also like to thank Alexis Twiddy for all of her hard work both when preparing for data collection, and when collecting data in the field. Alexis this would not have gone as smoothly without you.

Secondly, I would like to thank my supervisor Dr. Joan Stevenson and Mike Agnew for all their guidance and help throughout the entirety of this process. Joan, you are the hardest working person I know. Getting emails from you at 4 in the morning always made me laugh (and cry). Aristotle once said "What we have to learn to do, we learn by doing" and you ensure that this is true for everyone in our lab. Who knew that in order to get a Master's in Kinesiology I would have to computer program, solder, and sew among other things? Nevertheless, it has made me a better student, a better researcher, and a better person, and I am grateful. Mike, without your teaching I do not believe things would have turned out the way they did. Many of the things I have learned are the direct result of your mentoring and I truly appreciate all the help.

Next, I would like to thank my family and friends. Mom and Dad, and Adam I guess (ha), I would not be who or where I am today without your constant financial, emotional, and physical support. I love you guys. I would also like to thank the Wu's for graciously accepting me into their family. You are the most generous people I know, and Tati and I are very lucky to have you. To all my friends, thank you for making this process a lot more fun than it was stressful. All the workouts, golf games, video game 
sessions, and the occasional "beverage" made these two years a blast. It's a good thing that I managed to get my work done.

Last, but not least, I would like to thank my beautiful fiancée Tatianna Wu. Tati, you followed me here to Kingston so I could complete my degree, and I am very grateful. Thank you for always knowing how to cheer me up when I am down, calm me when I am stressed, and most importantly thank you for all the meals that you cook for me! You give me balance in this crazy world, and everyday that I spend with you is filled with laughs and good times. I can't wait to see what the future has in store for us. Everything, 我愛你. 


\section{TABLE OF CONTENTS}

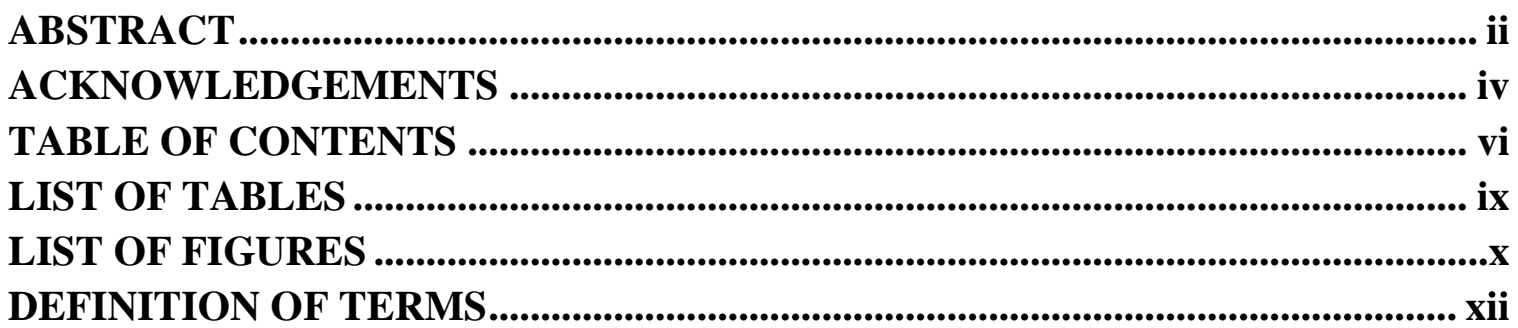

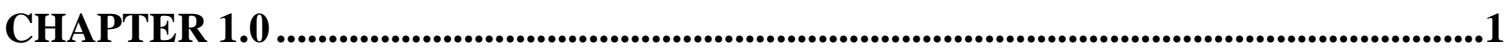

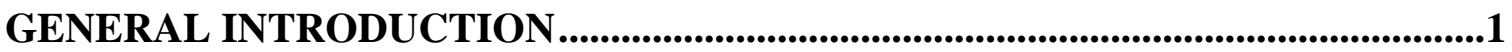

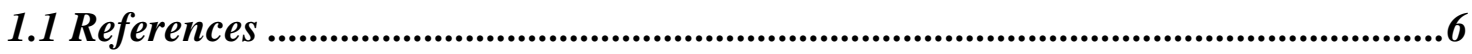

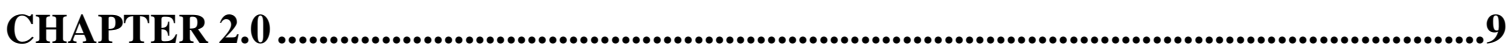

LITERATURE REVIEW ................................................................................................9

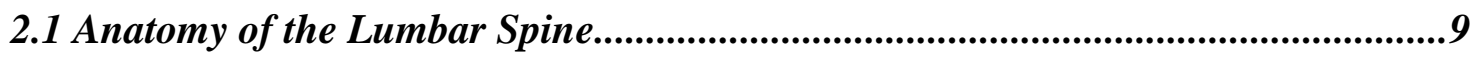

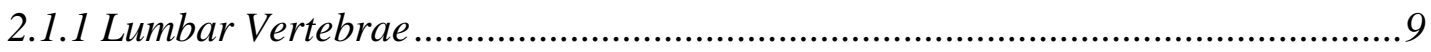

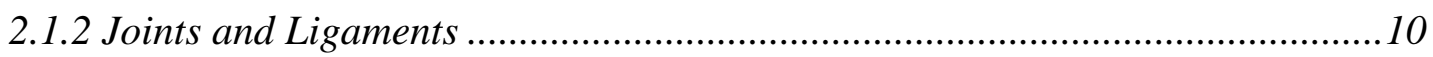

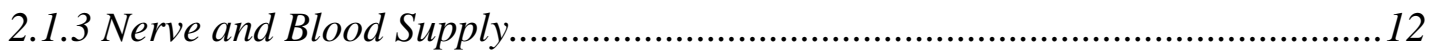

2.1.4 Low Back Muscles..................................................................................13

2.2 Spinal Loading and Injury Mechanisms.........................................................14

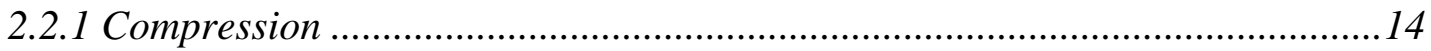

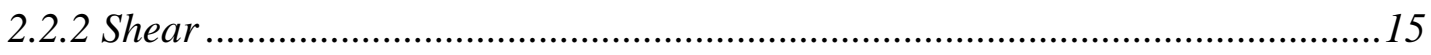

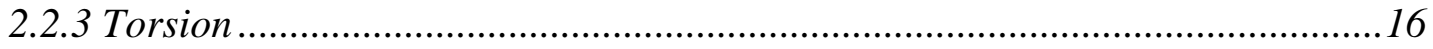

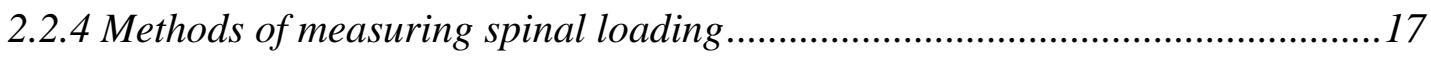

2.3 Occupational Risk Factors ...........................................................................19

2.3.1 Forward Bending and Static Holding.........................................................19

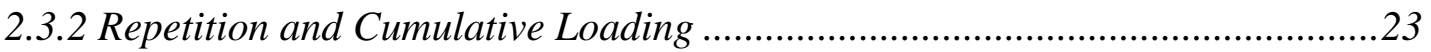

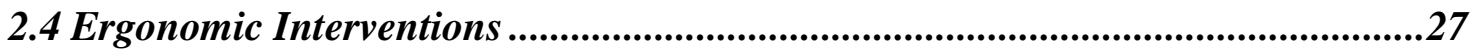

2.4.1 Ergonomic Tools and Tolerance Limit Values(TLVS) ....................................2

2.4.2 Job Rotation and Participatory Ergonomics ...................................................29

2.4.3 Materials Handling Devices (MHDs) .............................................................

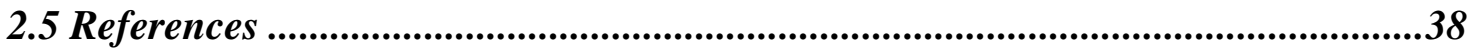

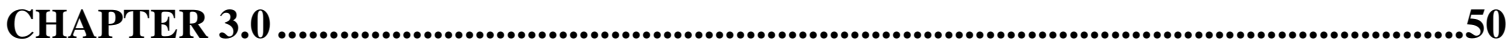
THE SELECTION OF INDIVIDUALIZED TENSIONS BASED ON EXCURSION AND ANTHROPOMETRY ..........................................................................................50

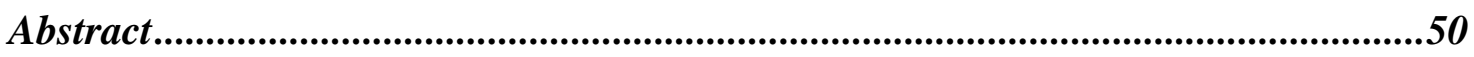

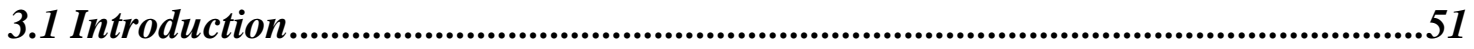

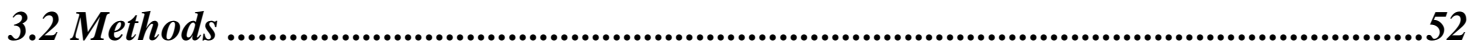




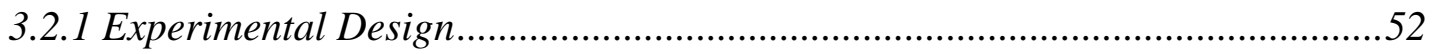

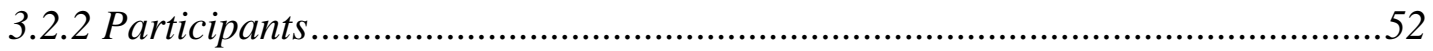

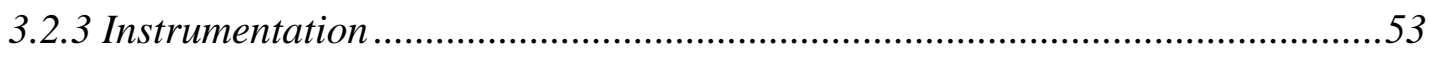

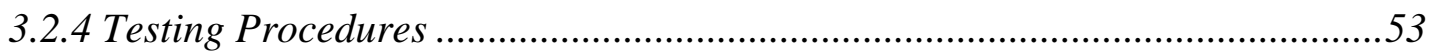

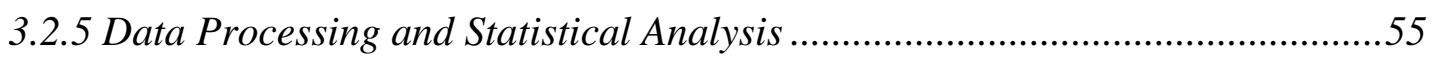

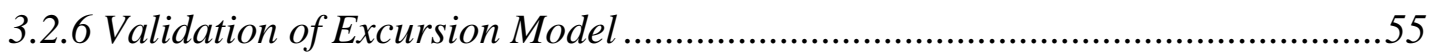

3.2.7 Calculating Spring Stiffness Requirements for Offsetting X Percentage of the

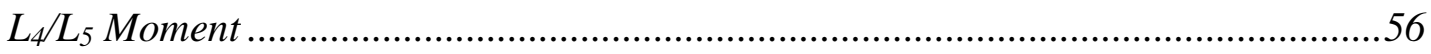

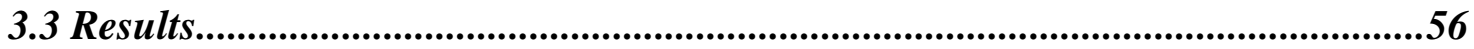

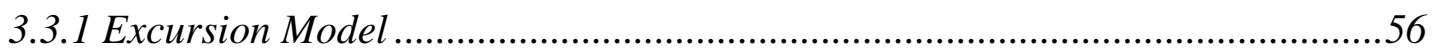

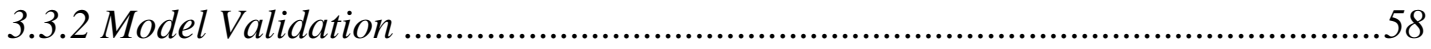

3.3.3 Custom Computer Program .......................................................................58

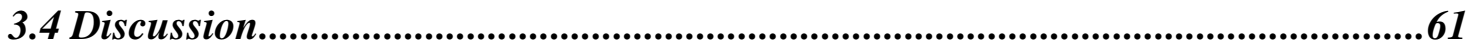

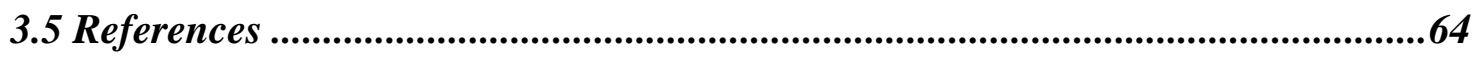

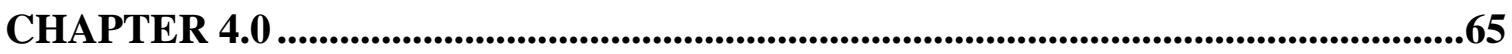

EFFECTIVENESS OF AN ON-BODY LIFTING AID AT REDUCING LOWBACK PHYSICAL DEMANDS DURING AN AUTOMOTIVE ASSEMBLY TASK: ASSESSMENT OF EMG RESPONSE AND USER ACCEPTABILITY ..................65

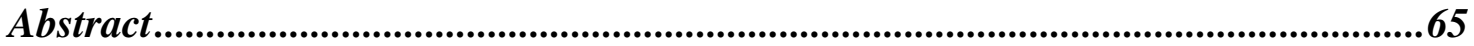

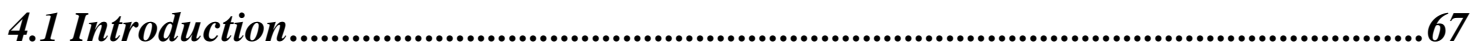

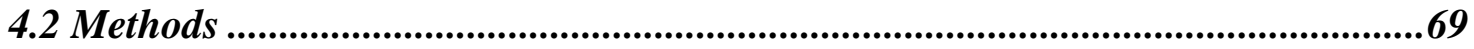

4.2.1 Experimental Design...............................................................................69

4.2.2 Participants ........................................................................................69

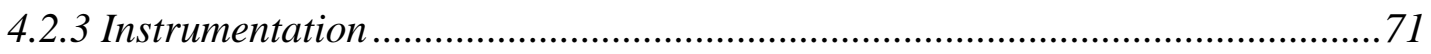

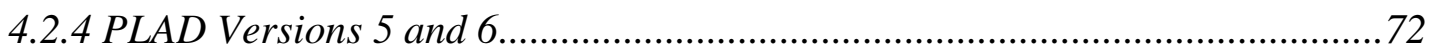

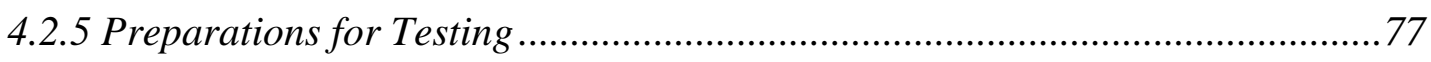

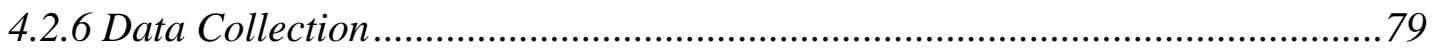

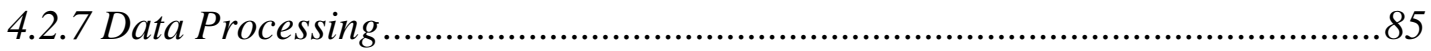

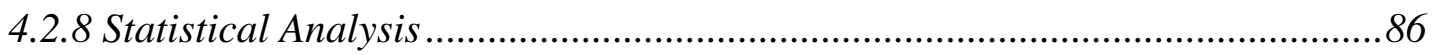

4.3 Results...................................................................................................................89

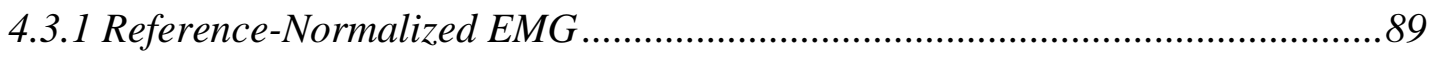

4.3.2 Compression-Normalized EMG $(C N E M G)$...................................................

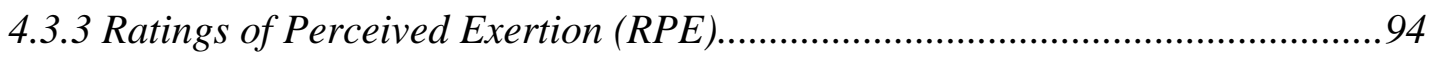

4.3.4 Trunk Inclination Angle .........................................................................96

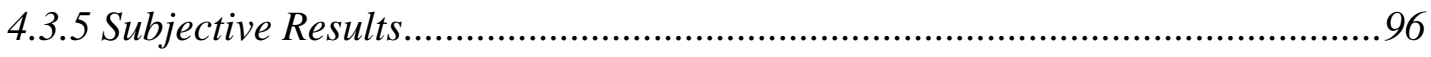

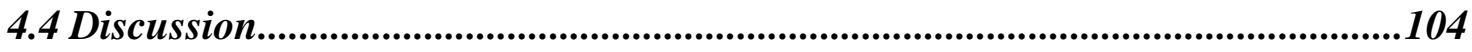

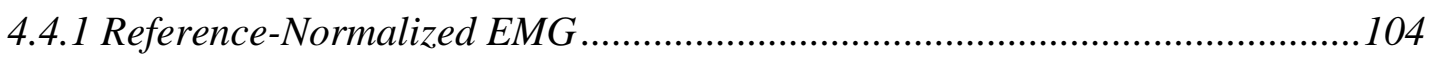

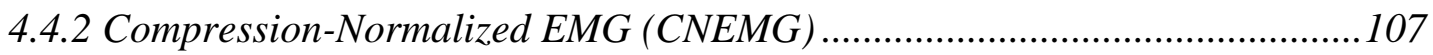

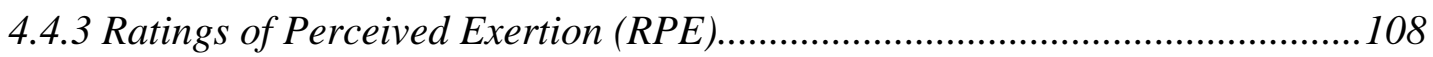

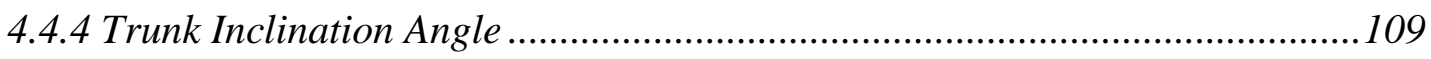




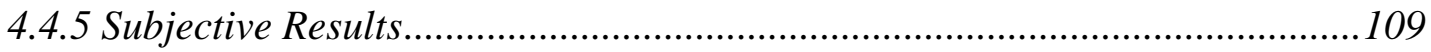

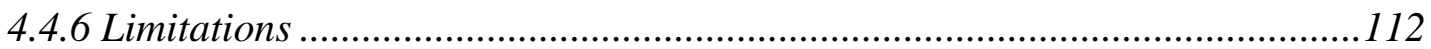

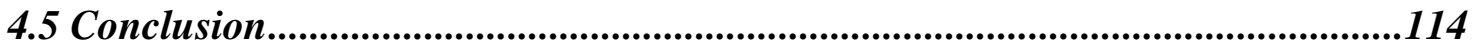

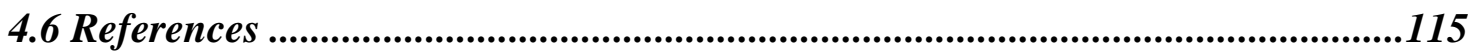

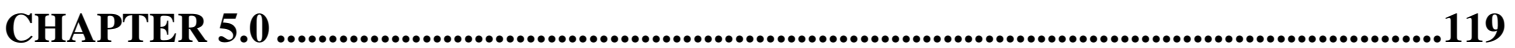

GENERAL DISCUSSION ........................................................................................119

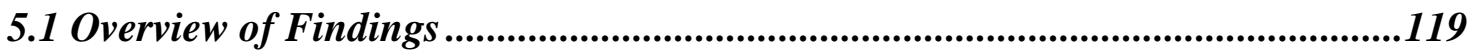

5.2 Relevance to Industry...............................................................................................121

5.3 Other Areas Where the PLAD May be Useful ...................................................122

5.4 Future Research ...................................................................................................122

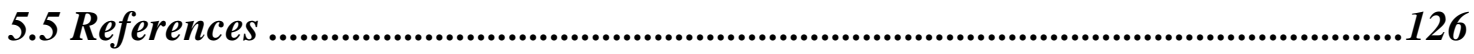

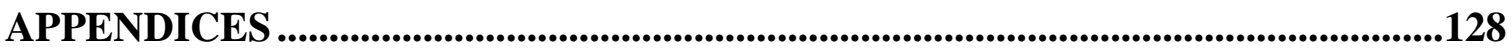

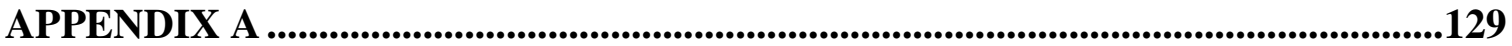

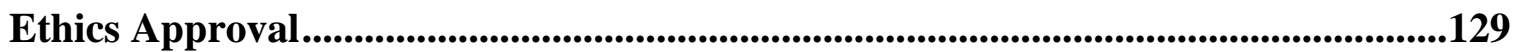

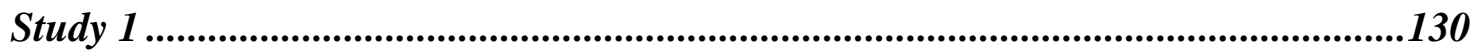

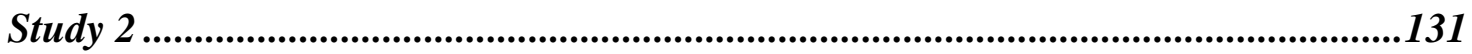

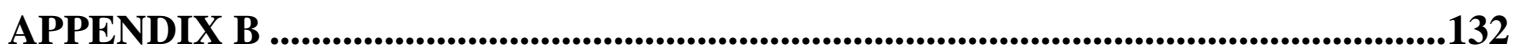

Written Consent .................................................................................................................132

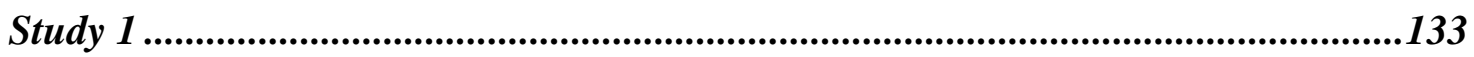

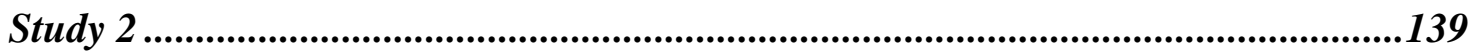

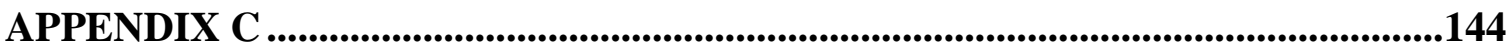

Automotive Assembly Job Task Details...........................................................................144

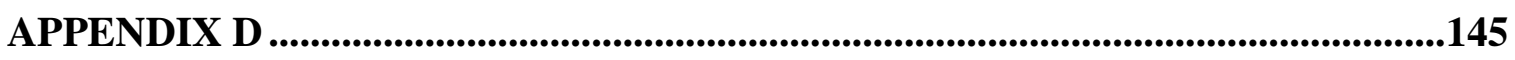

Sample Size Power Calculation ........................................................................................145

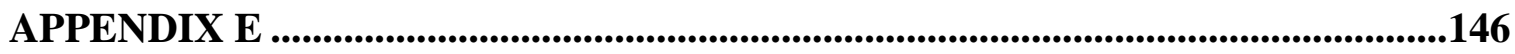

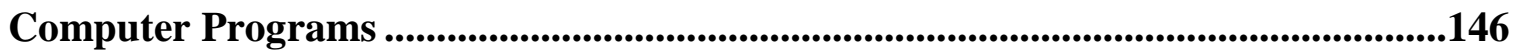

Labview 8.0 Electromyography (EMG) Processing Program ....................................147

Labview 8.0 Angle Processing Program ...................................................................148

Matlab R2007a Spring Optimization Program .........................................................149

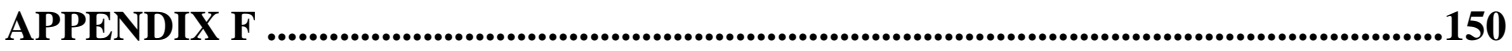

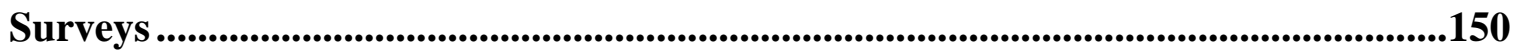

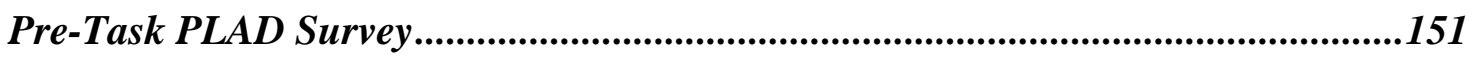

During-Task PLAD Survey ...................................................................................153

Post-Task PLAD Survey .......................................................................................154

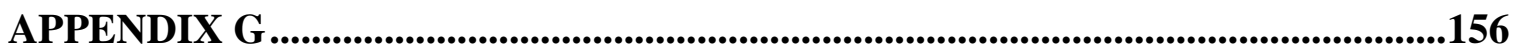

Root Mean Squared (RMS) Difference: Filtered and Non-Filtered Data .................156

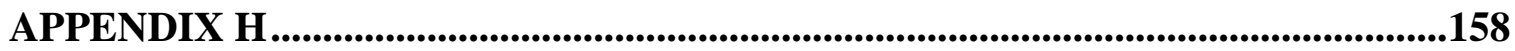

Trial 1-12 (Time) Difference: ANOVA Results for Thoracic Erector Spinae...........158 


\section{LIST OF TABLES}

\section{CHAPTER 3.0 \\ THE SELECTION OF INDIVIDUALIZED TENSIONS BASED ON EXCURSION AND ANTHROPOMETRY}

Table 3.1. Spring excursion model coefficients, standard error, and significance values

CHAPTER 4.0

EFFECTIVENESS OF AN ON-BODY LIFTING AID AT REDUCING LOWBACK PHYSICAL DEMANDS DURING AN AUTOMOTIVE ASSEMBLY TASK: ASSESSMENT OF EMG RESPONSE AND USER ACCEPTABILITY

Table 4.1. A PLAD feature decision matrix created by Queen's University and the automotive manufacturing company. 73

Table 4.2. Inputs and outputs from the customized computer program for determining the required spring stiffness for offloading $20 \%$ of each subject's $\mathrm{L}_{4} / \mathrm{L}_{5}$ moment................ 78

Table 4.3. The measured voltages from the $\mathrm{Y}$ and $\mathrm{Z}$ accelerometer axes at a series of inclinations from 0-90 degrees. 81

Table 4.4. Calculated compression values (Newtons) for electromyographical (EMG) normalization for all 10 subjects on the two testing days 84

Table 4.5. Differences between the No-PLAD and PLAD conditions and results of the two-way repeated measures ANOVA

Table 4.6. Borg scale ratings of perceived exertion (RPE) for the 10 automotive operators under the two testing conditions

Table 4.7. Trunk inclination angles (Degrees) for the 10 automotive operators under the two testing conditions 98

Table 4.8. Pre-task baseline survey results for the 10 automotive operators................... 99

Table 4.9. During-task questionnaire results for the 10 automotive operators 101

Table 4.10. Post-task PLAD user acceptability survey results for the 10 automotive operators 102

Table 4.11. Post-task user acceptability responses (direct quotes) for the 10 automotive operators. 103 


\section{LIST OF FIGURES}

\section{CHAPTER 2.0}

\section{LITERATURE REVIEW}

Figure 2.1. Three on-body materials handling devices; a) The Happyback, b)The Bendezy, and c) BNDR.

Figure 2.2. PLAD design iterations from Version 1 (a) to Version 4 (d)........................ 37

\section{CHAPTER 3.0}

THE SELECTION OF INDIVIDUALIZED TENSIONS BASED ON EXCURSION AND ANTHROPOMETRY

Figure 3.1. In-lab setup for determining spring length changes due to trunk inclination and knee flexion using Fastrak ${ }^{\mathrm{TM}}$ sensors (a) and a displacement transducer (b, c), and the two-way moveable pulley located inside the PLAD (d) 54

Figure 3.2. Actual versus model-predicted spring excursion measurements $(\mathrm{cm})$ with trend-line for all ten subjects.

Figure 3.3. Custom "Spring Stiffness Calculator" program developed within Labview Version 8.0. 60

\section{CHAPTER 4.0}

EFFECTIVENESS OF AN ON-BODY LIFTING AID AT REDUCING LOWBACK PHYSICAL DEMANDS DURING AN AUTOMOTIVE ASSEMBLY TASK: ASSESSMENT OF EMG RESPONSE AND USER ACCEPTABILITY

Figure 4.1. The automotive assembly task done without (a) and with (b) the PLAD...... 70

Figure 4.2. The finalized PLAD (Version 6) and its features from three different camera angles.

Figure 4.3. Custom-developed spring mount device (to scale) used within the PLAD... 76

Figure 4.4. The accelerometer calibration jig used to determine the $\mathrm{Y}$ and $\mathrm{Z}$ axis voltages at a series of inclination angles $\left(0-90^{\circ}\right)$ 80

Figure 4.5. The reference posture used for electromyographical (EMG) normalization, as well as the biomechanical model used for determining spinal compression. 83

Figure 4.6. A flow chart of the electromyography (EMG) processing technique. 87

Figure 4.7. A trunk inclination angle versus time curve for one car during the automotive assembly task..... 88 
Figure 4.8. An example of the relationship between the trunk inclination angle and the amplitude probability distribution function (APDF) percentiles................................... 91

Figure 4.9. A time of sample versus reference-normalized electromyographical activation graph......

Figure 4.10. Electromyographical (EMG) activation as a percentage of reference contraction for thoracic (T) and lumbar (L) erector spinae (ES), and rectus abdominus (RA) at three amplitude probability distribution function (APDF) percentiles. 93

Figure 4.11. Compression-normalized electromyography (EMG) for thoracic (T) and lumbar (L) erector spinae (ES) at three amplitude probability distribution function

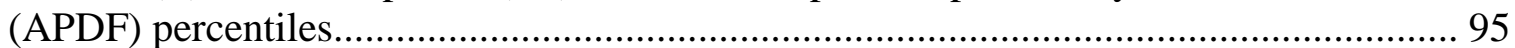




\section{DEFINITION OF TERMS}

\begin{tabular}{|c|c|}
\hline 2-D & Two-Dimensional \\
\hline 3-D & Three-Dimensional \\
\hline $\mathbf{A F}$ & Annulus Fibrosus \\
\hline ANOVA & Analysis of Variance \\
\hline $\mathbf{A P}$ & Antero-Posterior \\
\hline APDF & Amplitude Probability Distribution Function \\
\hline CI & Confidence Interval \\
\hline CNEMG & Compression-normalized EMG \\
\hline CNS & Central Nervous System \\
\hline $\mathbf{C}_{\mathbf{X}}$ & Cervical Vertebrae X \\
\hline DC & Direct Circuit \\
\hline EO & External Oblique \\
\hline ES & Erector Spinae \\
\hline EMG & Electromyography \\
\hline $\mathbf{H z}$ & Hertz \\
\hline IO & Internal Oblique \\
\hline I-V & Intervertebral \\
\hline $\mathbf{L}_{1-5}$ & Lumbar Vertebrae 1-5 \\
\hline LES & Lumbar Erector Spinae \\
\hline LBD & Low Back Disorders \\
\hline LBP & Low Back Pain \\
\hline LSM & Linked-Segment Model \\
\hline MHD & Materials Handling Device \\
\hline MHT & Maximum Holding Time \\
\hline MSD & Musculoskeletal Disorders \\
\hline $\mathbf{N N}$ & Neural Network \\
\hline NP & Nucleus Pulposus \\
\hline OR & Odds Ratio \\
\hline PE & Participatory Ergonomics \\
\hline PLAD & Personal Lift-Assist Device \\
\hline $\mathbf{R}$ & Pearson's Coefficient \\
\hline $\mathbf{R}^{2}$ & Coefficient of Determination \\
\hline $\mathbf{R A}$ & Rectus Abdominus \\
\hline RPE & Ratings of Perceived Exertion \\
\hline RF & Risk Factors \\
\hline RMS & Root Mean Squared \\
\hline SD & Standard Deviation \\
\hline TES & Thoracic Erector Spinae \\
\hline TLV & Tolerance Limit Value \\
\hline Trunk Inclination & Trunk Flexion Angle from the Vertical $\left(0^{\circ}\right)$ \\
\hline $\mathbf{T}_{1-12}$ & Thoracic Vertebrae 1-12 \\
\hline WTD & Weight Transfer Device \\
\hline
\end{tabular}




\section{CHAPTER 1.0}

\section{GENERAL INTRODUCTION}

Musculoskeletal disorders (MSD) are a significant problem affecting hundreds of millions of people around the world, and are thus imposing a major burden on individuals, health systems, and social care systems (Woolf \& Pfleger, 2003). Based on data from the United States, Canada, and Finland, MSD are the most common cause of global long-term pain and disability, with more workers disabled from them than from any other disorder (Bernard, 1997). Low back disorders (LBD), including low back pain (LBP), have an estimated lifetime prevalence of $49 \%-84 \%$ in industrialized countries (van Tulder et al., 2002; Walker, 2000) and a point prevalence of 4\%-33\% of the global population (Papageorgiou et al., 1996; van Tulder et al., 2002; Woolf \& Pfleger, 2003). LBD are associated with considerable financial costs and loss of quality of life (Punnett et al., 2005): the direct care and costs of LBD was \$26.3 billion in 1998 in the U.S. alone (Luo et al., 2004). In a recent German study examining the comorbidity of LBP, it was determined that, of 31 examined morbidities, all were more common in subjects with LBP than in those without (Schneider et al., 2007). For the aforementioned reasons, causes, symptoms, and remediation of LBD have been examined extensively in the literature.

The causes of LBD and LBP are multi-factorial in nature: occurence has been linked with previous episodes of LBP, health and lifestyle influences, physical attributes, cultural influences, psychological and psychosocial issues, and occupational factors (Davis \& Heaney, 2000; Marras, 2000; Stevenson et al., 2001; Woolf \& Pfleger, 2003). In a recent study examining the global burden of LBP by Punnett et al. (2005), it was 
discovered that $37 \%$ of LBP is directly attributable to occupational risk factors (RF), with a twofold variation across geographical regions with varying cultural backgrounds. Moreover, it was found that men are more likely to develop LBP due to their higher presence in the labour force and the physical nature of their occupations. It is evident from these statistics that the study of occupationally related LBD is very important in reducing prevalence and associated costs. Epidemiologic studies and reviews have identified occupationally-related RF for LBD in a variety of industries, including the automotive industry where quality, efficiency, and productivity are essential. These RF include: heavy physical work and manual materials handling, lifting and forceful movements, whole-body vibration, psychosocial factors such as job satisfaction, awkward postures such as bending and twisting, static work postures, and repetition and cumulative loading (Bernard, 1997; Davis \& Heaney, 2000; Marras et al., 1995; Norman et al., 1998). The single largest RF has been shown to be lifting (Bigos et al., 1986).

Under realistic work conditions, loading of the spine happens in three-dimensional (3-D) space in three different ways: compression, shear, and torsion (Marras, 2000). During lifting and forward bending, the center of gravity of the trunk is anterior to the lumbar region, causing a large sagittal plane moment on the osteoligamentous structures of the lumbar spine (Bonato et al., 2003). In order to balance the moment, large extensor muscle forces are applied to the posterior elements of the spine, which cause large compressive and shear forces in the disc (Kumar, 1999). Spinal loading is further increased due to gravity, inertial motion, external loads, tensile forces, and twisting (Bazrgari et al., 2006; van Dieen et al., 1999). Moreover, an individual's tolerance to spinal loading is dependent on: frequency, posture, hydration, genetics, ageing, and 
individual anatomical variations (Marras, 2000). Most injuries are thought to be a result of strains or tears to connective or contractile tissues, disc bulging or ruptures, or injury to the joints (Ferguson \& Marras, 1997).

With the realization that LBD have become a global problem and the findings that occupational RF play a significant role in LBD causation, worker low back safety has become a critical focus in many industries. Ergonomic interventions such as job rotation, participatory ergonomics, and materials handling devices (MHD's) have become increasingly popular as ergonomists and job designers attempt to make jobs easier on workers' low backs and musculoskeletal systems (Chaffin et al., 1999). The goal of each intervention is the same: reduce the load (acute or cumulative) that individuals' muscles and low backs must bear throughout the workday. One such MHD was developed at Queen's University and is known as the personal lift-assist device (PLAD) ${ }^{1}$ (Abdoli-E, 2005).

The PLAD functions by reducing the muscular requirement of the erector spinae for tasks involving lifting, lowering, and static holding when the trunk is in forward flexion. The PLAD is an external 'on-body' device that involves an external element positioned nearly parallel to the erector spinae muscles in the back (Abdoli-E, 2005). This element provides a mechanical advantage at $\mathrm{L}_{4} / \mathrm{L}_{5}$ and the hip joints by adding a large external moment arm, while at the same time transferring the forces on the lumbar spine to the shoulders, pelvic girdle, and feet. During PLAD-assisted lifting, the elements stretch during the down phase and return their stored energy during the up phase, thus decreasing muscular demand. During PLAD-assisted static holding, the elements'

\footnotetext{
${ }^{1}$ PLAD's name was changed from "Personal Lift Augmentation Device" to "Personal Lift-Assist Device" in 2006.
} 
stiffness provides a restorative moment that offsets a portion of the moment created as a result of the upper body weight and external load, once again reducing muscular requirements (Abdoli-E, 2005).

Abdoli-E et al. (2007) have shown that, depending on lifting technique and load, the PLAD provided an added torque of $23-26 \mathrm{Nm}$ to assist the back muscles during lifting tasks, which resulted in a reduction in spinal compression and shear. For these same lifting tasks, the PLAD significantly reduced the integrated electromyographic (iEMG) activity of two erector spinae (ES) sites $\left(\mathrm{L}_{3}\right.$ and $\mathrm{T}_{9}$ ) by $14.4 \%-27.5 \%$ (Abdoli-E et al., 2006). Similar results were shown for women (Stevenson et al., 2007) and for asymmetrical lifting (Abdoli-E \& Stevenson, 2008). Moreover, Lotz et al. (2008), who studied muscular fatigue during a 45-minute continuous lifting task in men, found that the PLAD was effective at decreasing the onset and level of muscular fatigue in the back muscles. Beneficial and significant differences were also found in the PLAD conditions for ratings of perceived exertion (RPE), maximum endurance holding time (MHT), and erector spinae $\left(\mathrm{L}_{3}\right.$ and $\left.\mathrm{T}_{9}\right)$ EMG median frequency and amplitude.

These results provide convincing evidence that the PLAD is effective at reducing low back muscular demand and spinal loading in a laboratory setting during lifting tasks. However, previous studies involving the PLAD have not attempted to keep the assistance of the device relatively constant across individuals, leading to large variability between subjects. Thus, the first purpose of the present work was to develop "sizing" equations to control for spring support based on body posture and anthropometry. It was hypothesized that a mathematical model could accurately predict the required spring stiffness for offsetting a given percentage of a wearer's low back moment. 
New research is also required because the benefits of the PLAD have yet to be proven for static holding tasks, and effectiveness and user acceptability remains to be demonstrated in an industrial setting. Furthermore, the current version of the PLAD (Version 6), which is enclosed in a coverall-like suit, uses springs instead of rubber band elements, and possesses a shorter moment arm than previous versions, has yet to be tested scientifcally. Therefore, the primary purpose of the present study was to test the PLAD's (Version 6) effectiveness and user acceptability during static forward bending in an automotive assembly plant. It was hypothesized that findings would be similar to results calculated in the laboratory, whereby the PLAD was effective at significantly reducing erector spinae muscle activity and ratings of perceived exertion (Abdoli-E et al., 2006; Lotz et al., 2008). Moreover, it was hypothesized that PLAD users would feel the device's support and want to use it when working. A further hypothesis was that the EMG reductions when wearing the PLAD would be equivalent to the amount of support preplanned for each individual based on a mathematical model determination. 


\subsection{References}

Abdoli-E, M. (2005). Design and instrumentation of a dynamic mechanical personal lift augmentation device (PLAD) for manual lifting tasks. PhD Dissertation, Queen's University, Kingston, Ontario, Canada.

Abdoli-E, M., \& Stevenson, J. (2008). The effect of on-body lift assistive device on the lumbar 3-D dynamic moments and EMG during assymetric freestyle lifting. Clinical Biomechanics , 23, 372-380.

Abdoli-E, M., Agnew, M., \& Stevenson, J. (2006). An on-body personal lift augmentation device (PLAD) reduces EMG amplitude of erector spinae during lifting tasks. Clinical Biomechanics , 21, 456-465.

Abdoli-E, M., Stevenson, J., Reid, S., \& Bryant, T. (2007). Mathematical and empirical proof of principle for an on-body personal lift augmentation device. Journal of Biomechanics , 40, 1694-1700.

Bazrgari, B., Shirazi-Adl, A., \& Arjmand, N. (2006). Load distribution between spinal active-passive systems in squat and stoop dynamic lifts. Spine, S101.

Bernard, B. (1997). Musculoskeletal disorders and workplace factors: A critical review of epidemiologic evidence for work-related musculoskeletal disorders of the neck, upper extremity, and low back. Cincinatti, $\mathrm{OH}$ : Department of Health and Human Services, National Institute for Occupational Health and Safety.

Bigos, S., Spengler, D., Martin, N., Zeh, J., Fisher, L., Nachemson, A., \& Wang, M.H. (1986). Back Injuries in Industry: A retrospective Study II: Injury Factors. Spine , 11 (3), 246-251.

Bonato, P., Ebenbichler, G., Roy, S., Lehr, S., Posch, M., Kollmitzer, J., \& Della Croce, U. (2003). Muscle fatigue and fatigue-related biomechanical changes during a cyclic lifting task. Spine , 28 (16), 1810-1820.

Chaffin, D., Stump, B., Nussbaum, M., \& Baker, G. (1999). Low-back stresses when learning to use a materials handling device. Ergonomics , 42 (1), 94-110.

Davis, K., \& Heaney, C. (2000). The relationship between psychosocial work characteristics and low back pain: underlying methodological issues. Clinical Biomechanics , 15, 389-406.

Ferguson, S., \& Marras, W. (1997). A literature review of low back disorder surveillance and risk factors. Clinical Biomechanics , 12 (4), 211-226.

Kumar, S. (1999). Biomechanics in Ergonomics (1st ed.). London: Taylor and Francis. 
Lotz, C., Agnew, M., Godwin, A., \& Stevenson, J. (2008). The effect of an on-body personal lift-assist device (PLAD) on fatigue during a repetitive lifting task. Journal of Electromyography and Kinesiology, In Press.

Luo, X., Pietrobon, R., Sun, S., Liu, G., \& Hey, L. (2004). Estimates and patterns of direct health care expenditures among individuals with back pain in the United States. Spine , 29, 79-86.

Marras, W. (2000). Occupational low back disorder causation and control. Ergonomics, 43 (7), 880-902.

Marras, W., Lavender, S., Leurgans, S., Fathallah, F., Ferguson, S., Allread, W., \& Rajulu, S.L. (1995). Biomechanical risk factors for occupationally related low back disorders. Ergonomics , 38 (2), 377-410.

Norman, R., Wells, R., Neumann, P., Frank, P., Shannon, H., \& Kerr, M. (1998). A comparison of peak vs cumulative physical work exposure risk factors for the reporting of low back pain in the automotive industry. Clinical Biomechanics , 13, 561-573.

Papageorgiou, A., Croft, P., Thomas, E., Ferry, S., Jayson, M., \& Silman, A. (1996). Influence of previous pain experience on the episode incidence of low back pain: results from the South Manchester Back Pain Study. Pain , 66 (2-3), 181-185.

Punnett, L., Pruss-Ustun, A., Imel Nelson, D., Fingerhut, M., Leigh, J., Tak, S., \& Phillips, S. (2005). Estimating the global burden of low back pain attributable to combined occupational exposures. American Journal of Industrial Medicine , 48, 459469.

Schneider, S., Mohnen, S., Schiltenwolf, M., \& Rau, C. (2007). Comorbidity of low back pain: Representative outcomes of a national health study in the Federal Republic of Germany. European Journal of Pain , 11, 387-397.

Stevenson, J., Weber, C., Smith, J., Dumas, G., \& Albert, W. (2001). A longitudinal study of the development of low back pain in an industrial population. Spine , 26 (12), 13701377.

van Dieen, J., Hoozemans, M., \& Toussaint, H. (1999). Stoop or squat: a review of biomechanical studies on lifting technique. Clinical Biomechanics , 14, 685-696.

van Tulder, M., Koes, B., \& Bombardier, C. (2002). Low back pain. Best Practice and Research in Clinical Rheumatology, 16 (5), 761-775.

Walker, B. (2000). The prevalence of low back pain: systematic review of the literature from 1966 to 1998. Journal of Spine Disorders , 13, 205-217. 
Woolf, A., \& Pfleger, B. (2003). Burden of major musculoskeletal conditions. Bulletin of the World Health Organization , 81 (9), 646-656. 


\section{CHAPTER 2.0}

\section{LITERATURE REVIEW}

\subsection{Anatomy of the Lumbar Spine}

\subsubsection{Lumbar Vertebrae}

The lumbar vertebral column consists of five vertebrae, each composed of two parts: the vertebral body and the neural arch (Adams, 2004). The vertebral body lies anteriorly and consists of a large kidney-bean-shaped block of bone whose dimensions gradually increase from cephalad to caudal (Ebraheim et al., 2004). Vertebral bodies are designed to resist large axial compressive forces and deliver nutrients to the intervertebral (I-V) discs via nutrient foramina (Adams, 2004; Bogduk, 2004). The outer wall of each vertebral body is composed of relatively stiff cortical bone, whereas the smooth top and bottom, known as end plates, are made from deformable cartilage (McGill, 2002). End plates are approximately $0.6 \mathrm{~mm}$ thick and are thinnest in the central region (Roberts et al., 1989). The inside of each vertebral body is composed of sponge-like cancellous bone in a unique arrangement: the bone possesses strong and lightweight vertical and transverse struts (trabeculae), which are essential in shock absorbing and load bearing (Amling et al., 1996; Bogduk, 2004; McGill, 2002). When compressed, the vertebral walls remain rigid, whereas the disc's nucleus pressurizes, causing the end plates to bulge inward and compress the deformable cancellous bone (McGill, 2002).

The neural arch is located posteriorly to the vertebral body and consists of two pedicles that project from the superior postero-lateral surface of the body and join a pair of fused laminae, thus creating the vertebral foramen (Ebraheim et al., 2004). The vertebral foramen is triangular in shape and protects the spinal cord in a ring of bone 
(Adams, 2004). Inferior and superior articular processes extend from each lamina, and there is a smooth area of bone on the medial and lateral surfaces of the superior and inferior articular processes respectively (Bogduk, 2004). These smooth areas are known as articular facets; when two lumbar vertebrae are placed on top of each other, the inferior and superior articular facets lock together to form a facet joint, which resists forward sliding and twisting of the vertebral bodies (Bogduk, 2004; Kalichman \& Hunter, 2007). Projecting posteriorly from the junction of the two laminae is the spinous process, whereas projecting laterally from the junction of each lamina and pedicle are the transverse processes (Bogduk, 2004). Posterior spinal elements also possess a shell of cortical bone with a cancellous bony core; the trabecular structure of the vertebral body extends posteriorly into the neural arch and tolerates both tension and bending forces here (Bogduk, 2004; McGill, 2002).

\subsubsection{Joints and Ligaments}

Three joints are formed when any two lumbar vertebrae are placed together: the I$\mathrm{V}$ disc anteriorly, and the aforementioned zygapophyseal (facet) joints posteriorly (Ebraheim et al., 2004). I-V discs separate adjacent vertebral bodies and possess three major components: the nucleus pulposus (NP), annulus fibrosus (AF), and vertebral end plates (Adams, 2004). The NP is a "toothpaste-like" semi-fluid mass of mucoid material composed of $70-90 \%$ water (this percentage decreases with age), proteoglycans, collagen fibrils, cartilage cells, and other proteins (Bogduk, 2004). Conversely, the AF is composed primarily of highly ordered collagenous fibres arranged in approximately 10 to 20 sheets called lamellae (Taylor, 1990). The lamellae are arranged obliquely in concentric rings at about $65-70^{\circ}$ from vertical (Hickey \& Hukins, 1980), and the 
peripheral fibres insert into the vertebral end plates (Ebraheim et al., 2004). There is no distinct boundary between the NP and AF; the peripheral parts of the nucleus merge with deeper annular fibres (McGill, 2002). I-V discs allow small movements between vertebrae and distribute compressive loading evenly on the vertebral bodies. During flexion/extension and forward bending, the nucleus, annulus, and end plates work together to support compressive loads; the nucleus behaves like a pressurized fluid and generates hydraulic forces on the end plates vertically and tensile stresses on the annulus horizontally, which are absorbed (Adams, 2004). Facet joints are true synovial joints, containing hyaline cartilage, synovial membranes, fibrous capsules, joint cavities, and meniscoids (Kalichman \& Hunter, 2007). The lumbar facet joints are oriented more vertically (approximately $170^{\circ}$ to vertical in the sagittal plane) than those in other spinal sections (Panjabi et al., 1993); this is important as these joints resist horizontal forces acting on the lumbar spine and protect lumbar discs from excessive shear and torsion, thus increasing spinal stability (Adams et al., 2002).

Several ligaments play an important role in spinal stabalization (Sharma et al., 1995). Lumbar vertebrae join to create the spinal column via the anterior and posterior longitudinal ligaments, which have bony attachments to the vertebral bodies and collagenous attachments to the $\mathrm{L}_{1}-\mathrm{L}_{5}$ discs (McGill, 2002). Their primary functions are to prevent separation of the anterior and posterior ends of the vertebral bodies, thus limiting spinal extension and flexion (Bogduk, 2004). The ligamentum flavum is a short, thick and primarily elastic ( $80 \%$ elastin) ligament that joins the laminae of consecutive vertebrae (Yahia et al., 1990). Ligamentum flavum's specific function is debatable; however, it has been hypothesized that it acts as a barrier to material that could buckle and impinge 
nervous structures located directly beside it (Bogduk, 2004; McGill, 2002). Ligamentum flavum is also involved in resisting trunk flexion (Gillespie \& Dickey, 2004). The interspinous and supraspinous ligaments are the posterior ligaments of the spinal column, connecting the spinous processes with one another (Ebraheim et al., 2004). Each possesses individual fibres that resist flexion moments and share interacting fibres that are important; together, the suprapinous/interspinous complex was found to be the largest contributor to the resistance of flexion motion (35.9\%) (Gillespie \& Dickey, 2004).

\subsubsection{Nerve and Blood Supply}

There are 11 pairs of spinal nerves in the lumbar region: 5 lumbar, 5 sacral and 1 coccygeal; each nerve consists of ventral and dorsal roots that leave and enter the spinal cord respectively (Ebraheim et al., 2004). Each spinal nerve emerges from under its respective vertebrae, exits the intervertebral foramen, and splits into a large ventral ramus and a small dorsal ramus (Bogduk, 2004; Ebraheim et al., 1997). The ventral rami are long and run infero-laterally in the lumbar region to form the lumbar and sacral plexuses; these large plexuses supply nerves to the lower extremeties (Gray, 1974). Conversely, the dorsal rami run posteriorly to supply the spinal ligaments, muscles, and skin of the back (Ebraheim et al., 2004).

Arterial and venous supply of the lumbar spine is very complex. A pair of lumbar arteries arise from the back of the aorta in front of $\mathrm{L}_{1}$ to $\mathrm{L}_{4}$; the lumbar artery at $\mathrm{L}_{5}$ comes from the median sacral artery (Ratcliffe, 1980). Each lumbar artery passes around its respective vertebral body and branches many times once it reaches the intervertebral foramina to supply the following: the abdominal wall, back muscles, neural arches, vertebral bodies, paravertebral muscles, spinal ligaments, and the $\mathrm{L}_{1}-\mathrm{L}_{5}$ discs (Bogduk, 
2004). Lumbar veins accompany the arteries around the vertebral bodies and drain into the inferior vena cava (Bogduk, 2004).

\subsubsection{Low Back Muscles}

Muscles that surround the lumbar spine can generally be divided into groups depending on where they are located. The lateral or antero-lateral muscles of the low back include psoas major and quadratus lumborum (Ebraheim et al., 2004). Psoas arises from the antero-lateral aspect of the lumbar spine and crosses over the ileum to insert on the femur's lesser trochanter; the quadratus lumborum is a rectangular-shaped muscle joining the $12^{\text {th }}$ rib and first four lumbar vertebrae to the iliac crest and the $\mathrm{L}_{5}$ transverse process (Stokes \& Gardner-Morse, 1999). The primary action of the psoas is flexion of the hip (Bogduk, 2004); however, it is also a major stabilizer of the lumbar spine (McGill, 2002). Quadratus lumborum is also highly involved in spinal stabilization and assists in trunk extension, lateral flexion, and respiration (Kendall et al., 2005).

The posterior lumbar spine muscles can be divided into superficial, intermediate, and deep layers (Ebraheim et al., 2004). The most superficial layer consists of the thick and strong thoracolumbar (or lumbodorsal) fascia, which may work in conjunction with attached abdominal and back muscles to stabilize the lumbar spine (McGill, 2002). The intermediate layer is made up of serratus posterior inferior, whereas the deep layer consists of the vertically oriented erector spinae (ES) muscles (Ebraheim et al., 2004). The ES exist in three distinct columns: spinalis medially, longissimus centrally, and iliocostalis laterally (Kendall et al., 2005). Spinalis is the smallest of the erector spinae muscles and can be divided into spinalis thoracis, spinalis cervicis, and spinalis capitis; longissimus is the largest and can be divided into longissimus thoracis, longissimus 
cervicis, and longissimus capitis; iliocostalis can be divided into iliocostalis lumborum, iliocostalis thoracis, and iliocostalis cervicis (Bogduk, 2004; Kendall et al., 2005). The part of ES that transmits force over the lumbar spine consists of iliocostalis lumborum and longissimus thoracis (Bogduk, 2004; Bogduk, 1980). These muscles are powerful lumbar spine extensors; both originate over the posterior sacrum and medial iliac crest, and both possess pars lumborum and pars thoracis fibres ${ }^{2}$. Even deeper than the ES are several short muscles known as semispinalis, multifidi, and rotators; these muscles route in an oblique direction between the transverse and spinous processes of the spine (Ebraheim et al., 2004). Their functions include extension, lateral bending, and rotation of the spine (Kendall et al., 2005).

\subsection{Spinal Loading and Injury Mechanisms}

\subsubsection{Compression}

Compressive loading on the lumbar spine acts down the longitudinal axis, perpendicular to the $\mathrm{L}_{1}-\mathrm{L}_{5}$ discs, and is primarily the result of tension in the vertically oriented extensor muscles in the back caused by lifting or forward bending (Dolan et al., 1994). These muscles include both the thoracic and lumbar components of iliocostalis lumborum and longissimus thoracis (McGill, 2002). The spinal vertebral body always fails before the I-V disc under compression (Adams, 2004); which part of the vertebral body fails is dependent on compressive load rate. At low load rates, the end plates are the first to fail; at higher load rates, the trabeculae in the cancellous bone will fracture first (Gunning et al., 2001). Radial end-plate fractures can be large enough to allow the NP to squirt through into the vertebral body; this only occurs when the spine is compressed in

\footnotetext{
${ }^{2}$ Note: "pars lumborum" refers to the part of a muscle that attaches to the lumbar vertebrae, whereas "pars thoracis" refers to that which attaches to the thoracic vertebrae (Bogduk, 1980)
} 
neutral posture (McGill, 1997). It is generally accepted that $3400 \mathrm{~N}$ represents the level at which vertebral end plate microfractures begin to occur; $6400 \mathrm{~N}$ is the level where $50 \%$ of people under 40 will be affected (NIOSH, 1981). However, trabecular microfracture can occur with repetitive loading at compression levels well below accepted failure levels (Lu et al., 2001). Vertebral body damage due to repetitive compression is a common event in life, because healing and microfractured trabeculae are found in most cadaveric vertebral bodies (Adams, 2004). Moreover, spinal disc degeneration can occur as a result of compression as injured vertebral bodies can decompress the adjacent disc, causing internal mechanical damage and thereby initiating the degeneration process (Holm et al., 2004; Marras, 2000). Compression in the $\mathrm{L}_{1}-\mathrm{L}_{5}$ discs may also result in altered cell metabolism and cell death (Lotz \& Chin, 2000). Disc herniation can also occur as a result of compression, but only when the spine is also fully flexed for a repeated or prolonged period of time, as flexing the spine can decrease its compressive tolerance by up to $40 \%$ (Gunning et al., 2001).

\subsubsection{Shear}

Spinal shear acts perpendicular to the long axis of the lumbar spine at the location of the I-V joint; shear forces can be directed anteriorly/posteriorly or medially/laterally (Bogduk, 2004). Antero-posterior (AP) shear of the $\mathrm{L}_{1}-\mathrm{L}_{5}$ joint occurs as a motion coupled with flexion-extension, such that flexion from neutral causes an anterior shearing motion of the superior vertebra (olisthesis), and extension causes a posterior shearing motion of the anterior vertebra (retrolisthesis) (Lu et al., 2005). Anterior shear forces are partly offset by posterior shear forces caused by iliocostalis lumborum pars lumborum and longissimus thoracis pars lumborum, which possess a line of action directed 
posteriorly and caudally (Kingma et al., 2007; McGill, 2004). This line of action is lost under severe flexion, and many spinal injuries occur in this posture. Unlike compression, excessive shear forces cause injury to the posterior vertebral elements ( $\mathrm{Lu}$ et al., 2005). It has been documented by Cripton et al. (1995) that anterior shear forces exceeding roughly $2000 \mathrm{~N}$ acting on the superior vertebra can cause pars and facet fractures leading to spondylolisthesis. Conversely, excessive posterior shear of the superior vertebrae can cause ligamentous damage, vertebral failure, and end-plate avulsion (Yingling \& McGill, 1999). AP shear injury type is once again modulated by loading rate (Gunning et al., 2001). No definite shear tolerances have been put forth to date; however, it appears that 2000-2800N is the limit for one-time loading (McGill, 2004); repetition significantly decreases this limit to approximately 500N (Norman et al., 1998).

\subsubsection{Torsion}

Axial rotation of the lumbar spine involves torsion of the I-V discs, impaction of the facet joint being strained by compression, tension in the capsule of the opposite facet joint, and tension in the supraspinous and interspinous ligaments (Adams \& Hutton, 1981). Thus, torsional injuries are primarily found in these areas (Bogduk, 2004). When the $\mathrm{L}_{1}-\mathrm{L}_{5}$ discs are under torsion, the AF fibres that are inclined toward the direction of rotation become strained (Bogduk, 2004). It has been shown that the maximum range of motion of a disc, before the lamellae begin to fail microscopically, is approximately $3^{\circ}$ (Hickey \& Hukins, 1980). It has also been proven that the facet joints become compacted after only $1^{\circ}-3^{\circ}$ of axial rotation at which point the ligaments/capsule are considerably stretched (Adams et al., 2002). Therefore, it appears that the facet joints protect the $\mathrm{L}_{1}-\mathrm{L}_{5}$ discs from excessive torsion (Bogduk, 2004). In fact, removal of the $\mathrm{L}_{4}-\mathrm{L}_{5}$ facet 
substantially increases the axial rotation, intra-discal pressure, maximum fibre strain, and ligament strain at the same $\mathrm{L}_{4}-\mathrm{L}_{5}$ level (Shirazi-Adl, 1994). Failure to these joints occurs in the form of fractures to the facets, laminae, or vertebral bodies and tears in the joint capsules (Bogduk, 2004); specific force tolerances have yet to be estimated. In addition, it appears that torsion significantly reduces the compressive strength of the spine, which has significant ramifactions when lifting/forward bending and twisting at the same time (Aultman et al., 2004).

\subsubsection{Methods of measuring spinal loading}

In-vivo measurement through the use of intradiscal pressure sensors is the only way for direct recordings of the load on the spine; this method of data collection is very invasive, and thus only a few researchers have taken this approach, including Nachemson (1966), Takahashi et al. (2006), and Wilke et al. (1999). A more common approach is to estimate and solve the activity of the internal forces via biomechanical models. The first 2-D stick-figure models were crude and assumed that a single ES muscle force equivalent could represent the internal muscle forces (Marras, 2000). It soon became evident that this was not adequate, and Schultz \& Andersson (1981) presented procedures for calculating 3-D loads on the lumbar spine and the contraction forces in various trunk muscles. Static and dynamic linked-segment model (LSM) use is still very common and is a quick and effective way of estimating internal loads (Plamondon et al., 1995). Spinal forces can also be estimated with electromyography (EMG) (Mientjes et al., 1999). Advanced methods of calculating muscle activation and internal loads have become more common of late. Optimization-based models have been used to predict the forces produced by the muscles of the low back and abdominal regions; these models assume 
that the central nervous system (CNS) minimizes some performance criteria subject to the constraint that the required intersegmental moments are generated (Hughes et al., 1994). Artificial Neural Networks (ANNs), on the other hand, simulate lumbar muscle responses to different loads by acting as a motor control system that can be trained to produce desired results (Nussbaum et al., 1997). Biologically assisted models estimate spinal forces using measured EMG responses to external loads, and they can be used in conjuction with optimization models. These EMG-driven or EMG-assisted models can accurately predict 3-D loading of the spine under dynamic situations; they can assess how loading is different and unique in individual workers; and some even allow for the study of spinal stability (Cholewicki \& McGill, 1994; Granata \& Marras, 1995; McGill \& Norman, 1986). Kingma et al. (2001) compared three contrasting lumbar-loading measurement techniques: a linked-segment model, an EMG-based model, and an ANN that used both EMG and inertial sensing techniques; they found that, in comparison with the LSM, the EMG technique determined a $25.5 \% \pm 33.4 \%$ higher peak torque and the ANN technique a $17.3 \% \pm 10.5 \%$ lower peak torque. The authors stated that these differences between techniques varied with lifting method and speed, and may have been the result of antagonistic muscle activity, damping of forces by various tissues, anthropometric assumptions, and misestimations of trunk flexion. They were unable to make any recommendations as to which model was superior, as direct validation of any of these models was not possible. Computer programs have been developed using data obtained via these modeling techniques to allow for quick and easy calculations of internal moments and forces if provided with joint coordinate data or a specific posture; these programs include 4DWATBAK $®$ (University of Waterloo) and 3DSSPP® (University of Michigan). Although it is unable to directly measure internal forces, the 
lumbar motion monitor (LMM) is a tool that can be used to assess trunk postures and kinematics in an industrial setting, measures that are helpful in estimating internal loading and calculating LBD RF (Marras et al., 1993; Marras et al., 1995).

\subsection{Occupational Risk Factors}

\subsubsection{Forward Bending and Static Holding}

Forward bending and static holding are prominent ergonomic issues in occupational settings and often occur concurrently. Punnett et al. (1991) evaluated the health effects of non-neutral trunk postures in automobile assembly workers, and they discovered that LBD were associated with mild (21-45 ${ }^{\circ}$ from standing) trunk flexion $(\mathrm{OR}=4.9,95 \% \mathrm{CI}=1.4-17.4)$ and severe $\left(>45^{\circ}\right.$ from standing $)$ trunk flexion $(\mathrm{OR}=5.7$, 95\% $\mathrm{CI}=1.6-20.4)$; risk was amplified with multiple exposures or increased duration. Many of the jobs studied involved sizeable postural demands, loading of the trunk muscles, and highly static postural demands and $84 \%$ and $51 \%$ of subjects were found to work with mild or severe trunk flexion for any length of time respectively. Moreover, subjects were found to maintain mild flexion postures for up to $80 \%$ of the work cycle and severe flexion postures for up to $74 \%$ of the cycle. The short-term effects were found to be fatigue, pain, increased muscular activity, and increased intradiscal pressure.

There are generally three working situations where you get forward bending: 1) the work surface is below elbow height, 2) reach is beyond the length of the extended arm, and 3) work is beyond the visual field, all of which are very common in industrial settings (Sanders \& McCormick, 1993). The reason that forward bending increases back muscle activity and thus spinal loading is the increased moment about the low back; a moment is the product of the weight up the upper body/external load and its lever arm 
(moment $=$ force $\mathrm{x}$ distance), and thus increasing the external load or lever arm subsequently increases the spinal moment (Giat \& Pyke, 1992). In a study examining trunk motion and workplace LBD RF, it was determined that the most powerful single variable in distinguishing between risk and no risk groups was the maximum sagittal moment $(\mathrm{OR}=4.04)($ Marras et al., 1993, 1995).

With a more flexed trunk in a standing position, both external moments and internal muscular activity increase significantly at the $\mathrm{L}_{4} / \mathrm{L}_{5}$ joint, thereby increasing lumbar compression and shear (Kahrizi et al., 2007). There is, however, increased spinal stability (Granata \& Wilson, 2001). Further, there is a curvilinear increase in the maximal static extensor moment with forward bending, with a slight decrease in the moment on each side of neutral (Gravel et al., 1997). Moreover, the activity of the ES has been shown to significantly increase with the trunk flexion angle up to $45^{\circ}$, and reach silence at $90^{\circ}$ of flexion (Sakamoto \& Swie, 2003). Schultz et al. (1982) measured trunk muscle EMG while subjects performed 20 isometric weight-holding and force-resisting industrial tasks in various postures with multiple loads. They discovered that posterior ES trunk muscle activity closely reflected the magnitude of the net reaction flexion moment and that standing with the trunk flexed and without external load was more stressful than the heaviest weight-holding task with the trunk upright $(80 \mathrm{~N})$. As well, they determined that twisting and lateral bend did not significantly increase trunk muscle loading when bent forward (Schultz et al., 1982).

Seroussi \& Pope (1987) found a linear correlation between the sum of ES EMG and the sagittal plane lifting moment $\left(r^{2}=0.96\right)$ during isometric contractions, and similar results have been shown in other studies, thereby proving a near direct relationship 
between the two (Dolan \& Adams, 1993). It appears that low back EMG can be used to provide good estimates of a subject's trunk extensor moment, relative to maximum, under isometric conditions (Potvin et al., 1996). In another study analyzing EMG and static forward flexion, it was discovered that alterations in lumbar lordosis significantly changed muscle forces and internal spinal loads calculated using a non-linear finite element model; in comparison to kyphotic postures, lordotic postures increase the active component of the extensor muscle force, segmental axial compression, and lumbar shear forces (Arjmand \& Shirazi-Adl, 2005). EMG activity in extensor muscles also significantly increases with load magnitude (Bonato et al., 2003; El-Rich et al., 2004). Moreover, using EMG it is possible to discriminate LBP patients from normal subjects; LBP patients produce less muscular activity during static holding tasks and also differ in the nature of trunk muscle coactivation (Chiou et al., 1999).

Static forward bending is a highly stressful posture whose mean maximum holding time (MHT), a reflection of the back extensor muscles as a whole, has been found to be approximately 16 minutes, with large interindividual differences (Reneman et al., 2001). At a group level, body-part discomfort has been found to be linearly related to MHT; the type of task performed while maintaining a static forward posture has a great influence on MHT. Miedema et al. (1997) grouped occupational postures into comfortable (MHT >10min), moderate (MHT 5-10min), or uncomfortable (MHT <5min) and recommended that static postures should be held for less than $20 \%$ of their MHTs and no more than 2 minutes. Boussenna et al. (1982) investigated the relationship between joint torques, MHT, and perceived discomfort at four different extents of straight-legged forward bend. They found that changes in posture towards greater trunk flexion corellated 
significantly with changes in MHT and discomfort; morever, they found that discomfort levels in the body segment immediately superior to the joint studied were significantly related to the torque at the joint. Similar results have been found by Keyserling et al. (2005), who discovered increased low back discomfort with increased forward flexion levels. Greater lumbar spine flexion increases low back joint torques and discomfort and subsequently decreases MHT.

Daily exposure to static efforts over a long period of time may result in joint discomfort, as well as aches and pains in the joints, tendons, muscles and other soft tissues. Additionally, static loads are associated with an increased risk of arthritis of the joints, inflammation of the tendon sheaths and points of attachment of the tendons, symptoms of chronic joint degeneration, painful muscle spasms, and $\mathrm{L}_{1}-\mathrm{L}_{5}$ disc troubles (Genaidy \& Karwowski, 1993). During prolonged static trunk flexion, the ES and back muscles become fatigued; EMG amplitudes tend to increase, and there is an increase in the lower frequency components of the EMG spectrum known as spectral shift (De Luca, 1984). Ng et al. (1997) analyzed EMG amplitude and frequency changes in iliocostalis lumborum and multifidus during a 60 -second trunk isometric contraction and found that the multifidus muscle showed a higher level of activity, initial mean frequency (MF), and normalized MF slope (fatigued more quickly) than did iliocostalis lumborum; however, there was no difference in the normalized root mean squared (RMS) slope between the two muscles. Static flexed postures can also lead to muscle imbalances between the muscles that stabilize (abdominals) and the muscles that move (back extensors), which can lead to further problems (Valachi \& Valachi, 2003). Moreover, prolonged contractions of the lumbar ES at as low as $2 \%$ maximum voluntary contraction (MVC) 
reduce tissue oxygenation, potentially leading to muscle ischemia and necrosis (McGill et al., 2000). Under normal conditions, damaged tissue can repair itself during rest periods; however, in many occupational settings, including automotive assembly where static postures are very common, damage often occurs faster than repair can take place (Valachi \& Valachi, 2003). Without movement, nutrition to the NP is also diminished and degenerative changes can occur (McGill et al., 2000). It becomes quite evident from the aforesaid findings that static forward bending is an important occupational RF for LBD. When feasible, preventing these postures should be a priority; however, when they are inevitable, decreasing the forward bending moment is an effective way of reducing one's risk. Furthermore, it has been shown that improving trunk posture is associated with improvements in occupational performance; this may be an added benefit of making this ergonomic change (Bhatnager et al., 1985).

\subsubsection{Repetition and Cumulative Loading}

Although peak spinal moments and forces have the potential to cause LBD when a certain threshold is exceeded, more often, occupational injuries occur as the result of cumulative trauma from repetitive sub-failure magnitude loads or static loading (Andersson, 1985; Kumar, 1990; Norman et al., 1998). Repetition is very common in automotive assembly plants, and workers may be required to carry out hundreds of repetitions in a single day. Just as static holding causes muscular fatigue and spinal injury, so too does sub-maximal lifting and forward bending; repetition greatly reduces the spine's ability to resist compression, shear, and torsion, and many injuries can occur under very little load. As tissues fatigue with each cycle of load, the failure tolerance lowers and the margin of safety eventually approaches zero; at this point, a low back 
injury will occur (McGill, 2002). For example, Brinkmann et al. (1988) have shown that the compressive strength of the spine is reduced by $30 \%$ after 10 loading cycles and by $50 \%$ after 5000 loading cycles.

Cumulative loads in an occupational setting can be estimated by calculating the integrated load, which is the task peak force/moment multiplied by the number of repetitions during a shift and the duration of each repetition (Norman et al., 1998). Therefore, the task peak instants would be the moment or force experienced during a lift or hold, the repetitions would be the number of times it is carried out, and the duration would be the length that the posture/lift is held (static holding). Cumulative loading can also be accurately quantified from digitized video using several frames per second (Andrews \& Callaghan, 2003). Norman et al. (1998) examined cumulative loading in the automotive industry (integrated lumbar moment, compression, and shear), and found that all cumulative variables were significantly different at $\mathrm{p}<0.05$ between LBP cases and non-cases. They also discovered that cumulative spinal load per shift provides information that is much different from peak spinal load in distinguishing LBP patients, and that the integrated lumbar moment is an important independent variable. Along similar lines, it was discovered by Kerr et al. (2001) that physical measure RF for LBP at work include peak lumbar shear, peak load handled, and cumulative lumbar disc compression. Moreover, Kumar (1990) found that cumulative compression and shear were significantly higher in a group of institutional aids with LBP than in those without. Seidler et al. (2001) also found that individuals who were exposed to greater than $9 \times 10^{6}$ Newton hours of cumulative compression were 8.5 times more likely to obtain radiographically confirmed osteochondrosis or spondylosis of the lumbar spine. This is 
approximately equal to carrying a $7.5 \mathrm{~kg}$ weight for four hours a day, 220 days per year, for 4.5 years. Further, in a meta-analysis examining the association between cumulative spinal loading and LBD it was concluded that those exposed to cumulative loading had a meta-odds ratio of 1.66 (95\% CI= 1.46-1.89) for developing a LBD (Waters et al., 2006). It is quite evident that cumulative loading is an important occupational RF for LBD. Two problems in predicting cumulative loading are: 1) the tedious nature of counting every repetition and digitizing each posture, and 2) the fact that workers tend to overestimate their repetitions; poor agreement has been found between observational and self-report methods (Andrews et al., 1998).

As mentioned, cumulative loading due to repetition causes localized muscular fatigue similar to that found during static holding tasks, which can result in injury. Bonato et al. (2003) examined muscle fatigue and fatigue-related biomechanical changes during a cyclic task and found that the EMG instantaneous MF significantly decreased over time in the low back muscles; the changes were consistent with self-reports of fatigue and decreases in trunk extension strength. Interestingly, they also discovered significant fatigue-related kinematic changes in the angular displacements of the knee, hip, trunk, and elbow, associated with increased peak torque forces at the $\mathrm{L}_{4} / \mathrm{L}_{5}$ vertebral segment. Potvin \& Norman (1993) also looked at ES muscle fatigue during a repetitive task and found that extensor strength decreased $17 \%$ and $21 \%$, and endurance times decreased $60 \%$ and $62 \%$, during 2 hour and 20 minute sessions, repectively. Moreover, lumbar and thoracic EMG mean power frequency significantly decreased, whereas amplitude significantly increased, during the same lifting sessions. Another study examined the effects of lift (bend) frequency and exposure duration on low back muscle oxygenation 
and found that oxygen saturation in the ES increased during an 8-hour liftng period (Yang et al., 2007). Moreover, as lift frequency increased from 2-12 lifts per minute, so too did muscle oxygenation; this is an indication of muscular fatigue, as more oxygen was required to carry out the work. It has also been stated that back muscle fatigue after repetitive lifting can result in different muscle recruitment strategies and altered patterns of spinal loading (Marras \& Granata, 1997). In a study examining lumbar injury due to cyclic loading in a feline model, it was determined that viscoelastic tissue creep caused by cyclic loading desensitizes mechanoreceptors within these tissues (Solomonow et al., 1999). As a result, reflex muscular activation, the primary contributor to spinal stabilization, is dimished, allowing joint laxity and full exposure to instability and injury even before muscular fatigue sets in. Physically offsetting the laxity provided a full restoration of EMG activity at all lumbar levels.

Adequate rest between occupational tasks is required to prevent LBD. As aforementioned, if sufficient rest is not provided between tasks, then injury can occur. Courville et al. (2005) evaluated the effects of short rest periods after static lumbar flexion on the development of cumulative LBD in a feline model and found that a short rest period of 2:1 load-to-rest ratio leads to a cumulative LBD (delayed muscle hyperexcitability, strained viscoelastic tissues, and creep), whereas a longer rest at 1:1 and 1:2 load-to-rest ratio is more favorable for preventing and attenuating the development of a disorder. Conversely, Lariviere et al. (2003) found that 10-15 minutes of rest is required to allow low back muscles to recover completely, from an EMG point of view, after a 30-second static contraction at $75 \%$ MVC. No matter if workers are lifting, forward bending, or static holding, it is crucial to ensure that they are receiving 
sufficient rest betweeen tasks to maintain a safe-zone between what they are experiencing and what they can tolerate, in order to prevent LBD.

\subsection{Ergonomic Interventions}

Ergonomic intervention methods in industry, including automotive assembly, generally aim at improvements in productivity, quality, and efficiency; however, the ultimate aim of an intervention is to alter worker's mechanical exposure to acute and cumulative RF, thereby improving their musculoskeletal health (Westgaard \& Winkel, 1997). Two strategies for reducing the risk of developing work-related LBD are administrative and engineering controls. Administrative controls alter the duties or the design of the job (job rotation and participatory ergonomics), whereas engineering controls decrease the actual exposure to RF by making physical changes to hazards and routes of exposure (materials handling devices) (Frazer et al., 2003). Controls are commonly implemented when a tolerance limit value (TLV) is exceeded. It is crucial to note that any intervention that changes the mechanical exposure of workers may also result in changes in productivity and/or psychosocial and physical exposure factors (Westgaard \& Winkel, 1997). This must be taken into account when any ergonomic changes within industry are made.

\subsubsection{Ergonomic Tools and Tolerance Limit Values(TLVs)}

Ergonomic interventions for improved mechanical exposure are based on ergonomic guidelines describing proper exposure levels to achieve good MS health (Westgaard \& Winkel, 1997). Ergonomic interventions and changes are implemented when a TLV is exceeded and a specific job is deemed "unsafe". Many different ergonomic tools with TLVs have been put forth by numerous researchers over the years; 
all have the same goal of reducing MSD and LBD in an occupational setting. Several tools that are effective means of assessing LBD risk from an EMG and spinal loading point of view include the amplitude probability distribution function (APDF) and compression-normalized EMG (CNEMG).

The amplitudes of the EMG signal are highly correlated with muscle force, and thus they can be normalized to indicate the relative exertion of each muscle being observed. The time-history of these amplitudes provides an amplitude probability distribution function (APDF), which can be compared to standards to see if a worker is at risk of becoming fatigued or developing a cumulative trauma disorder (Jonsson, 1982). When carrying out repetitive work, workers should spend $10 \%$ of their time at or below $2 \%$ of maximum muscle activation (Static Level), $50 \%$ of their time at or below $10 \%$ of maximum muscle activation (Median Level), and $90 \%$ of their time at or below $50 \%$ of maximum muscle activation (Peak Level). An unacceptable risk exists if the muscle activation times deviate from these guidelines, and changes must be made. It is important to note that when carrying out APDF analysis, the entire duty cycle (work cycle + rest cycle) must be taken into account in order to accurately quantify muscle activation over time (Moore et al., 1991).

Although APDF is an excellent analysis technique for determining muscular fatigue and injury risk during repetitive work, it requires a maximal muscular contraction to compare to the TLVs. It has been determined that it is hard to get a 'true' maximal contraction from the erector spinae musculature, especially when testing is done in an industrial setting (Potvin et al., 1996). Potvin et al. (1990) have put forth a method for normalizing EMG called compression-normalized EMG (CNEMG), whereby EMG at a 
specific posture is linearly normalized to spinal compression in that same posture, determined via a biomechanical model. Thus, spinal compression can be continuously estimated over time using EMG data and can then be presented in the form of an APDF, where one is provided with the probability that compression was above or below a specific level during the entire work cycle (Wells et al., 1994). Mientjes et al. (1999) have shown that the exposure time at a specific level of compression was on average within $6.5 \%$ of the time calculated by a biomechanical model, with accuracy decreasing as axial twisting movements increased. Therefore, CNEMG is a simple field-acceptable method of estimating spinal compression over time, allowing for simple comparisons to proposed limits and reducing the need to measure maximal muscular contractions prior to testing.

\subsubsection{Job Rotation and Participatory Ergonomics}

Job rotation has become a widely recommended and implemented administrative ergonomic control in industry (Frazer et al., 2003). Job rotation initiatives aim to alter the mechanical exposure of the workers and thereby improve their MS health (Westgaard \& Winkel, 1997). More specifically, job rotation is implemented in order to alleviate the fatigue and stress of a particular set of muscles by rotating employees among other jobs that use primarily different muscle groups (U.S. Department of Labour, 1993). Some benefits of job rotation include: a cross-trained workforce, increased worker motivation, reduced boredom and monotony, reduced work stress, increased production, lower turnover rates and absenteeism, and reduced cumulative trauma disorders (Triggs \& King, 2000). However, there are also some negatives to job rotation. Frazer et al. (2003) looked at the effects of job rotation on the risk of reporting LBP in an automotive industry and found that those individuals who rotate into higher demand jobs experience an increase in 
reporting probability due to increases in peak loading parameters. Although some individuals rotate out of high demand jobs, others must fill their spots, and thus the overall workplace exposure to RF is not reduced. Also, tasks that are different but use similar muscle groups do not possess a risk reduction benefit (Kuijer et al., 1999). For these reasons and others, the effectiveness of job rotation is debatable.

During the past 20 years, many automotive companies, including Volvo and Toyota, have shifted their work organization from specialized tasks to more enlarged and enriched jobs and a "team" concept (Christmansson et al., 1999). Participatory Ergonomics (PE) is defined as the involvement of people/workers in planning and controlling a significant portion of their own work activities, as well as giving them sufficient knowledge and power to influence both processes and outcomes in order to acheive desirable goals (Wilson \& Haines, 1998). The effectiveness of PE has been proven in the automotive industry. Sundin et al. (2004) found that a PE approach facilitated communication and co-operation among team members, improved assembly productivity and ergonomics, and offered a better understanding among product designers, production engineers, and other employees. It appears that PE has the potential to improve productivity, job satisfaction, and work dynamics.

\subsubsection{Materials Handling Devices (MHDs)}

Back belts are devices used to: 1) remind people to lift properly, 2) support shear loading on the spine, 3) reduce compressive loading on the lumbar spine, 4) reduce range of motion, 5) provide warmth to the lumbar region, 6) enhance proprioception and stability, and 7) reduce muscular fatigue (McGill, 2002). There is no question that back belts are effective in generating torque through elastic recoil and in generating torso 
stiffness to reduce the risk of buckling during extremely heavy lifts (McGill, 2004). However, the more important question is whether back belts are effective in reducing RF and preventing LBD in industry. Kraus et al. (1996) surveyed low back injury rates of approximately 36,000 Home Depot employees in California between 1989 and 1994 when a mandatory back belt use policy was implemented by the company; they found that back-belt wearing reduced the risk of low back injury in younger males and those older than 55 years, but increased the risk for men working longer than four years by $27 \%$. Back-belt use can decrease ES muscle activity and may result in deconditioning (Bauer et al., 1999). In another study run by the Centre of Disease Control and NIOSH, 13,873 employees were surveyed at newly opened stores of a major retailer to analyze if backbelt use reduced the incidence of back-injury claims. Eighty-nine stores had mandatory belt use, whereas 71 stores had voluntary use; no significant differences were found between the incidence rates of workers' compensation claims among employees who reported using back belts two or fewer times per month versus those who wore a belt everyday (Wassell et al., 2000). Moreover, no significant differences were found in the incidence of self-reported back pain or between the rate of back-injury claims in stores with mandatory versus voluntary belt use. Further, in a systematic review carried out by Ammendolia et al. (2005) looking at occupational LBP and back belts, it was concluded that there is no conclusive evidence to support back-belt use to prevent or reduce lost time from occupational LBP. It has also been shown that back-belt use can increase intraabdominal pressure, blood pressure, heart rate, and oxygen consumption (Bobick et al., 2001; Rafacz \& McGill, 1996). Moreover, back belts may provide individuals with a false sense of security (Pan et al., 1999). It appears that back belts should be worn only for the 
first few days after a severe back injury while the area is healing, by individuals with no history of cardiovascular disease (DoD Ergonomics Working Group, 2005).

Mechanical lifting aids, including load balance arms and hoists, have become very popular in industrial settings where large loads are handled by workers (Chaffin et al., 1999). There are many types of mechanical lifting aids; however, all work in a similar fashion. Mechanical lifting aids are off-body MHDs and are powered in the vertical direction. These aids thus remove the lifting requirements of the operator; the operator must only push and pull the load horizontally (Resnick \& Chaffin, 1997). These aids have been shown to be beneficial in reducing $\mathrm{L}_{4} / \mathrm{L}_{5}$ spinal compression, even when lifted loads are much heavier than manual loads (Chaffin et al., 1999). Moreover, Hermans et al. (1999) examined the influence of a mechanical lifting aid on physical loads experienced during the end assembly of cars at Volvo Cars Europe and found that mechanical lifting tools significantly reduce awkward postures and back muscular activity under most assembly situations. Nevertheless, there are some disadvantages to mechanical lifting aids. Some aids cause significant spinal stresses due to the inertia of the device and load when moved dynamically. Woldstad \& Chaffin (1994) have shown that lifting aids can cause large peak hand forces during the acceleration and deceleration of loads; when combined with awkward working postures, large bending moments are created, which can result in injury (Hermans et al., 1999). The lifting aid that allows for the fastest movement requires the highest internal stresses and muscle activation to control the device (Resnick \& Chaffin, 1997). Several other disadvantages include the fact that using these devices can be time and space consuming, workers will tend not to use them if loads fall within their strength capacity, the position of the device hinders movements, ample 
learning is required, and finally, these devices are quite costly (Chaffin et al., 1999; Hermans et al., 1999).

On-body MHDs have become more common of late due to their lack of movement inertia, ease of incorporation into the workplace, small size and practicality, manoeuvrability, and negligible costs. These on-body MHDs aim at reducing occupational LBD not by removing the lifting requirement, but rather by transferring the loads on the lower back to the hips and lower limbs (Barrett \& Fathallah, 2001). For this reason, these devices are also known as weight transfer devices (WTDs). Three such devices are: 1) The Happyback (ErgoAg Company, Aptos, CA), 2) The Bendezy (Bendezy LiteTop Company, Mount Barker, Western Australia), and 3) The Bending Non-Demand Return (BNDR) (Limbic Systems Inc., Ventura, CA) (Figure 2.1) . The Happyback is composed of fiberglass rods and fabric; it contains a chest harness, a low back pad, and thigh straps that wrap around and buckle together above the knees. The fiberglass rods have memory, and when bent they attempt to bring the user back to an upright position; this lift component allows the body to reach equilibrium in a foward bent position, thus removing stress from the low back. The Bendezy is an all-metal support, with backpack-like straps as well as feet and ankle straps. Extending from a counterweight lever, springs load when the operator bends to lift the load and remove stresses from the spine and ES muscles. Lastly, the BNDR is a metal frame with a resistive articulation around the hip joint and pads at the thighs and chest; these resist forward bending and therefore take some of the load off the lumbar spine. All three devices have been compared using EMG, and the activity level of the ES muscles was reduced with all devices when compared to no device at all: Happyback, Bendezy, and BNDR provided $23 \%, 21 \%$, and $31 \%$ reductions in back muscle activity, respectively 

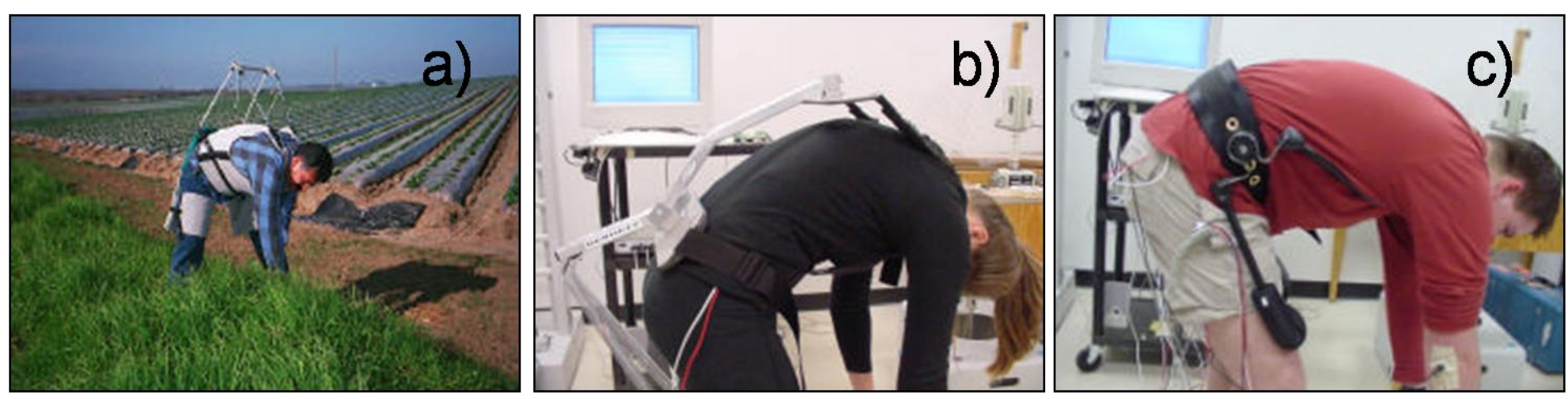

Figure 2.1. Three on-body materials handling devices; a) The Happyback, b) The Bendezy, and c) BNDR. 
(Barrett \& Fathallah, 2001). However, the Happyback and Bendezy devices also increased knee flexor muscle activity, thereby increasing stress on the knee.

The PLAD was developed at Queen's University and functions as a WTD in a similar fashion as the aforementioned on-body ergonomic aids. The PLAD transfers spinal loads to the shoulders, pelvic girdle, knees, and/or feet through the use of an external element, which possesses a mechanical advantage over the ES muscles in the back (Abdoli-E, 2005). This element recoils during lifting and offsets a proportion of the low-back moment during bending, and thus reduces the ES requirements during these tasks. The PLAD has undergone many design changes over time (Figure 2.2), but has maintained the same overall concept. The first three prototypes were developed before the start of the present research study and used by Abdoli-E and Stevenson (2008), Abdoli-E et al. (2006; 2007), and Lotz et al. (2008) for their research. These researchers showed that the PLAD was effective at reducing low-back moments and forces (Abdoli-E et al., 2007) and low-back muscular activity during symmetrical (Abdoli-E et al., 2006), assymetrical (Abdoli-E \& Stevenson, 2008), and repetitive lifting (Lotz et al., 2008). The first PLAD prototype possessed a common bar and six external elastic elements, the second a common bar and continuous rubber bands, and the third a double bar worn on the pelvis, and two elastic elements. The fourth PLAD prototype was similar to the third but posessed only one external elastic element with two moveable pulleys to split the force between the shoulders and lower limbs. Moreover, the knee mechanism (below the knee pad) was changed from a rigid to a non-rigid material and served only as a direction change for the ropes running from the pelvis to the feet. This change was instituted to remove excessive pressure and forces at the knees, which may cause injury due to large 
forces and repetitive movements. The present studies took place to: 1) develop a way to control for how much assistance the PLAD provides, 2) to institute changes in the PLAD design so that field testing could occur, and 3) to test the PLAD's effectiveness and user acceptability in an automotive manufacturing plant. 

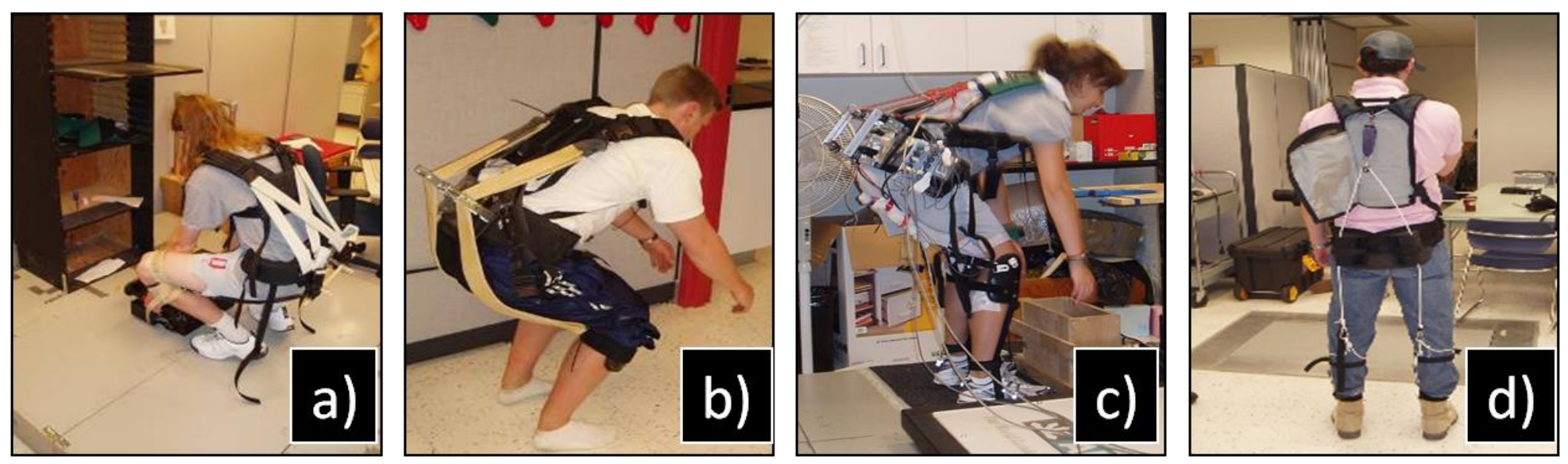

Figure 2.2. PLAD design iterations from Version 1 (a) to Version 4 (d). 


\subsection{References}

Abdoli-E, M. (2005). Design and instrumentation of a dynamic mechanical personal lift augmentation device (PLAD) for manual lifting tasks. PhD Dissertation, Queen's University, Kingston, Ontario, Canada.

Abdoli-E, M., \& Stevenson, J. (2008). The effect of on-body lift assistive device on the lumbar 3-D dynamic moments and EMG during assymetric freestyle lifting. Clinical Biomechanics , 23, 372-380.

Abdoli-E, M., Agnew, M., \& Stevenson, J. (2006). An on-body personal lift augmentation device (PLAD) reduces EMG amplitude of erector spinae during lifting tasks. Clinical Biomechanics , 21, 456-465.

Abdoli-E, M., Stevenson, J., Reid, S., \& Bryant, T. (2007). Mathematical and empirical proof of principle for an on-body personal lift augmentation device. Journal of Biomechanics , 40, 1694-1700.

Adams, M. (2004). Biomechanics of Back Pain. Acupuncture in Medicine , 22 (4), 178188.

Adams, M., \& Hutton, W. (1981). The relevance of torsion to the mechanical derangement of the lumbar spine. Spine , 6 (3), 241-248.

Adams, M., Bogduk, N., Burton, K., \& Dolan, P. (2002). The Biomechanics of Back Pain. Edinburgh: Churchill Livingstone.

Amling, M., Herden, S., Posl, M., Hahn, M., Ritzel, H., \& Delling, G. (1996).

Heterogeneity of the skeleton: comparison of the trabecular microarchitecture of the spine, the iliac crest, the femur, and the calcaneus. Journal of Bone and Mineral Research , $11(1), 36-45$.

Ammendolia, C., Kerr, M., \& Bombardier, C. (2005). Back belt use for prevention of occupational low back pain: a systematic review. Journal of Manipulative and Physiological Therapeutics , 28 (2), 128-134.

Andersson, G. (1985). Posture and compressive spine loading: intradiscal pressures, trunk myolectric activity, intra-abdominal pressures, and biochemical analyses. Ergonomics , $28(1), 91-93$.

Andrews, D., \& Callaghan, J. (2003). Determining the minimum sampling rate needed to accurately quantify cumulative spine loading from digitized video. Applied Ergonomics , 34 (6), 589-595. 
Andrews, D., Norman, R., Wells, R., \& Neumann, P. (1998). Comparison of self-report and observer methods for repetitive posture and load assessment. Occupational Ergonomics , 1 (3), 211-222.

Arjmand, N., \& Shirazi-Adl, A. (2005). Biomechanics of Changes in Lumbar Posture in Static Lifting. Spine, 30 (23), 2637-2648.

Aultman, C., Drake, J., Callaghan, J., \& McGill, S. (2004). The effect of static torsion on the compressive strength of spines: An in vitro analysis using a porcine spine model. Spine , 29 (15), E304-309.

Barrett, A., \& Fathallah, F. (2001). Evaluation of four weight transfer devices for reducing loads on the lower back during agricultural stoop labor. ASAE Annual International Meeting Paper Number: 01-8056 (pp. 1-8). Sacramento, CA: ASAE.

Bauer, J., Fry, A., \& Carter, C. (1999). The use of lumbar-supporting weight belts while performing squats: erector spinae electromyographic activity. Journal of Strength and Conditioning Research, 13, 384-388.

Bazrgari, B., Shirazi-Adl, A., \& Arjmand, N. (2006). Load distribution between spinal active-passive systems in squat and stoop dynamic lifts. Spine, S101.

Bernard, B. (1997). Musculoskeletal disorders and workplace factors: A critical review of epidemiologic evidence for work-related musculoskeletal disorders of the neck, upper extremity, and low back. Cincinatti, OH: Department of Health and Human Services, National Institute for Occupational Health and Safety.

Bhatnager, V., Drury, C., \& Schiro, S. (1985). Posture, Postural Discomfort, and Performance. Human Factors , 27 (2), 189-199.

Bigos, S., Spengler, D., Martin, N., Zeh, J., Fisher, L., Nachemson, A., \& Wang, M.H. (1986). Back Injuries in Industry: A retrospective Study II: Injury Factors. Spine , 11 (3), 246-251.

Bobick, T., Belard, J., Hsiao, H., \& Wassell, J. (2001). Physiological effects of back belt wearing during assymmetric lifting. Applied Ergonomics , 32 (6), 541-547.

Bogduk, N. (1980). A reappraisal of the anatomy of the human lumbar erector spinae. Journal of Anatomy, 131 (3), 525.

Bogduk, N. (2004). Clinical Anatomy of the Lumbar Spine and Sacrum (4th ed.). Philadelphia: Elsevier- Churchill Livingstone. 
Bonato, P., Ebenbichler, G., Roy, S., Lehr, S., Posch, M., Kollmitzer, J., \& Della Croce, U. (2003). Muscle fatigue and fatigue-related biomechanical changes during a cyclic lifting task. Spine , 28 (16), 1810-1820.

Boussenna, M., Corlett, E., \& Pheasant, S. (1982). The relations between discomfort and postural loading at the joints. Ergonomics , 25 (4), 315-322.

Brinkmann, P., Biggemann, M., \& Hilweg, D. (1988). Fatigue fracture of human lumbar vertebrae. Clinical Biomechanics , 3 (suppl.1), S1-23.

Chaffin, D., \& Andersson, G. (1991). Occupational Biomechanics (2nd ed.). New York: John Wiley \& Sons, Inc.

Chaffin, D., Stump, B., Nussbaum, M., \& Baker, G. (1999). Low-back stresses when learning to use a materials handling device. Ergonomics , 42 (1), 94-110.

Chiou, W.-K., Lee, Y.-H., \& Chen, W.-J. (1999). Use of the surface EMG coactivational pattern for functional evaluation of trunk muscles in subjects with and without low-back pain. International Journal of Industrial Ergonomics , 23, 51-60.

Cholewicki, J., \& McGill, S. (1994). EMG assisted optimization: A hybrid approach for estimating muscle forces in an indeterminate biomechanical model. Journal of Biomechanics , 27, 1287-1289.

Christmansson, M., Friden, J., \& Sollerman, C. (1999). Task design, psycho-social work climate and upper extremity pain disorders- effects of an organisational redesign on manual repetitive assembly jobs. Applied Ergonomics , 30, 463-472.

Courville, A., Sbriccoli, P., Zhou, B.-H., Solomonow, M., Lu, Y., \& Burger, E. (2005). Short rest periods after static lumbar flexion are a risk factor for cumulative low back disorder. Journal of Electromyography and Kinesiology, 15, 37-52.

Cripton, P., Berlemen, U., Visarino, H., Begman, P., Nolte, L., \& Presad, P. (1995). Response of the lumbar spine due to shear loading. In: Proceedings of a Symposium on Injury Prevention through Biomechanics. Detroit, May 4-5: Wayne State University.

De Luca, C. (1984). Myoelectrical manifestations of localized muscular fatigue in humans. Critical Reviews in Biomedical Engineering , 11, 251-279.

Dolan, P., \& Adams, M. (1993). The relationship between EMG activity and extensor moment generation in the erector spinae muscles during bending and lifting activities. Journal of Biomechanics , 26 (4-5), 513-522.

Dolan, P., Earley, M., \& Adams, M. (1994). Bending and compressive stresses acting on the lumbar spine during lifting activities. Journal of Biomechanics , 27 (10), 1237-1248. 
Dolan, P., Kingma, I., van Dieen, J., de Looze, M., Toussaint, H., Baten, C., \& Adams, M.A. (1999). Dynamic forces acting on the lumbar spine during manual handling. Can they be estimated using electromyographic techniques alone? Spine , 24 (7), 698-703.

Ebraheim, N., Hassan, A., Lee, M., \& Xu, R. (2004). Functional Anatomy of the Lumbar Spine. Seminars in Pain Medicine, 2, 131-137.

Ebraheim, N., Xu, R., Darwich, M., \& Yeasting, R. (1997). Anatomic relations between the lumbar pedicle and the adjacent neural structures. Spine , 22 (20), 2338-2341.

El-Rich, M., Shirazi-Adl, A., \& Arjmand, N. (2004). Muscle Activity, internal loads, and stability in the human spine in standing postures: Combined model and in vivo studies. Spine, 29 (23), 2633-2642.

Ferguson, S., \& Marras, W. (1997). A literature review of low back disorder surveillance and risk factors. Clinical Biomechanics , 12 (4), 211-226.

Frazer, M., Norman, R., Wells, R., \& Neumann, W. (2003). The effects of job rotation on the risk of reporting low back pain. Ergonomics , 46 (9), 904-919.

Genaidy, A., \& Karwowski, W. (1993). The effects of neutral posture deviations on perceived joint discomfort ratings in sitting and standing postures. Ergonomics , 36 (7), 785-792.

Giat, Y., \& Pyke, N. (1992). Mechanical and electromyographic comparison between the stoop and the squat lifting methods. Journal of Safety Research , 23, 95-105.

Gillespie, K., \& Dickey, J. (2004). Biomechanical role of lumbar spine ligaments in flexion and extension: Determination using a parallel linkage robot and a porcine model. Spine , 29 (11), 1208-1216.

Granata, K., \& Marras, W. (1995). An EMG-assisted model of trunk loading during freedynamic lifting. Journal of Biomechanics , 28 (11), 1309-1317.

Granata, K., \& Wilson, S. (2001). Trunk posture and spinal stability. Clinical Biomechanics , 16, 650-659.

Gravel, D., Gagnon, M., Plamondon, A., \& Desjardins, P. (1997). Development and application of predictive equations of maximal static moments generated by the trunk musculature. Clinical Biomechanics , 12 (5), 314-324.

Gray, H. (1974). Gray's Anatomy. Philadelphia: Running Press.

Group, D. E. (2005). Back Belts: No "Support" from the Surgeon General or DoD. DoD Ergonomics Working Group NEWS (39), 1-2. 
Gunning, J., Callaghan, J., \& McGill, S. (2001). The role of prior loading history and spinal posture on the compressive tolerance and type of failure in the spine using a porcine trauma model. Clinical Biomechanics , 16 (6), 471-480.

Hagg, G., Luttmann, A., \& Jager, M. (2000). Methodologies for evaluating electromyographic field data in ergonomics. Journal of Electromyography and Kinesiology , 10, 301-312.

Hermans, V., Hautekiet, M., Spaepen, A., Cobbaut, L., \& De Clerq, J. (1999). Influence of material handling devices on the physical load during the end assembly of cars. International Journal of Industrial Ergonomics , 24, 657-664.

Hickey, D., \& Hukins, D. (1980). Relation between the structure of the annulus fibrosus and the function and failure of the intervertebral disc. Spine , 5, 100-116.

Hickey, D., \& Hukins, D. (1980). X-ray diffraction studies of the arrangment of collagen fibres in human fetal interertebral disc. Journal of Anatomy, 131, 81-90.

Holm, S., Holm, A., Ekstrom, L., Karladani, A., \& Hansson, T. (2004). Experimental disc degeneration due to endplate injury. Journal of Spinal Disorders and Techniques, 17 (1), 64-71.

Hughes, R., Chaffin, D., Lavender, S., \& Andersson, G. (1994). Evaluation of muscle force prediction models of the lumbar trunk using surface electromyography. Journal of Orthopaedic Research, 12, 689-698.

Jonsson, B. (1982). Measurement and evaluation of local muscular strain in the shoulder during constrained work. Journal of Human Ergology, 11, 73-88.

Kahrizi, S., Parnianpour, M., Firoozabadi, S., Kasemnejad, A., \& Karimi, E. (2007). Evaluation of spinal internal loads and lumbar curvature under holding static load at different trunk and knee positions. Pakistan Journal of Biological Sciences , 10 (7), 10361043.

Kalichman, L., \& Hunter, D. (2007). Lumbar facet joint osteoarthritis: A review. Seminars in Arthritis and Rheumatology, Article In Press.

Kendall, F., McCreary, E., Provance, P., Rodgers, M., \& Romani, W. (2005). Muscles: Testing and Function With Posture and Pain (5th ed.). Baltimore: Lippincott Williams \& Wilkins.

Kerr, M., Frank, J., Shannon, H., Norman, R., Wells, R., Neumann, W., \& Bombardier, C. (2001). Biomechanical and psychosocial risk factors for low back pain at work. American Journal of Public Health , 91 (7), 1069-1075. 
Keyserling, W., Sudarsan, S., Martin, B., Haig, A., \& Armstrong, T. (2005). Effects of low back disability status on lower back discomfort during sustained and cyclical trunk flexion. Ergonomics , 48 (3), 219-233.

Kingma, I., Baten, C., Dolan, P., Toussaint, H., van Dieen, J., de Looze, M., \& Adams, M.A. (2001). Lumbar loading during lifting; a comparative study of three measurement techniques. Journal of Electromyography and Kinesiology , 11, 337-345.

Kingma, I., Staudenmann, D., \& van Dieen, J. (2007). Trunk muscle activation and associated lumbar spine joint shear forces under different levels of external forward force applied to the trunk. Journal of Electromyography and Kinesiology, 17, 14-24.

Kraus, J., Brown, K., McArthur, D., Peek-Asa, C., Samaniego, L., \& Kraus, C. (1996). Reduction of acute low back injuries by use of back supports. Journal of Occupational and Environmental Health, 2, 264-273.

Kuijer, P., Visser, B., \& Kemper, H. (1999). Job rotation as a factor in reducing physical workload at a refuse collecting department. Ergonomics , 42, 1167-1178.

Kumar, S. (1999). Biomechanics in Ergonomics (1st ed.). London: Taylor and Francis.

Kumar, S. (1990). Cumulative load as a risk factor for back pain. Spine , 15 (12), 13111316.

Labour, U. D. (1993). Ergonomics program management guidelines for meatpacking plants (Occupational Safety and Health Administration Publication No. 3123).

Washington, D.C: Occupational Safety and Health Administration.

Lariviere, C., Gravel, D., Arsenault, A., Gagnon, D., \& Loisel, P. (2003). Muscle recovery from a short fatigue test and consequence on the reliability of EMG indices of fatigue. European Journal of Applied Physiology , 89, 171-176.

Lotz, C., Agnew, M., Godwin, A., \& Stevenson, J. (2008). The effect of an on-body personal lift-assist device (PLAD) on fatigue during a repetitive lifting task. Journal of Electromyography and Kinesiology, In Press.

Lotz, J., \& Chin, J. (2000). Intervertebral disc cell death is dependent on the magnitude and duration of spinal loading. Spine , 25 (12), 1477-1483.

Lu, W., Luk, K., Cheung, K., Fang, D., Holmes, A., \& Leong, J. (2001). Energy absorption of human vertebral body under fatigue loading. In: Abstracts, International Society for the Study of the Lumbar Spine. Edinburgh, Scotland, June 19-23. 
Lu, W., Luk, K., Holmes, A., Cheung, K., \& Leong, J. (2005). Pure shear properties of lumbar spinal joints and the effect of tissue sectioning on load sharing. Spine , 30 (8), E204-E209.

Luttmann, A., Sokeland, J., \& Laurig, W. (1996). Electromyographical study on surgeons in urology, part II: Determination of muscular fatigue. Ergonomics , 39 (2), 285-297.

Marras, W. (2000). Occupational low back disorder causation and control. Ergonomics, 43 (7), 880-902.

Marras, W., \& Granata, K. (1997). Changes in trunk dynamics and spine loading during repeated trunk exertions. Spine, 22, 2564-2570.

Marras, W., Lavender, S., Leurgans, S., Rajulu, S.L., Allread, W.G., Fathallah, F.A., \& Ferguson, S.A. (1993). The role of dynamic three-dimensional trunk motion in occupationally-related low back disorders: the effects of workplace factors, trunk position and trunk motion characteristics on risk of injury. Spine, 18, 617-628.

Marras, W., Lavender, S., Leurgans, S., Fathallah, F., Ferguson, S., Allread, W., \& Rajulu, S.L. (1995). Biomechanical risk factors for occupationally related low back disorders. Ergonomics , 38 (2), 377-410.

Masset, D., Malchaire, J., \& Lemoine, M. (1993). Static and dynamic characteristics of the trunk and history of low back pain. International Journal of Industrial Ergonomics , $11,279-290$.

McGill, S. (1997). Invited Paper: Biomechanics of low back injury: Implications on current practice and the clinic. Journal of Biomechanics , 30 (5), 464-475.

McGill, S. (2004). Linking latest knowledge of injury mechanisms and spine function to the prevention of low back disorders. Journal of Electromyography and Kinesiology, 14, 43-47.

McGill, S. (2002). Low Back Disorders: Evidence-Based Prevention and Rehabilitation (1st ed.). Windsor: Human Kinetics.

McGill, S. (2004). Ultimate Back Fitness and Performance. Waterloo, ON: Wabuno Publishers.

McGill, S., \& Norman, R. (1986). Partitioning of the L4-L5 dynamic moment into disc, ligamentous, and muscular components during lifting. Spine , 11 (7), 666-678.

McGill, S., Hughson, R., \& Parks, K. (2000). Lumbar erector spinae oxygenation during proloned contractions: implications for prolonged work. Ergonomics , 43 (4), 486-493. 
Miedema, M., Douwes, M., \& Dul, J. (1997). Recommended maximum holding times for prevention of discomfort of static standing postures. International Journal of Industrial Ergonomics , 19, 9-18.

Mientjes, M., Norman, R., Wells, R., \& McGill, S. (1999). Assessment of an EMG-based method for continuous estimates of low back compression during asymmetrical occupational tasks. Ergonomics , 42 (6), 868-879.

Moore, A., Wells, R., \& Ranney, D. (1991). Quantifying exposure in occupational manual tasks with cumulative trauma disorder potential. Ergonomics , 34 (12), 14331453.

Nachemson, A. (1966). The load on lumbar discs in different positions of the body. Clinical Orthopaedics , 45, 107-122.

Ng, J. K.-F., Richardson, C., \& Jull, G. (1997). Electromyographic amplitude and frequency changes in the iliocostalis lumborum and multifidus muscles during a trunk holding test. Physical Therapy, 77 (9), 954-961.

NIOSH. (1981). Work Practices Guide for Manual Lifting. Department of Health and Human Services (DHHS), National Institute of Safety and Health (NIOSH).

Norman, R., Wells, R., Neumann, P., Frank, P., Shannon, H., \& Kerr, M. (1998). A comparison of peak vs cumulative physical work exposure risk factors for the reporting of low back pain in the automotive industry. Clinical Biomechanics , 13, 561-573.

Nussbaum, M., Martin, B., \& Chaffin, D. (1997). A neural network model for simulation of torso muscle coordination. Journal of Biomechanics , 30 (3), 251-258.

Panjabi, M., Oxland, T., Takata, K., Goel, V., Duranceau, J., \& Krag, M. (1993). Articular facets of the human spine: quantitative three-dimensional anatomy. Spine , 18, 1298-1310.

Plamondon, A., Gagnon, M., \& Desjardins, P. (1995). Validation of two 3-D segment models to calculate the net reaction forces and moments at the L5/S1 joint in lifting. Clinical Biomechanics , 11 (2), 101-110.

Potvin, J., \& Norman, R. (1993). Quantification of erector spinae muscle fatigue during prolonged, dynamic lifting tasks. European Journal of Applied Physiology, 67, 554-562.

Potvin, J., Norman, R., \& McGill, S. (1996). Mechanically corrected EMG for the continuous estimation of erector spinae muscle loading during repetitive lifting. European Journal of Applied Physiology, 74, 119-132. 
Potvin, J., Norman, R., \& Wells, R. (1990). A field method for continuous estimation of dynamic compressive forces on the L4/L5 disc during the performance of repetitive tasks. 23rd Annual Conference of the Human Factors Association of Canada. Ottawa, ON, Canada.

Punnett, L., Fine, L., Keyserling, W., Herrin, G., \& Chaffin, D. (1991). Back disorders and nonneutral trunk postures of automobile assembly workers. Scandinavian Journal of Work and Environmental Health, 17, 337-346.

Punnett, L., Pruss-Ustun, A., Imel Nelson, D., Fingerhut, M., Leigh, J., Tak, S., \& Phillips, S. (2005). Estimating the global burden of low back pain attributable to combined occupational exposures. American Journal of Industrial Medicine , 48, 459469.

Rafacz, W., \& McGill, S. (1996). Abdominal belts increase diastolic blood pressure. Journal of Occupational and Environmental Medicine. , 9, 925-927.

Ratcliffe, J. (1980). The arterial anatomy of the adult human vertebral body: a microarteriographic study. Journal of Anatomy, 131, 57-79.

Reneman, M., Bults, M., Engbers, L., Mulders, K., \& Goeken, L. (2001). Measuring maximum holding times and perception of static elevated work and forward bending in healthy young adults. Journal of Occupational Rehabilitation , 11 (2), 87-97.

Resnick, M., \& Chaffin, D. (1997). An ergonomic evaluation of three classes of material handling devices (MHD). International Journal of Industrial Ergonomics , 19 (3), 217229.

Roberts, S., Menage, J., \& Urban, J. (1989). Biomechanical and structural properties of the cartilage end plate and its relationship to the intervertebral disc. Spine , 14, 166.

Sakamoto, K., \& Swie, Y. (2003). EMG characteristics of low back and lower limb muscles during forward bending posture. Electromyography and Clinical Neurophysiology , 43 (6), 335-347.

Sanders, M., \& McCormick, E. (1993). Human factors in engineering and design (7th ed.). New York, NY, USA: McGraw-Hill.

Schultz, A., \& Andersson, G. (1981). Analysis of loads on the lumbar spine. Spine , 6 (1), 76-82.

Schultz, A., Andersson, G., Ortengren, R., Bjork, R., \& Nordin, M. (1982). Analysis and quantitative myolectric measurements of loads on the lumbar spine when holding weights in standing postures. Spine , 7 (4), 390-397. 
Seidler, A., Bolm-Audorff, U., Heiskel, H., Henkel, N., Roth-Kuver, B., Kaiser, U., Bickeboller, W.J., Willingstorfer, W.J., Beck, W., \& Elsner, G. (2001). The role of cumulative physical work load in lumbar spine disease: risk factors for lumbar osteochondrosis and spondylosis associated with chronic complaints. Occupational and Environmental Medicine, 58, 735-746.

Seroussi, R., \& Pope, M. (1987). The relationship between trunk muscle electromyography and lifting moments in the sagittal and frontal planes. Journal of Biomechanics , 20 (2), 135-146.

Sharma, M., Langrana, N., \& Rodriguez, J. (1995). Role of ligaments and facets in lumbar spinal stability. Spine , 20 (8), 887-900.

Shirazi-Adl, A. (1994). Non linear stress analysis of the whole lumbar spine in torsionmechanics of facet articulation. Journal of Biomechanics , 27 (3), 289-299.

Solomonow, M., Zhou, B.-H., Baratta, R., Lu, Y., \& Harris, M. (1999). Biomechanics of increased exposure to lumbar injury caused by cyclic loading: Part 1 . Loss of reflexive stabalization. Spine, 24 (23), 2426-2434.

Stevenson, J., Weber, C., Smith, J., Dumas, G., \& Albert, W. (2001). A longitudinal study of the development of low back pain in an industrial population. Spine , 26 (12), 13701377.

Stokes, I., \& Gardner-Morse, M. (1999). Quantitative anatomy of the lumbar musculature. Journal of Biomechanics, 32, 311-316.

Sundin, A., Christmansson, M., \& Larsson, M. (2004). A different perspective in participatory ergonomics in product development improves assembly work in the automotive industry. International Journal of Industrial Ergonomics , 33, 1-14.

Takahashi, I., Kikuchi, S.-I., Sato, K., \& Sato, N. (2006). Mechanical load of the lumbar spine during forward bending motion of the trunk- A biomechanical study. Spine , 31 (1), 18-23.

Taylor, J. (1990). The development and adult structure of lumbar intervertebral discs. Journal of Manipulative Medicine , 5, 43-47.

Triggs, D., \& King, P. (2000). Job rotation: an administrative strategy for hazard control. Professional Safety , 45, 32-34.

Valachi, B., \& Valachi, K. (2003). Mechanisms leading to musculoskeletal disorders in dentistry. Journal of the American Dental Association, 134, 1344-1350. 
van Dieen, J., Hoozemans, M., \& Toussaint, H. (1999). Stoop or squat: a review of biomechanical studies on lifting technique. Clinical Biomechanics , 14, 685-696.

Veiersted, K., Westgaard, R., \& Andersen, P. (1993). Electromyographic evaluation of muscular work pattern as a predictor of trapezius myalgia. Scandinavian Journal of Work and Environmental Health, 1993, 284-290.

Walker, B. (2000). The prevalence of low back pain: systematic review of the literature from 1966 to 1998. Journal of Spine Disorders , 13, 205-217.

Wassell, J., Gardner, L., Landsittel, D., Johnston, J., \& Johnston, J. (2000). A prospective study of back belts for prevention of back pain and injury. Journal of the American Medical Association. , 284 (21), 2727-2734.

Waters, T., Yeung, S., Genaidy, A., Callaghan, J., Barriera-Viruet, H., \& Deddens, J. (2006). Cumulative spinal loading exposure methods for manual material handling taks. Part 1: Is cumulative spinal loading associated with lower back disorders. Theoretical Issues in Ergonomics Science , 7 (2), 113-130.

Wells, R., Moore, A., Potvin, J., \& Norman, R. (1994). Assessment of risk factors for development of work-related musculoskeletal disorders (RSI). Applied Ergonomics , 25 (3), 157-164.

Westgaard, R., \& Winkel, J. (1997). Review article- Ergonomic intervention research for improved musculoskeletal health: A critical review. International Journal of Industrial Ergonomics , 20, 463-500.

Wilke, H., Neef, P., Caimi, M., Hoogland, T., \& Claes, L. (1999). New in vivo measurements can predict pain on discography. Spine , 24 (8), 755-762.

Wilson, J., \& Haines, H. (1998). Development of a Framework for Participatory Ergonomics. United Kingdom: HSE Books.

Woldstad, J., \& Chaffin, D. (1994). Dynamic push and pull forces while using a manual material handling assist device. IIE Transactions , 26 (3), 77-88.

Yahia, L., Garzon, S., Strukowski, H., \& Rivard, C. (1990). Ultrastructure of the human interspinous ligamnet and ligamentum flavum: a preliminary study. Spine , 15 (4), 262268.

Yang, G., Chany, A.-M., Parakkat, J., Burr, D., \& Marras, W. (2007). The effects of work experience, lift frequency and exposure duration on low back muscle oxygenation.

Clinical Biomechanics , 22, 21-27. 
Yingling, V., \& McGill, S. (1999). Mechanical properties and failure mechanics of the spine under posterior shear load: Observations from a porcine model. Journal of Spinal Disorders , 12 (6), 501-508. 


\section{CHAPTER 3.0}

\section{THE SELECTION OF INDIVIDUALIZED TENSIONS BASED ON EXCURSION}

AND ANTHROPOMETRY

\section{Abstract}

The ability to individually control for and customize how much help the personal lift-assist device (PLAD) provides would greatly enhance its effectiveness. Thus, the purpose of the present study was to develop a computerized model that could predict element excursion and required element stiffness for various individuals based on their anthropometry (gender, height, weight and trunk depth), and working posture (trunk inclination and knee angles). In order to do so, 30 subjects (15 male, 15 female) were required to carry out a protocol that simulated unloaded stoop, squat, and freestyle lifting. Trunk inclination and knee angles were determined via three Fastrak $^{\mathrm{TM}}$ sensors, and a displacement transducer attached in-line with the PLAD measured excursion when the trunk or knees flexed. A model was then developed to predict excursion: Excursion $(\mathrm{cm})$ $=12.565+.195\left(\right.$ Trunk Angle $\left.\left(^{\circ}\right)\right)-.079\left(\right.$ Knee Angle $\left.\left(^{\circ}\right)\right)-.034($ Height $(\mathrm{cm}))+.118$ $($ Weight $(\mathrm{kg}))+1.273($ Gender $(0=$ male, $1=$ female $))\left(\mathrm{R}^{2}=0.885, \mathrm{SE}=2.873\right)$, and was validated with 10 additional subjects $\left(\mathrm{R}^{2}=0.923\right.$, RMS Error $\left.=2.124\right)$. A computer program was also developed using this excursion model and various mathematical equations to determine the required spring stiffness for offsetting a proportion of the $\mathrm{L}_{4} / \mathrm{L}_{5}$ bending moment for unique individuals in various postures. This work should greatly reduce the coefficient of variation in a population of PLAD wearers, and it should provide users and researchers alike with a means of achieving an accurate and customized amount of support when wearing the device. 


\subsection{Introduction}

The personal lift-assist device (PLAD) is an on-body ergonomic device that uses external elements to reduce the requirements of the erector spinae muscles. Previous studies examining the PLAD possessed several limitations with respect to these elastic elements. Abdoli-E et al. (2006) allowed subjects to select their own stiffness levels for the PLAD's elastic elements; however, they reported concern that this could lead to deconditioning if subjects chose such stiff elastic elements that muscular requirements were inadequate to maintain strength. Furthermore, Lotz et al. (2008) used the same elastic element for all subjects during testing and felt that this added to variability in PLAD's effect across the subject pool. Lotz and colleagues also reported that an optimal configuration of the device would utilize an elastic stiffness matched proportionally to the wearer's body mass. From these results, it became evident that the ability to individually control for and customize element stiffness would greatly enhance the effectiveness of the PLAD.

Extension springs with a linear stress/strain relationship are readily available in the marketplace, with each spring responding to a given force with a given displacement called spring stiffness. Customizable springs makes their use advantageous over a rubber band element, and thus current PLAD versions utilize spring elements instead of rubber ones. If the PLAD is to provide a given percentage (e.g., 20\%) of the low back moment for each individual, it must be determined which springs to insert into the PLAD. The appropriate springs will need to be selected for individuals based on their gender, height, weight, and trunk depth, as well as their trunk and knee angles required for a specific job. Therefore, the purpose of the present study was to take inputs based on measurements 
from the $10^{\text {th }}-90^{\text {th }}$ percentile height and weight of men and women and create a computer program that uses a model to calculate and output accurate and customized spring tensions for each worker in an industrial population. It was hypothesized that the customized software could be developed and validated to achieve this purpose.

\subsection{Methods}

\subsubsection{Experimental Design}

The present study was designed to obtain normative data for predicting spring excursion. With these data a model was created and validated, and this model was integrated within a customized computer program for calculating a stiffness that would offset a given percentage of a PLAD wearer's low back moment.

\subsubsection{Participants}

Thirty (15 male, 15 female) healthy university-aged students were recruited for the initial research study. Participants were carefully recruited to cover the $10^{\text {th }}-90^{\text {th }}$ percentile ranges based on height and weight (Peebles \& Norris, 1998). Participants were 20-37 years old $($ mean $=24.87, \mathrm{SD}=3.40)$, and the mean height and mass were 173.32 $\mathrm{cm}(\mathrm{SD}=8.79)$ and $74.53 \mathrm{~kg}(\mathrm{SD}=12.92)$, respectively. For study validation, 10 additional randomly selected subjects (5 male, 5 female) were recruited. These participants were $24-28$ years old $($ mean $=25.60, \mathrm{SD}=1.65)$, and mean height and mass were $173.60 \mathrm{~cm}(\mathrm{SD}=6.65)$ and $72.75 \mathrm{~kg}(\mathrm{SD}=10.77)$, respectively. Any participant who had a history or complaint of chronic pain, major injury or trauma, or major surgery to the back was excluded from the study. Prior to their participation in the study, all participants were provided with detailed knowledge of all testing that was to be 
performed. The Queen's University Research Ethics Board approved the procedures (Appendix A), and all participants provided informed written consent (Appendix B).

\subsubsection{Instrumentation}

A Fastrak ${ }^{\mathrm{TM}}$ electromagnetic tracking system by Polhemus (Cochester, VT, USA) was used to calculate kinematic data in the form of trunk inclination and knee flexion angles. Three motion sensors were placed on the subject's body at the locations of the sternum, mid thigh, and mid shank (Figure 3.1a), and were securely mounted using Tufskin $^{\circledR}$ spray followed by stretchy fabric-based adhesive tape to ensure they remained affixed throughout the remainder of the testing protocol. Data from each sensor were collected at 30Hz. A PT101 cable extension displacement transducer by Celesco (Chatsworth, CA, USA) was used to estimate spring-length change. It was attached inline with the PLAD and recorded a voltage when the trunk or knees flexed (Figure 3.1b; 3.1c); a calibration process converted the voltage output (V) to displacement $(\mathrm{cm})$. The PLAD's external element was replaced with a non-elastic rope so that all displacements caused by flexion were recorded by the transducer (Figure 3.1b; 3.1d). Because two-way pulleys, a physical aspect of the PLAD attached to the external element (Figure 3.1d), possess a mechanical advantage of two over the rope, the displacement transducer recording was divided by two to obtain the change in spring length. Data were also collected at $30 \mathrm{~Hz}$ to match the Fastrak ${ }^{\mathrm{TM}}$ sampling rate.

\subsubsection{Testing Procedures}

Subjects were required to carry out a protocol that simulated unloaded stoop, squat, and freestyle lifting. The amount of spring excursion within the PLAD was tracked throughout a lifting range of motion, accounting for stoop styles, squat styles and a 

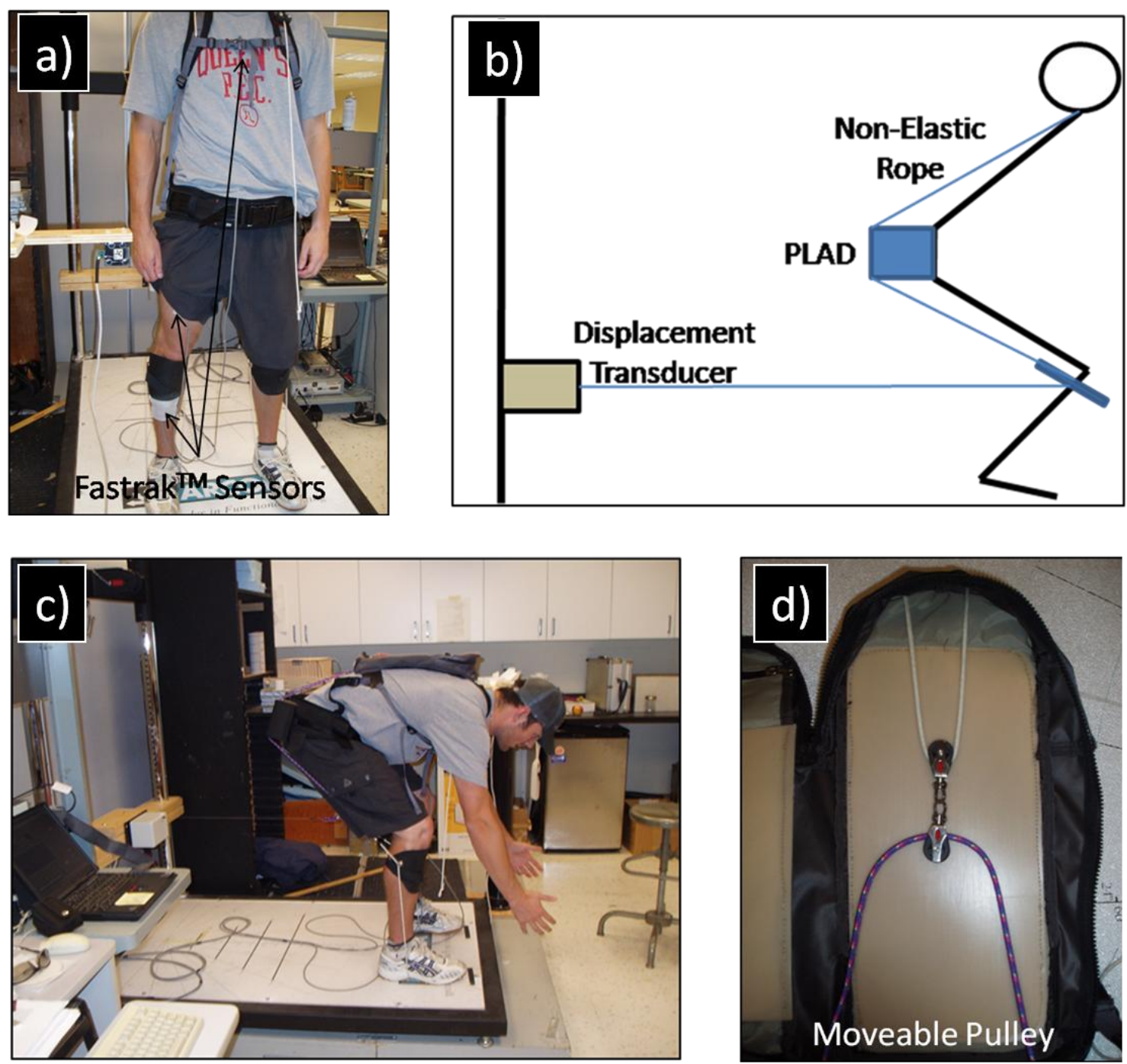

Figure 3.1. In-lab setup for determining spring length changes due to trunk inclination and knee flexion using Fastrak ${ }^{\mathrm{TM}}$ sensors (a) and a displacement transducer (b, c), and the two-way moveable pulley located inside the PLAD (d). 
combination of both. Subjects were outfitted with the three Fastrak ${ }^{\mathrm{TM}}$ sensors, fitted with the PLAD and its cable displacement gauge and then asked to perform practice trials until they were comfortable with the protocol. With the subjects in an upright standing position, the Fastrak ${ }^{\mathrm{TM}}$ system was bore-sighted and the displacement transducer was zeroed. Upon being told to begin, subjects carried out the three simulated lifts in a randomized order, where randomness was achieved via a computer program. For the stoop lift, subjects bent only their trunk and hips as far forward as possible without moving their feet or flexing their knees. For the squat lift, subjects flexed only their knees and hips, while retaining an upright trunk. For the freestyle lift, subjects combined trunk, hip, and knee flexion.

\subsubsection{Data Processing and Statistical Analysis}

Trunk inclination angles from vertical $\left(0^{\circ}\right)$ were calculated from the sternum sensor, and knee angles were calculated from the thigh and shank sensors for each point in time. These series of angles, as well as subject gender, height, and weight, were placed into SPSS 15 for Windows (SPSS Corporation, Chicago, IL, USA) statistical software in order to create a model for determining spring excursion based on these data. Entry into the model was forward-step in nature, where the numerous variables were assessed for their predictive power before being included in the model. When each variable entered the model, if it explained a significant and unique proportion of the variance $(\alpha=0.05)$, then it remained within the model; however, if it did not it was removed.

\subsubsection{Validation of Excursion Model}

In order to validate the model upon completion, data were collected on ten additional subjects using identical methods to the initial 30 . These data were then 
compared to predicted excursion data that were produced using the aforementioned model. Statistical correlation was carried out between the predicted and actual spring excursion data, and model validity was assessed via $\mathrm{R}$ (Pearson's coefficient), $\mathrm{R}^{2}$ (coefficient of determination), and RMS (root mean squared) values.

\subsubsection{Calculating Spring Stiffness Requirements for Offsetting X Percentage of the $L_{4} / L_{5}$ Moment}

After the model used to calculate spring excursion was validated, a custom Labview 8.0 (National Instruments Corporation, Austin, Texas, USA) computer program was developed, which calculated a desired spring stiffness to offset a set percentage (e.g., $20 \%$ ) of a PLAD wearer's low back moment. Program inputs included: 1) those required for calculating spring excursion using the aforementioned model; 2) trunk depth, which was required for calculating how PLAD's moment arm changes with forward bending; and 3) the peak $\mathrm{L}_{4} / \mathrm{L}_{5}$ bending moment required for the specific job. By knowing what percentage of the $\mathrm{L}_{4} / \mathrm{L}_{5}$ moment one wants to take away, PLAD's moment arm length, and the spring excursion at any static posture, it was possible to calculate the required overall spring stiffness.

\subsection{Results}

\subsubsection{Excursion Model}

All variables that were input into the forward-step model were determined significant at the $\mathrm{p}=0.05$ level and were thus not removed from the model (Table 3.1). The model predictors therefore included: 1) trunk inclination angle $\left.\left({ }^{\circ}\right), 2\right)$ knee angle $\left(^{\circ}\right)$, 3) height $(\mathrm{cm}), 4)$ weight $(\mathrm{kg})$, and 5) gender (male or female); whereas the dependent variable was spring excursion $(\mathrm{cm})$. The model possessed a Pearson's coefficient $(\mathrm{R})$ of 
Table 3.1. Spring excursion model coefficients, standard error, and significance values.

\begin{tabular}{|c|c|c|c|c|c|}
\hline Variable & $\begin{array}{c}\text { Unstandardized } \\
\text { Coefficients }\end{array}$ & $\begin{array}{c}\text { Standard } \\
\text { Error }\end{array}$ & $\begin{array}{c}\text { Standardized } \\
\text { Coefficients }\end{array}$ & $\mathbf{t}$ & Significance \\
\hline (Constant) & 12.565 & 0.474 & & 26.528 & 0.001 \\
\hline Trunk Angle & 0.195 & 0.000 & 0.819 & 394.580 & 0.001 \\
\hline Knee Angle & -0.079 & 0.000 & -0.530 & -255.832 & 0.001 \\
\hline Height & -0.034 & 0.003 & -0.035 & -11.461 & 0.001 \\
\hline Weight & 0.118 & 0.002 & 0.177 & 52.495 & 0.001 \\
\hline Gender & 1.273 & 0.051 & 0.075 & 25.121 & 0.001 \\
\hline
\end{tabular}


0.941 , a coefficient of determination $\left(\mathrm{R}^{2}\right)$ of 0.885 , and a standard error of 2.873 . These findings indicate that $88.5 \%$ of the variance in spring excursion can be explained by the current model, whereas prediction error can be estimated at $2.873 \mathrm{~cm}$.

\subsubsection{Model Validation}

The measured excursion values and those predicted via the model for the ten validation subjects matched very closely $\left(\mathrm{R}^{2}=0.923, \mathrm{RMS}\right.$ error $\left.=2.124\right)($ Figure 3.2$)$, thereby validating the effectiveness of the current model. As one can infer from these values, approximately $92 \%$ of the variance between the actual and predicted values could be accounted for, whereas the root mean squared (RMS) error was approximately $2 \mathrm{~cm}$. If one considers that this is across three styles of lifts and the entire range of motion, the model is very good at predicting excursion based on trunk inclination angle, knee angle, height, weight, and gender. Furthermore, when subjects were working in the mid range of knee and trunk flexion (5-15 cm excursion), similar to where they would be working in a motor manufacturing plant setting (Punnett et al., 1991), the actual and predicted values were linearly related and nearly identical (Figure 3.2).

\subsubsection{Custom Computer Program}

The custom computer program was generated to effectively determine the required overall stiffness for offsetting a given percentage of the low back moment in a specific static posture. As shown in Figure 3.3, after inputting the anthropometric, task, and desired moment reduction inputs, the program outputs the required overall spring stiffness. This was done by calculating PLAD's moment arm in the specific posture (Equation 1), and the required low back moment that must be offset by the PLAD 


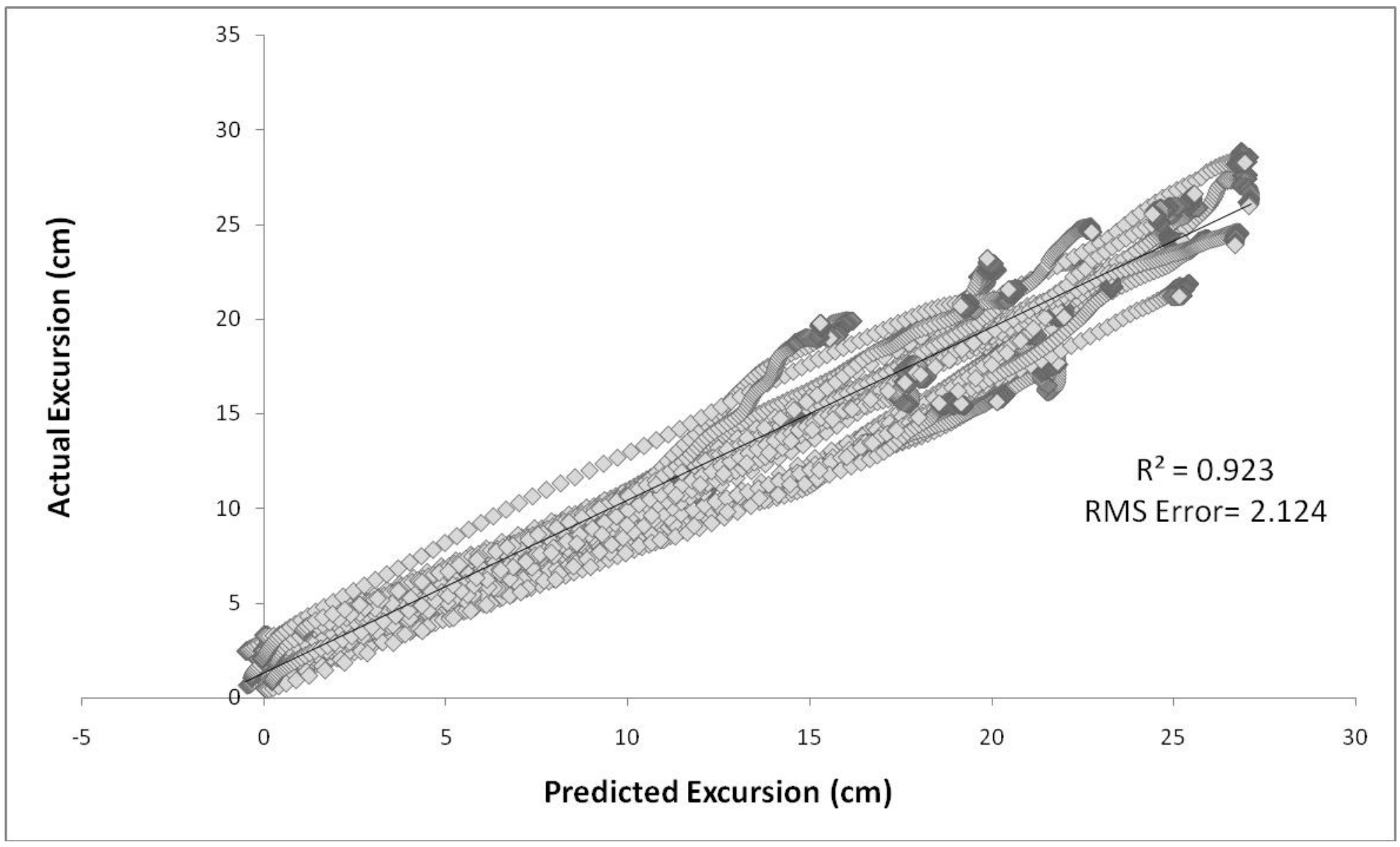

Figure 3.2. Actual versus model-predicted spring excursion measurements $(\mathrm{cm})$ with trend-line for all ten subjects. (Notice the large coefficient of determination $\left(\mathrm{R}^{2}\right)$ and small root mean squared (RMS) error values). 


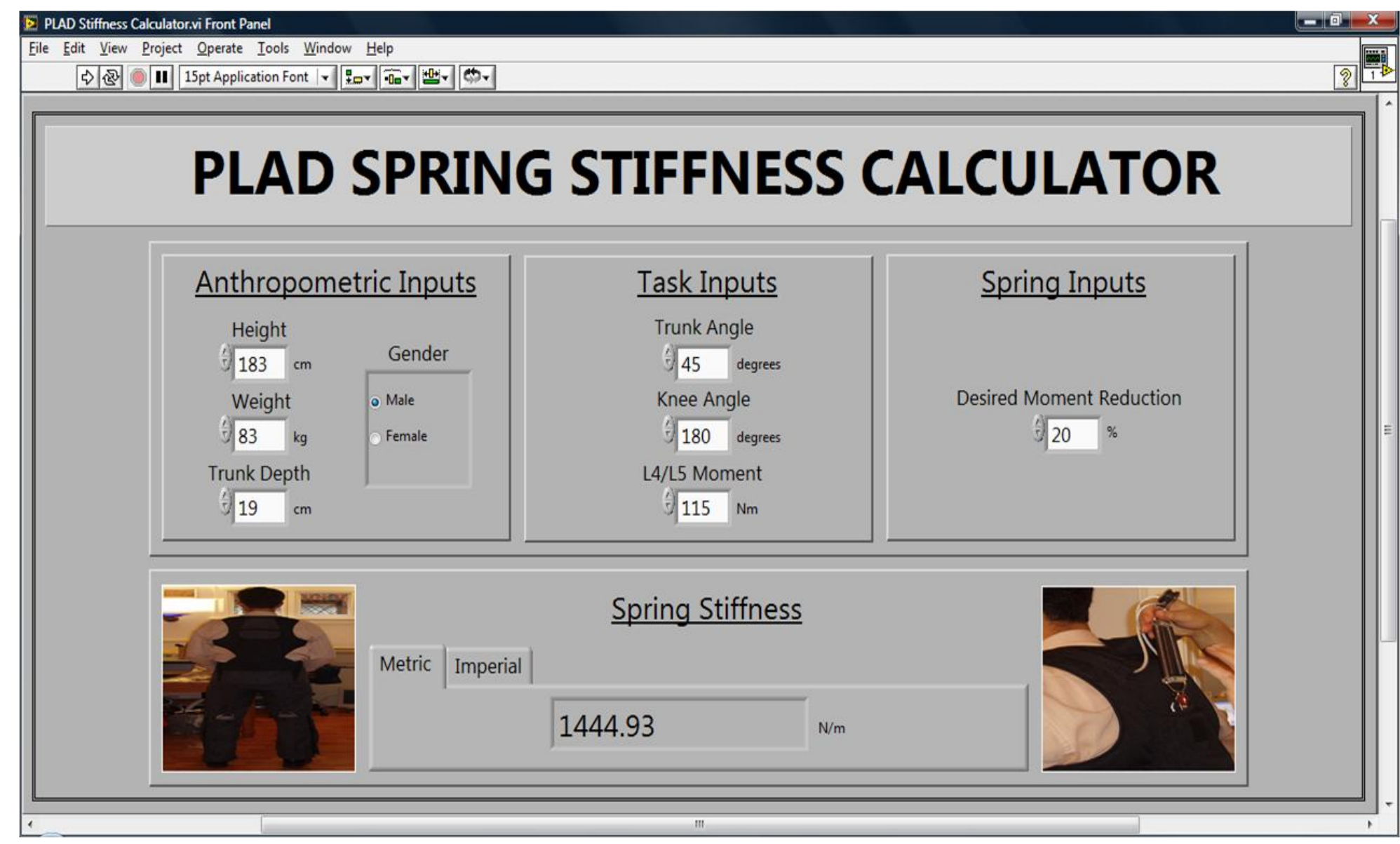

Figure 3.3. Custom “Spring Stiffness Calculator” program developed within Labview Version 8.0. 
(Equation 2); dividing this moment by PLAD's moment arm to get the force required for offsetting this moment (Equation 3); and then dividing this force by the spring excursion calculated via the model to get the required spring stiffness (Equation 4). The output can be viewed in both imperial (lbs/in) and metric $(\mathrm{N} / \mathrm{m})$ units in order to simplify the process of purchasing the necessary springs.

Moment Arm $(m)=(\operatorname{Trunk} \operatorname{Depth}(m) x 0.43)+\left[\left(\operatorname{cosine}\left(\operatorname{TrunkAngle}\left({ }^{\circ}\right)\right)\right) * 0.095 m\right]$

Where, $0.43 \%$ of trunk depth is the average distance from the centre of $\mathrm{L}_{4} / \mathrm{L}_{5}$ to the back surface (McGill et al., 1988), and 0.095m is the width of the back pelvic spacers used within the PLAD. Note that with increased trunk flexion the PLAD's moment arm decreases.

Moment to be Off set $(\mathrm{Nm})=\frac{L 4}{L 5} \operatorname{Moment}(\mathrm{Nm}) x\left(\frac{\text { Desired Moment Reduction (\%) }}{100}\right)$

Force to be Off set $(\mathrm{N})=\frac{\text { Moment to be Off set }(\mathrm{Nm})}{\text { PLAD's Moment Arm }(\mathrm{m})}$

Required Spring Stiffness $\left(\frac{N}{m}\right)=\frac{\text { Force to be Off } \operatorname{set}(N)}{\text { Spring Excursion }(m)}$

\subsection{Discussion}

The present study was designed to address previous limitations of the PLAD with respect to the rubber band elastic elements situated along the back of the device. Although the PLAD no longer possesses this type of element, but instead possesses a series of springs, the same questions needed to be addressed before carrying out field work in an automotive assembly plant. With the computer program that was generated, which takes into account the developed model for finding spring excursion, it is now 
possible to control the PLAD's force contribution and provide individuals with a customized amount of support based on their anthropometry and working posture.

The ability to customize and provide a specific amount of support to each individual should drastically decrease the amount of variation in results found between subjects within a study (Lotz et al., 2008). Previous studies undertaken with the PLAD provided every individual with a different amount of support depending on their anthropometry as well as their working style; the present work will allow researchers to control for both of these when the device is worn. This should be beneficial in seeing the true effects of the device as the purpose of the PLAD is to provide each user with a similar degree of assistance, instead of offloading each wearer's back an unknown amount.

Knowing exactly how much support the device will be providing for various individuals in differing postures will also be effective at ensuring that "too much" support is not provided, which may have the potential to cause deconditioning or alter spinal stability (Abdoli-E et al., 2006). The present work will allow control so that sufficient support is provided to aid in offloading the low back, while ensuring that the erector spinae muscles are not completely shut off. Moreover, if the PLAD is ever prescribed as a return-to-work tool in health care or physiotherapy clinics, workers will be able to be weaned off the device over time in an incremental and known fashion.

There are several limitations to the study. First, the validation process was conducted in a laboratory study with the spring element removed so that unrestricted excursion could be measured. Although the validation sample demonstrated excellent 
results with only a $2 \mathrm{~cm}$ error, this finding might not be the same when the elastic element was engaged in the PLAD. This result could occur because the PLAD materials themselves will add resistance that was not measured in the current study. Another strategy to measure PLAD support would be to connect a strain gauge in series with the spring elements and measure their resistance directly. This would probably result in a consistent offset that would need to be added to the equations.

In summary, although the present work cannot explain one hundred percent of the variance that causes differing amounts of spring excursion, it can explain approximately ninety percent. Thus, we can be much more accurate than before in the amount of support that we are providing to PLAD wearers, which has numerous benefits as previously mentioned. Future validation work will occur whereby the computer program that was developed will be used to provide a known and identical amount of support to all wearers in a subject pool; it is hypothesized that reductions in low back demand will be similar to the amount of help provided, and that the coefficient of variation will be relatively small as all individuals will be receiving a similar amount of support. 


\subsection{References}

Abdoli-E, M., Agnew, M., \& Stevenson, J. (2006). An on-body personal lift augmentation device (PLAD) reduces EMG amplitude of erector spinae during lifting tasks. Clinical Biomechanics , 21, 456-465.

Abdoli-E, M., Stevenson, J., Reid, S., \& Bryant, T. (2007). Mathematical and empirical proof of principle for an on-body personal lift augmentation device. Journal of Biomechanics , 40, 1694-1700.

Lotz, C., Agnew, M., Godwin, A., \& Stevenson, J. (2008). The effect of an on-body personal lift-assist device (PLAD) on fatigue during a repetitive lifting task. Journal of Electromyography and Kinesiology, In Press.

McGill, S., Patt, N., \& Norman, R. (1988). Measurement of the trunk musculature in active males using CT scan radiography: implications for force and moment generating capacity about the L4/L5 joint. Journal of Biomechanics , 21 (4), 329-341.

Peebles, L., \& Norris, B. (1998). Adult Data: The Handbook of Adult Anthropometric and Strength Measurements- Data for Design Safety. Nottingham, UK: Government Consumer Safety Research, Department of Trade and Industry.

Punnett, L., Fine, L., Keyserling, W., Herrin, G., \& Chaffin, D. (1991). Back disorders and nonneutral trunk postures of automobile assembly workers. Scandinavian Journal of Work and Environmental Health, 17, 337-346. 


\section{CHAPTER 4.0}

EFFECTIVENESS OF AN ON-BODY LIFTING AID AT REDUCING LOWBACK PHYSICAL DEMANDS DURING AN AUTOMOTIVE ASSEMBLY TASK: ASSESSMENT OF EMG RESPONSE AND USER ACCEPTABILITY

\section{Abstract}

The personal lift-assist device (PLAD) is an on-body ergonomic aid that has been proven effective at reducing low back muscular demand and localized muscle fatigue in laboratory simulated lifting tasks. The purpose of this study was to investigate the effectiveness and user acceptability of the PLAD (Version 6) at an automotive manufacturing facility, with operators who perform an assembly process requiring forward bending and static holding. Data were collected over two consecutive and randomized days on eight male and two female operators who build cars on an assembly line. Surface EMG data were collected at six sites on the low back and abdomen, and a tri-axial accelerometer was mounted on each subject's sternum to measure trunk inclination. Use of the PLAD significantly reduced the thoracic and lumbar erector spinae muscle activity and predicted-compressive force at the $10^{\text {th }}, 50^{\text {th }}$, and $90^{\text {th }}$ amplitude probability distribution (APDF) percentile levels $(\mathrm{p}<0.05)$ without significantly increasing rectus abdominus activity. Similarly, ratings of perceived exertion were found to be significantly lower when wearing the PLAD $(\mathrm{p}=0.006)$. Trunk inclination was not significantly different between days $(\mathrm{p}=0.298)$. Subjective opinions were positive, with workers providing an overall score of 4.2 out of $5(84 \%)$ on a questionnaire aimed at determining user acceptability. All subjects reported feeling positive assistance from the device, and 8/10 (80\%) said they would wear the device every day. With slight alterations, workers felt that PLAD would be beneficial at reducing low back forces and 
discomfort in various industrial tasks that place excessive physical demands on the low back. 


\subsection{Introduction}

Low back disorders (LBD) are the most prevalent of all musculoskeletal disorders and are a major health and socioeconomic problem in the western world (Woolf \& Pfleger, 2003). Although LBD are associated with many variables (e.g., age, physical fitness, smoking, excess body weight, psychological factors, back strength, and abdominal muscle strength), a recent study has shown that $37 \%$ of all LBD are directly attributable to occupational risk factors (RF) (Punnett et al., 2005). Forward bending and static holding are prominent occupational RF that often occur concurrently and repetitively in automotive settings (Punnett et al., 1991) where productivity, quality, and profitability are essential (Landsbergis et al., 1999). As a result of these RF, many automotive workers experience a LBD at some point in their careers. Punnett et al. (1991) evaluated the health effects through odds ratios (OR) of non-neutral trunk postures in automotive assembly workers and found that LBD were associated with mild $\left(21-45^{\circ}\right)$ $(\mathrm{OR}=4.9)$ or severe $(\mathrm{OR}=5.7)\left(>45^{\circ}\right)$ trunk flexion. Within this investigation, $84 \%$ and $51 \%$ of workers were found to work in mild or severely flexed postures respectively for various lengths of time. Moreover, these postures were held statically for up to $80 \%$ of the work cycle. To make matters worse, automotive assembly workers carry out these cycles repetitively for up to 10 hours a day (Punnett et al., 1991). Norman et al. (1998) and Kerr et al. (2001) found that cumulative loading variables, including the integrated lumbar moment and cumulative lumbar disc compression and shear, were all significantly different at $\mathrm{p}<0.05$ between automotive assembly LBD cases and non-cases.

Erector spinae muscle activity, which translates into the development of spinal compression and shear forces, has been found to significantly increase with trunk flexion 
up to $45^{\circ}$ (Sakamoto \& Swie, 2003). Futhermore, static loading of the low back at as low as $2 \%$ maximum voluntary contraction can reduce tissue oxygenation and disc nutrition, possibly leading to muscle ischemia (McGill et al., 2000). Static postures can also cause discomfort, aches, and pains; and are associated with increased risk of arthritis in the joints, tendons, and muscles (Genaidy \& Karwowski, 1993). Ergonomic off-body materials handling devices, such as hoists, lifts, and body slings, are some of the strategies presently being used to reduce workers' mechanical exposure to these acute and cumulative RF, while still maintaining a lean production strategy (Chaffin et al., 1999; Hermans et al., 1999). However, these devices possess limitations including: large spinal forces due to the inertia of the device and load when moved dynamically, using these devices can be time and space consuming, workers will tend not to use them if loads fall within their strength capacity, the position of the device hinders movements, ample learning is required, and finally, these devices are quite costly (Chaffin et al., 1999; Hermans et al., 1999; Resnick \& Chaffin, 1997; Woldstad \& Chaffin, 1994).

The personal lift-assist device (PLAD) is an on-body ergonomic aid that has proven effective at reducing low back muscular demand, spinal moments, and localized muscle fatigue in laboratory simulated lifting tasks (Abdoli-E \& Stevenson, 2008; Abdoli-E et al., 2006; Lotz et al., 2008). It possesses external elements that run posteriorly and along a similar line of action as the erector spinae. These elements are offset from the spinal column and thus possess a mechanical advantage over the erector spinae, which reduces their muscular force requirements when the trunk is flexed during lifting tasks. PLAD has yet to be evaluated for static forward bending tasks, and effectiveness and user acceptability also remain unproven in an industrial setting. 
Morever, the characteristics of PLAD Version 6 have not been studied scientifically. Thus, the purpose of the present study was to investigate these variables in an automotive manufacturing facility with operators who perform an assembly process requiring forward bending and static holds. It was hypothesized that the PLAD (Version 6) would significantly reduce low back muscular activity, predicted spinal compression, and ratings of perceived exertion, without significantly increasing abdominal muscle activity or trunk inclination. It was also believed that workers would have positive responses about the PLAD and would want to wear the device when completing a specific assembly task.

\subsection{Methods}

\subsubsection{Experimental Design}

The analyzed assembly task involved working on the front dash from the left side of each car (Figure 4.1), and required workers to spend approximately half of their time in a static flexed forward posture and half in a standing posture (see Appendix $\mathrm{C}$ for job task details). Data collection was test/re-test in nature, using a balanced and randomized design in terms of treatment order presentation, and occurred with automotive assembly operators who were building cars on an assembly line over two consecutive days (Condition X= No PLAD, Condition Y= PLAD). A new car came down the assembly line every 55 seconds, which was the length of the task duty cycle, and subjects repeated the identical task on each car for an entire two-hour job rotation.

\subsubsection{Participants}

Ten ( 8 male, 2 female) healthy automotive operators volunteered for the research study. This number of individuals was chosen based on a sample size calculation done using previous No-PLAD/PLAD EMG data (Abdoli-E et al., 2006) (Appendix D). 

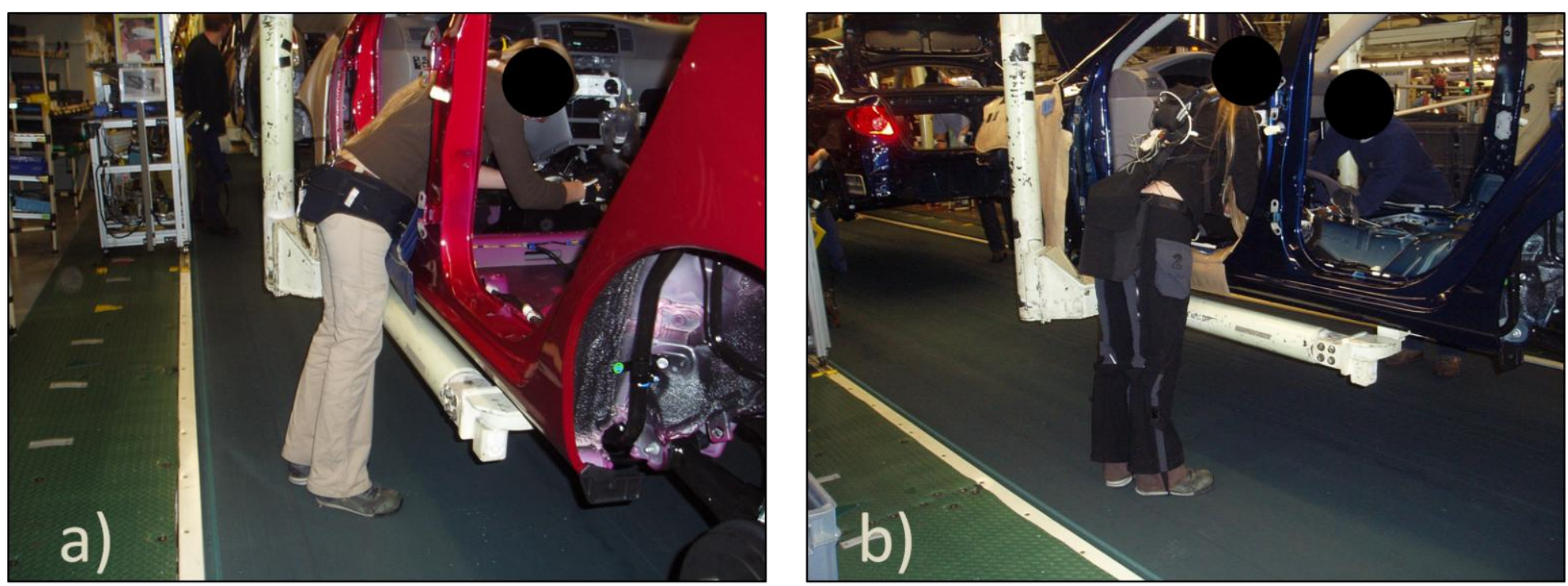

Figure 4.1. The automotive assembly task done without (a) and with (b) the PLAD. (Notice that subjects were forced to bend sagittally into the car and then twist to their left to complete work on the dash). 
Operators were identified well in advance of testing because it was necessary to size them for the PLAD (small, medium, large) and custom match the PLAD's spring stiffness. Participant mean height and mass were $177.33 \mathrm{~cm}(\mathrm{SD}=6.79)$ and $78.06 \mathrm{~kg}(\mathrm{SD}=8.81)$, respectively. Those participants who had history or complaint of chronic pain, major injury or trauma, or major surgery to the back were excluded from the study. Participants were provided with detailed knowledge of all testing procedures prior to participation in the study. The Queen's University Research Ethics Board approved the procedures (Appendix A), and all participants provided informed written consent (Appendix B).

\subsubsection{Instrumentation}

EMG was recorded using a Bluemyo Bluetooth ${ }^{\circledR}$ EMG Telemetry System (Invenium Technologies, Toronto, ON, Canada), an eight-channel system with an EMG bandwidth of $25-500 \mathrm{~Hz}$ and a sampling rate of $1000 \mathrm{~Hz}$. This system uses active AE-100 silver/silver-chloride EMG electrodes with a constant gain of 300V/V and a bandpass filter of $25-500 \mathrm{~Hz}$. EMG signals were collected at six sites on the low back and abdomen: thoracic erector spinae (TES) bilaterally at the level of $\mathrm{T}_{9}(3 \mathrm{~cm}$ lateral), lumbar erector spinae (LES) bilaterally at the level of $\mathrm{L}_{3}(5 \mathrm{~cm}$ lateral), and upper rectus abdominus (RA) bilaterally superior and collateral to the umbilicus (SENIAM, 2005). A reference electrode was also placed on the $\mathrm{C}_{7}$ spinous process. RA was chosen over the external or internal oblique muscles in order to see if greater abdominal activity was required to overcome the stiffness in the spring elements when forward bending. RA was also chosen because the location of oblique electrodes would have been pushing against the car and could have rubbed off. A tri-axial accelerometer (Crossbow Technology Incorporated, San Jose, CA, USA) was also mounted to each subject's sternum to calculate the forward 
inclination angle from standing $\left(0^{\circ}\right)$ under the two testing situations (Hansson et al., 2001). Data from the $Y$ and $Z$ axes were collected in conjunction with the EMG via the Bluemyo system. All data were transmitted for further processing to a Toshiba laptop computer (Toshiba, Markham, ON, Canada) through an AIRcable Host $\mathrm{XR}^{\mathrm{TM}}$ long-range industrial Bluetooth ${ }^{\circledR}$ USB-dongle (Wireless Cables Incorporated, Santa Cruz, CA, USA).

\subsubsection{PLAD Versions 5 and 6}

Prior to carrying out the present research in an automotive assembly plant, a redesign phase was initiated so the device was safer, easy to use, effective, and accepted by both workers and upper management. Although both groups were happy with how the PLAD (Version 4) functioned mechanically, several alterations were required in order to make field work feasible. To ensure that the necessary changes were made, a decision matrix was created by both Queen's University and the automotive manufacturing company using quality functional deployment design (Table 4.1). Both sides met and individually ranked critical PLAD features based on their needs using a maximum of 100 points, where a greater number indicates a greater importance. As one can infer from the matrix, critical PLAD features included: that the device was lightweight and comfortable, that workers could easily activate the elements within the device, that donning and doffing could occur in minimal time, no safety issues or surfaces that could scratch vehicles, and that there was a minimum $20 \%$ load reduction.

After the critical features were decided on, an industrial design firm from Toronto was hired to make the appropriate adjustments to the device. The first large alteration made was incorporating the device into a coverall-like suit; this was done in order to enclose all cords that could be catch hazards and to cover all material that could 
Table 4.1. A PLAD feature decision matrix created by Queen's University and the automotive manufacturing company.

\begin{tabular}{|c|c|c|}
\hline & $\begin{array}{c}\text { Queen's } \\
\text { Weighting }\end{array}$ & $\begin{array}{c}\text { Automotive Company } \\
\text { Weighting } \\
\end{array}$ \\
\hline Quality PLAD Features & $($ Score $=1-100)$ & $($ Score $=1-100)$ \\
\hline Lightweight PLAD & 12 & 16 \\
\hline Comfortable for winter or summer & 15 & 16 \\
\hline Ease of retracting pelvic spacers & 8 & 8 \\
\hline Ease of activating PLAD's elements & 18 & 16 \\
\hline Shoulders, knees and pelvic comfort & 8 & 10 \\
\hline Ease of fitting (sizing) & 12 & 8 \\
\hline $\begin{array}{l}\text { Ease of donning/ doffing (in a few } \\
\text { seconds) }\end{array}$ & 12 & 16 \\
\hline Ease of deactivation for sitting & 7 & 5 \\
\hline Load reduction factor beyond $20 \%$ & 8 & 5 \\
\hline $\begin{array}{c}\text { Total } \\
\end{array}$ & 100 & 100 \\
\hline Expected Features & $(\mathbf{Y} / \mathbf{N})$ & $(\mathbf{Y} / \mathbf{N})$ \\
\hline No safety issues (cords, etc.) & $\mathrm{Y}$ & $\mathrm{Y}$ \\
\hline No surfaces that will scratch vehicles & $\mathrm{Y}$ & Y \\
\hline Back load reduction by $20 \%$ & $\mathrm{Y}$ & $\mathrm{Y}$ \\
\hline
\end{tabular}


potentially cause system damage to vehicles. Having a coverall design also made donning and doffing simple, and ensured that the device was comfortable. PLAD prototype Version 5 was the first to be completely enclosed; however, it did possess some problems: it did not have adequate support in the shoulder or pelvic region; the knee mechanism was not acting solely as a change of direction; the material was much too thick, which could cause heat stresses when working in a hot environment; and the locking mechanism for the string used to tighten and activate the element did not serve its purpose. These issues were resolved in the final prototype (Version 6) used for testing. Figure 4.2 depicts the features of the PLAD design finalized for this field study. Within this design all cords are enclosed inside the suit; the material is light, comfortable, and will not scratch; and all size adjustments can be made at the shoulders, hips, and on the outer part of each lower leg.

One further safety issue that needed to be addressed before collecting field data in industry was the potential for injury that could occur if the single spring element within the PLAD broke at any point when forward bending or lifting. If the element snapped when working, a large perturbation to the spine could occur and cause injury. To resolve this issue, the idea of having several elements positioned in series was proposed. This was done using custom-built triangular stainless steel mounts, each of which attached to the mechanical pulley on one end and between one to five springs on the other (Figure 4.3). With this design if one element were to break there would be a backup, and the perturbation would be greatly reduced or avoided. 

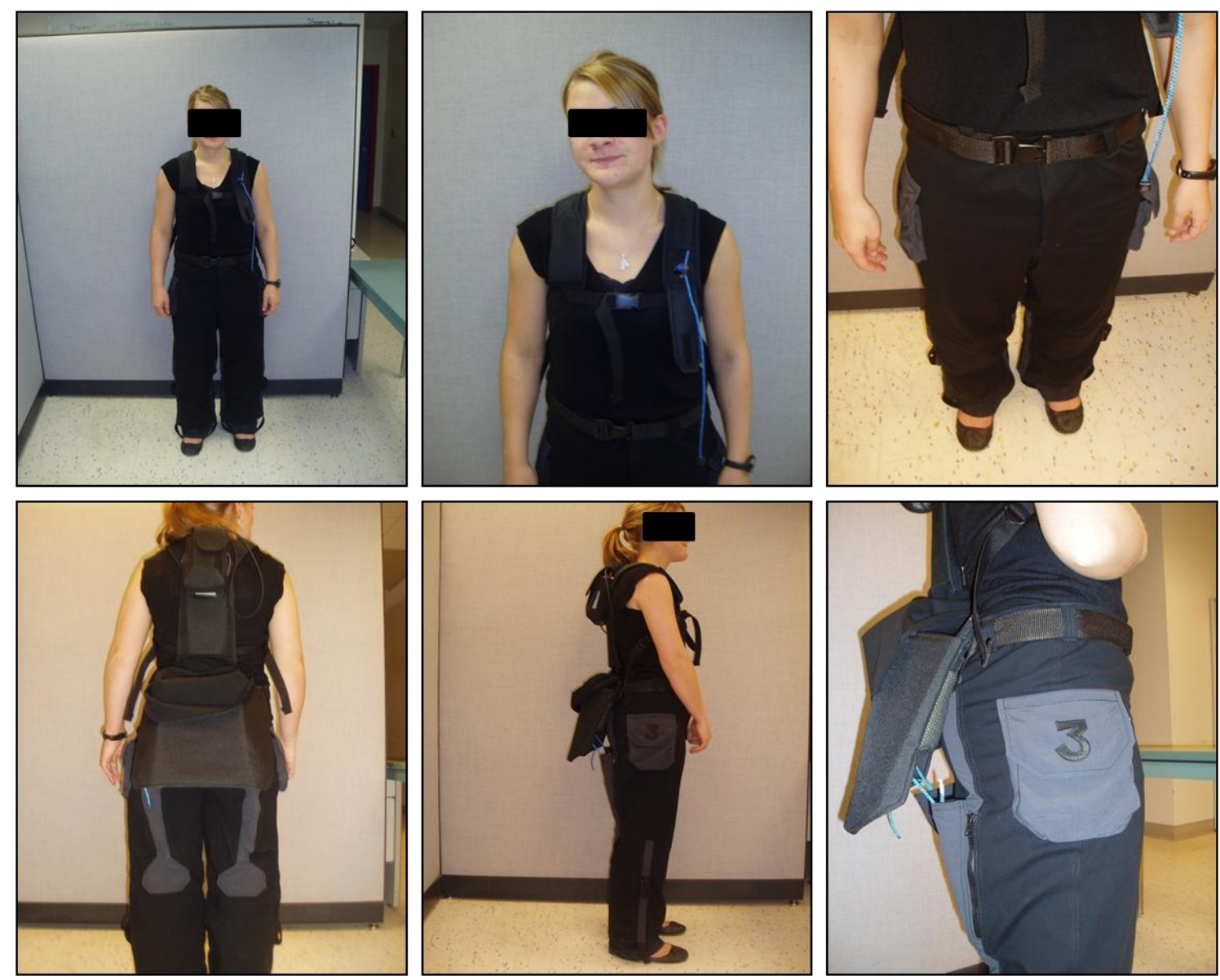

Figure 4.2. The finalized PLAD (Version 6) and its features from three different camera angles. 


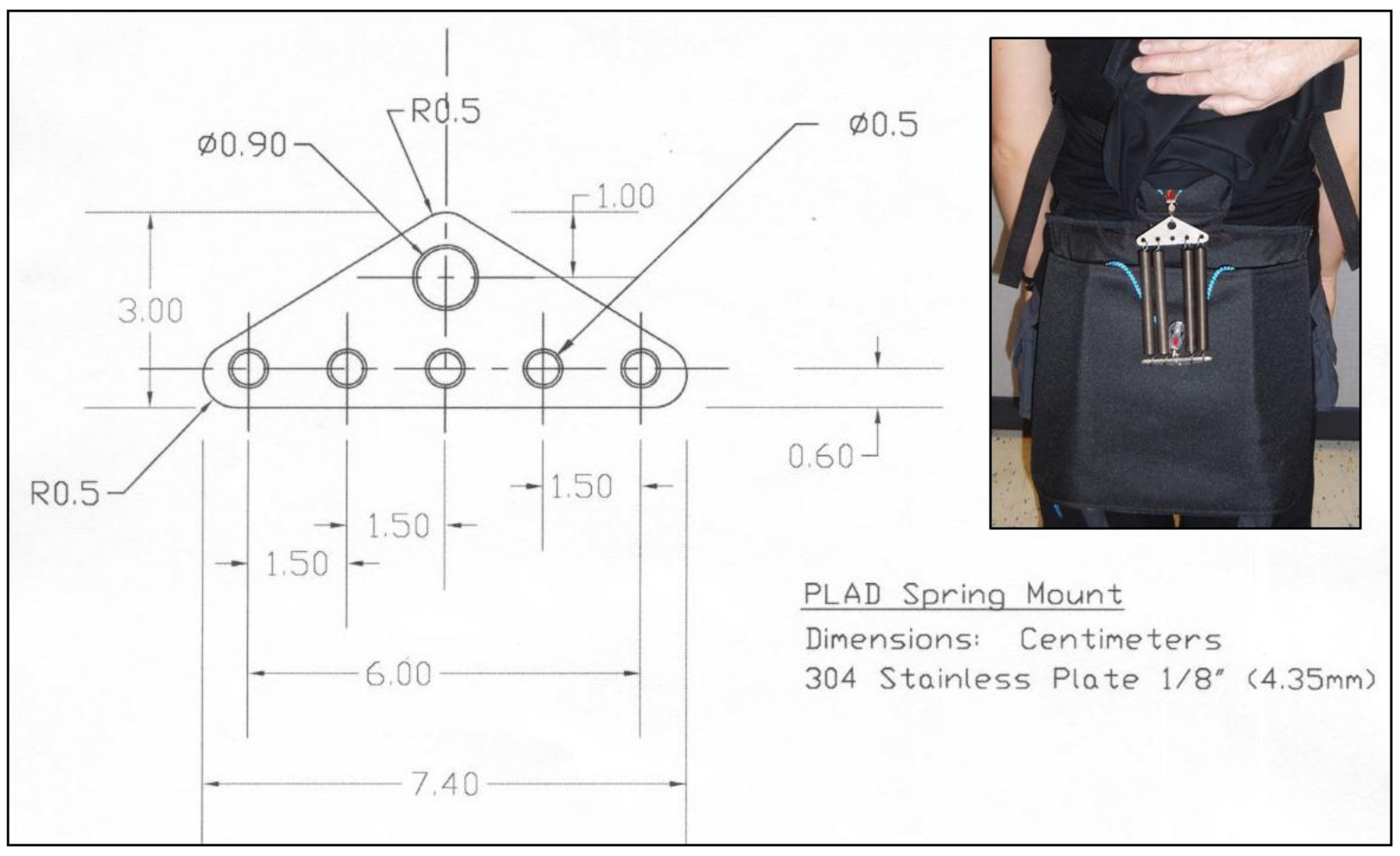

Figure 4.3. Custom-developed spring mount device (to scale) used within the PLAD. 


\subsubsection{Preparations for Testing}

PLAD spring stiffness was chosen to provide the right tension for supporting $20 \%$ of each individual's $\mathrm{L}_{4} / \mathrm{L}_{5}$ moment during the task duty cycle; this is the percent difference that has been observed between automotive workers who possessed a LBD and those who were healthy in terms of peak and cumulative spinal loads (Norman et al., 1998). A $20 \%$ EMG reduction has also been observed with other on-body ergonomic devices (Barrett \& Fathallah, 2001). During custom fitting trials that occurred several weeks before testing, anthropometric measurements and sagittal plane photos of each subject carrying out his/her job were taken. These photos were digitized using the Queen's University Q-Back and Q-Dig computer programs in order to calculate the trunk and knee angles, as well as the $\mathrm{L}_{4} / \mathrm{L}_{5}$ moment in the static working posture. These anthropometric measurements and joint angle calculations were entered into a customized computer program to calculate the required spring stiffness to offload the $\mathrm{L}_{4} / \mathrm{L}_{5}$ moment by $20 \%$ using custom "sizing equations". Although the target spinal offloading was a precise percentage, the resolution in selecting spring stiffness was not infinite. The PLAD design was limited by a maximum of five springs, and by the possible combinations that could be achieved with springs of two varying stiffnesses: $143.95 \mathrm{~N} / \mathrm{m}$ and $351.11 \mathrm{~N} / \mathrm{m}$, respectively. In order to get as close as possible to the desired stiffness, an optimization model was written within Matlab R2007a (The Math Works Inc, Natick, MA, USA) to determine the best combination of five springs (Appendix E). Table 4.2 displays the inputs and outputs from the customized computer program for determining the required spring stiffness, as well as the percent error between the required spring stiffness and that given to each worker. The average percent error was approximately $3 \%$, which indicates that the stiffness provided to each worker was very close to the desired amount. 
Table 4.2. Inputs and outputs from the customized computer program for determining the required spring stiffness for offloading $20 \%$ of each subject's $\mathrm{L}_{4} / \mathrm{L}_{5}$ moment. (Note the ideal combination of springs for each individual determined via an optimization program, as well as the percent error between the required spring stiffness and that given to each worker).

\begin{tabular}{|c|c|c|c|c|c|c|c|c|c|c|}
\hline$\frac{\text { Subject }}{\#}$ & $\frac{\text { Height }}{(\mathrm{cm})}$ & $\frac{\text { Weight }}{(\mathbf{k g})}$ & $\frac{\text { Trunk Depth }}{(\mathrm{cm})}$ & $\frac{\text { Trunk }}{\left.\text { Angle ( }{ }^{\circ}\right)}$ & $\underline{\text { Knee }}$ & $\frac{\text { Moment }}{(\mathrm{Nm})}$ & $\begin{array}{l}\text { Required Spring } \\
\text { Stiffness (N/m) } \\
\end{array}$ & $\begin{array}{l}\text { Ideal Combination } \\
\text { (1=light, } 2=\text { medium }) \\
\end{array}$ & $\frac{\text { Error }}{(\mathbf{N} / \mathbf{m})}$ & $\frac{\%}{\text { Error }}$ \\
\hline 1 & 183.00 & 95.50 & 24.00 & 40.00 & 175.00 & 152.59 & 1497.48 & 12222 & 50.91 & 3.40 \\
\hline 2 & 183.00 & 72.70 & 19.00 & 39.00 & 180.00 & 107.41 & 1662.50 & 22222 & 93.04 & 5.60 \\
\hline 3 & 178.00 & 86.40 & 25.00 & 54.00 & 180.00 & 141.79 & 1332.46 & 11222 & 8.78 & 0.66 \\
\hline 4 & 180.00 & 72.27 & 19.00 & 39.00 & 180.00 & 113.30 & 1627.52 & 12222 & 79.89 & 4.91 \\
\hline 5 & 175.00 & 75.00 & 18.00 & 44.00 & 180.00 & 108.35 & 1513.28 & 12222 & 35.11 & 2.32 \\
\hline 6 & 183.00 & 79.50 & 19.00 & 56.00 & 180.00 & 138.13 & 1648.46 & 22221 & 100.07 & 6.07 \\
\hline 7 & 175.26 & 67.30 & 17.50 & 53.00 & 180.00 & 110.20 & 1453.27 & 2222 & 49.16 & 3.38 \\
\hline 8 & 178.00 & 86.40 & 25.00 & 54.00 & 180.00 & 141.79 & 1332.46 & 11222 & 8.78 & 0.66 \\
\hline 9 & 178.00 & 75.00 & 19.00 & 58.00 & 175.00 & 111.14 & 1309.64 & 11222 & 31.60 & 2.41 \\
\hline 10 & 160.00 & 70.50 & 18.00 & 51.00 & 180.00 & 89.78 & 1051.57 & 222 & 1.76 & 0.17 \\
\hline Average & $\mathbf{1 7 7 . 3 3}$ & 78.06 & 20.35 & 48.80 & 179.00 & 121.45 & 1442.86 & & 45.91 & 2.96 \\
\hline STDEV & 6.79 & 8.81 & 3.04 & 7.50 & 2.11 & 20.40 & 190.87 & & 35.55 & 2.11 \\
\hline
\end{tabular}


Before the data from the accelerometer could be converted from voltages to inclination, the accelerometer had to be calibrated. In order to do so, a custom jig was created to allow the accelerometer to be brought through a series of known inclinations while recording the output voltages (Figure 4.4). Because the automotive assembly task was static in nature, it was possible to calibrate the accelerometer statically at an interval of five degrees $\left(0-90^{\circ}\right)$. Also, since a tri-axial accelerometer references a proportion of gravity in each axis when static, it was possible to take the voltages from two of the axes at each angle (Table 4.3) and create a regression equation for determining 2-D angles based on the $\mathrm{Y}$ and $\mathrm{Z}$ axis voltages using SPSS 15 (SPSS Corporation, Chicago, IL, USA). The regression equation used to calculate trunk inclination angles was thus:

Angle $\left({ }^{\circ}\right)=1130.961-222.585(Y$ Accel $(V))-216.745(Z$ Accel $(V))$

Where, $\mathrm{R}^{2}=0.999$ and $\mathrm{SE}=1.02476$.

\subsubsection{Data Collection}

In a private room, each subject was asked to complete a pre-test baseline survey regarding aches and pains, the assembly task, and perceptions about the PLAD (Appendix F). This was followed by outfitting subjects with an accelerometer and EMG electrodes. The accelerometer was mounted on the sternum with double-sided tape and stretchy fabric-based adhesive tape to ensure it remained affixed throughout the remainder of the testing protocol. The locations for electrodes were lightly abraded with rubbing alcohol and sprayed with anti-perspirant to prevent loss of signal due to excessive sweating. All electrodes were also held in place using double sided-tape and covered with stretchy fabric-based adhesive tape. 


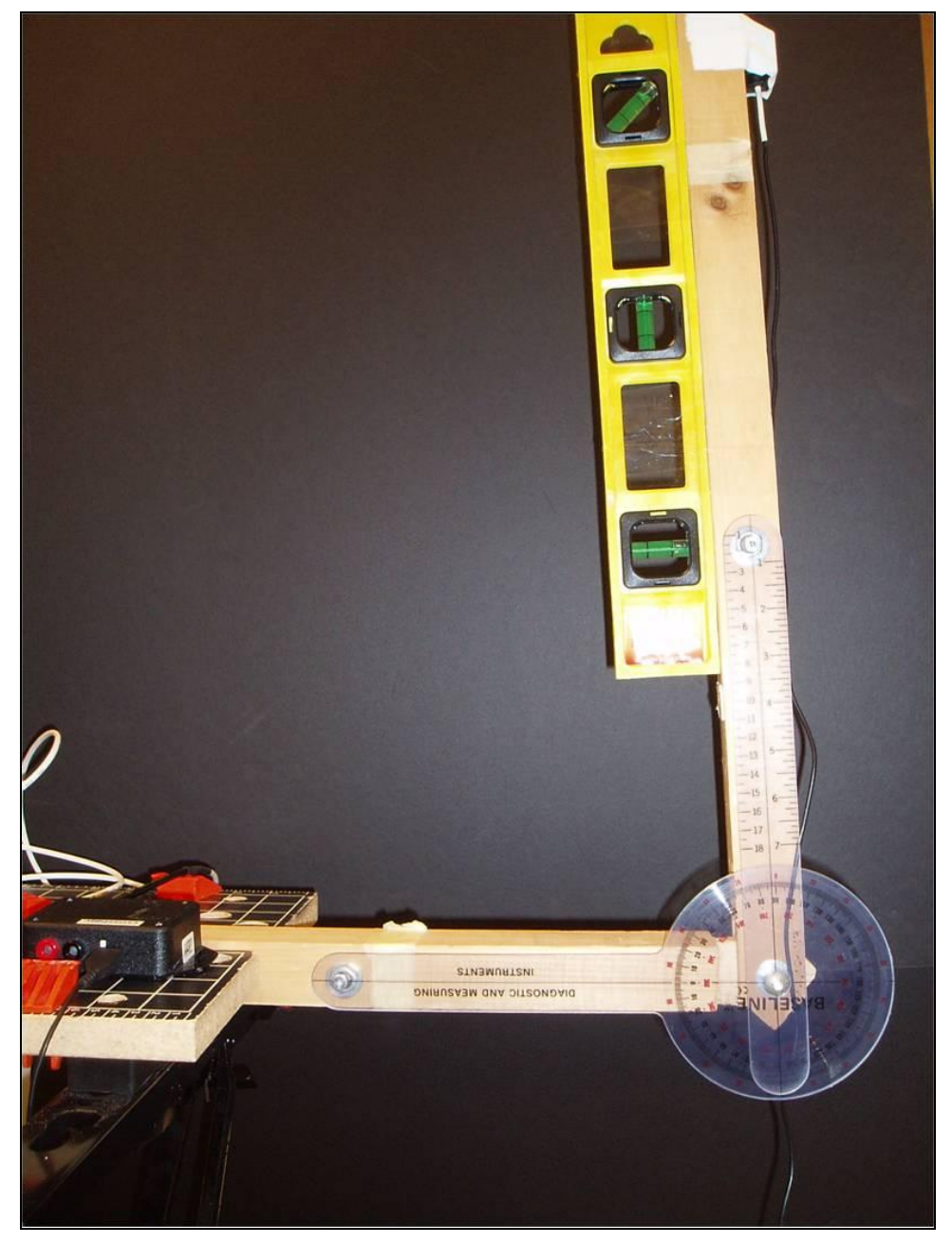

Figure 4.4. The accelerometer calibration jig used to determine the $\mathrm{Y}$ and $\mathrm{Z}$ axis voltages at a series of inclination angles $\left(0-90^{\circ}\right)$. 
Table 4.3. The measured voltages from the $\mathrm{Y}$ and $\mathrm{Z}$ accelerometer axes at a series of inclinations from 0-90 degrees.

\begin{tabular}{|c|c|c|}
\hline $\begin{array}{c}\text { Angle } \\
\text { (Degrees) }\end{array}$ & $\begin{array}{c}\text { Y Acceleration } \\
\text { (Voltage) }\end{array}$ & $\begin{array}{c}\mathbf{Z} \text { Acceleration } \\
\text { (Voltage) }\end{array}$ \\
\hline 0 & 2.6706 & 2.4694 \\
\hline 5 & 2.6707 & 2.4491 \\
\hline 10 & 2.6686 & 2.4315 \\
\hline 15 & 2.6659 & 2.415 \\
\hline 20 & 2.6611 & 2.3981 \\
\hline 25 & 2.6529 & 2.3821 \\
\hline 30 & 2.6454 & 2.3658 \\
\hline 35 & 2.6361 & 2.3517 \\
\hline 40 & 2.6261 & 2.3372 \\
\hline 45 & 2.6149 & 2.3249 \\
\hline 50 & 2.6017 & 2.3129 \\
\hline 55 & 2.5882 & 2.3021 \\
\hline 60 & 2.574 & 2.2936 \\
\hline 65 & 2.5564 & 2.2868 \\
\hline 70 & 2.5418 & 2.2798 \\
\hline 75 & 2.527 & 2.2746 \\
\hline 80 & 2.5139 & 2.2716 \\
\hline 85 & 2.5002 & 2.2688 \\
\hline 90 & 2.4693 & 2.2655 \\
\hline
\end{tabular}


To remove baseline noise, two five-second trials of resting EMG were collected. For EMG normalization, two different techniques were applied. Firstly, subjects assumed a 'reference position' with the knees slightly bent and the trunk bent to $45^{\circ}$, while holding a box with handles weighing 16kg (Figure 4.5). In order to ensure near identical postures each time subjects assumed the normalization posture, a large goniometer was used to measure the trunk inclination angle from vertical. EMG was recorded for five seconds twice and averaged, and later all EMG was normalized to this reference. Secondly, low back muscle EMG was normalized to compression (CNEMG), an EMG-based method developed by Potvin et al. (1990) for assessing spinal loading in the field. When all subjects were in the 'reference position', a still photo was taken in the sagittal plane, and spinal compression was calculated in that posture using the QBack biomechanical model (Table 4.4; Figure 4.5). This compression value was then divided by the average EMG in this posture in order to get a normalization factor (ratio) of spinal compression per unit of EMG. When calculating CNEMG, there was an bias applied to the signal so that at zero EMG activation there was a low back compression value equal to one half of the subject's body weight (Equation 5); this was used as a rough estimate of upper body weight.

$\operatorname{CNEMG}(N)=\left(\left(\frac{\text { Compression }(N)-\frac{1}{2} \text { Body Weight }(N)}{\text { Average Reference Posture EMG }(V)}\right) x\right.$ EMG $\left.(V)\right)+\frac{1}{2}$ Body Weight $(N)$

After normalization trials were completed, subjects were outfitted with the PLAD (Condition Y only) and asked to perform their normal work duties for a two-hour shift. In order to make the data files manageable for data processing, five duty-cycles (55 seconds per car) of EMG were collected followed by one cycle without EMG collection and so on. In total, approximately one hour (12 trials x five cars) of EMG data per subject per day 

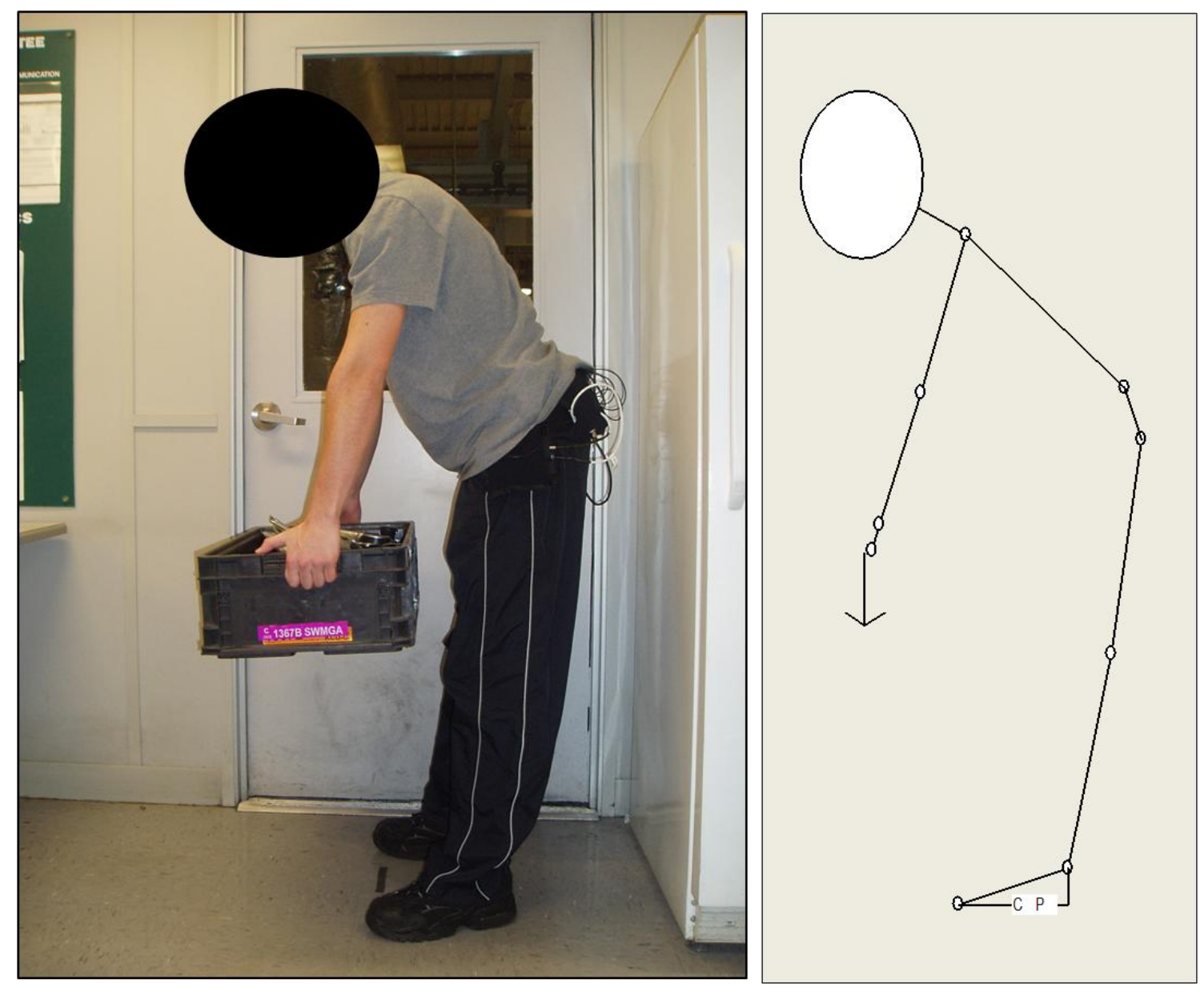

Figure 4.5. The reference posture used for electromyographical (EMG) normalization, as well as the biomechanical model used for determining spinal compression. 
Table 4.4. Calculated compression values (Newtons) for electromyographical (EMG) normalization for all 10 subjects on the two testing days.

\begin{tabular}{|c|c|c|}
\hline Subject \# & No PLAD (N) & PLAD (N) \\
\hline 1 & 3522.63 & 3594.83 \\
\hline 2 & 2702.30 & 2550.32 \\
\hline 3 & 2971.60 & 2991.26 \\
\hline 4 & 3038.37 & 2974.87 \\
\hline 5 & 3002.54 & 2996.65 \\
\hline 6 & 3217.52 & 3208.87 \\
\hline 7 & 2807.60 & 2705.01 \\
\hline 8 & 3057.45 & 2825.44 \\
\hline 9 & 2629.11 & 2612.68 \\
\hline 10 & 2375.97 & 2294.85 \\
\hline Average & $\mathbf{2 9 3 2 . 5 1}$ & $\mathbf{2 8 7 5 . 4 8}$ \\
\hline
\end{tabular}


were recorded. During-test questionnaires (every 10 minutes) and a post-test survey were given to assess user acceptability (Appendix F). Borg ratings of perceived exertion (RPE) were also implemented as an indicator of how hard individuals believed they were working both with and without the device. Following testing, all instrumentation was removed, and subjects returned to their normal work duties.

\subsubsection{Data Processing}

Custom software developed using Labview 8.0 (National Instruments, Austin, TX, USA) and Matlab R2007a (The Math Works Inc., Natick, MA, USA) was used for EMG and accelerometer data processing (Appendix E). All raw EMG signals were first centered about the mean of the signal to remove any DC components. Next, EMG data were band pass filtered between $30 \mathrm{~Hz}$ and $450 \mathrm{~Hz} ; 30 \mathrm{~Hz}$ was chosen in order to remove electrocardiogram contamination from the signals (Drake \& Callaghan, 2006). To remove unwanted harmonics from noise that was superimposed on the EMG signals, a series of notch filters $(66.67 \mathrm{~Hz} \pm 0.5 \mathrm{~Hz}, 133.33 \mathrm{~Hz} \pm 0.5 \mathrm{~Hz}, 200 \mathrm{~Hz} \pm 5 \mathrm{~Hz}, 267.67 \mathrm{~Hz} \pm 2 \mathrm{~Hz}$, $333.33 \mathrm{~Hz} \pm 2 \mathrm{~Hz}, 400 \mathrm{~Hz} \pm 5 \mathrm{~Hz})$ was used. To ensure that adequate power remained after the notch-filtering, a RMS percent difference calculation was carried out between the notched and unnotched EMG signal for all muscles during one trial of five cars for each individual on each testing day (Appendix G). It was determined that the average RMS percent difference across all muscles and subjects was 2.66\%; this was deemed acceptable for removing the unwanted noise. Then, filtered EMG data were rectified and the resting trial average was removed from each data point. Data were then dual pass filtered using a $2^{\text {nd }}$ order $3 \mathrm{~Hz}$ digital low pass Butterworth filter (Potvin et al., 1996) and normalized with respect to the reference contraction and spinal compresssion. For both 
conditions, data were then quantified based on the $10^{\text {th }}, 50^{\text {th }}$, and $90^{\text {th }}$ percentile activation amplitudes obtained from an amplitude probability distribution function analysis (APDF) (Jonsson, 1982). Refer to Figure 4.6 for a flow chart of this entire process. It is important to note that the RA data for subject 2 under the No PLAD condition were found to be problematic and were subsequently removed.

The accelerometer data from the $\mathrm{Y}$ and $\mathrm{Z}$ axes were converted into a trunk inclination angle using the aforementioned regression equation (Equation 5) and dual pass filtered ( $2^{\text {nd }}$ order low pass Butterworth) with a cut-off frequency of $0.25 \mathrm{~Hz}$ in order to smooth the data. All trials were zeroed based on standing at rest, where the inclination angle was considered to be zero. Next, the average trunk inclination angle for each car was calculated by finding at which point the subject bent into and stood up out of the car. These points were determined by using sliding cursors and taking the average of all data points between the two cursors (Figure 4.7). This process was carried out for every car under each condition (No PLAD, PLAD) in order to reveal a total average trunk inclination angle both when wearing and not wearing the PLAD. Trunk inclination angles were calculated in this fashion because large inconsistencies and spikes in the data (e.g., large spikes from forward bending after dropping something) made automation nonfeasible.

\subsubsection{Statistical Analysis}

All quantitative statistical analyses were performed with SPSS 15 for Windows (SPSS Corporation, Chicago, IL, USA) statistical software. Repeated measures analysis of variance (ANOVA), where the repeated measure was the same subject on two different days, was applied to make comparisons between the No PLAD and PLAD conditions. 


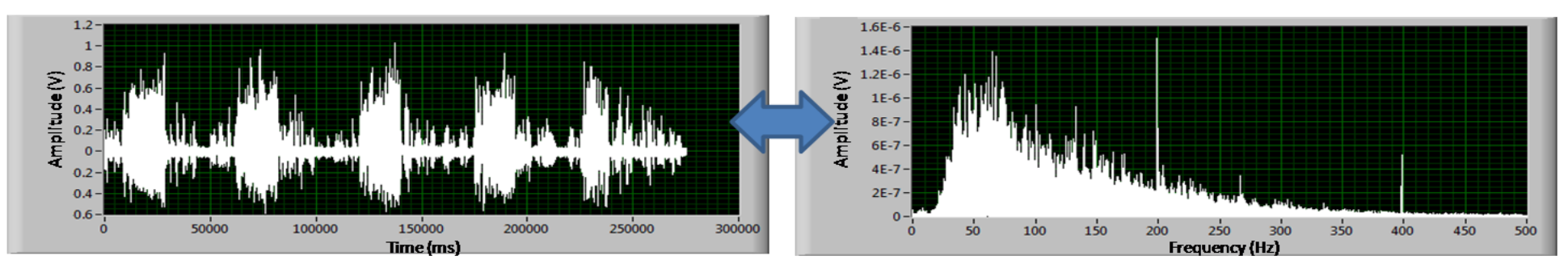

Bandpass \& Notch Filtered EMG Time Data

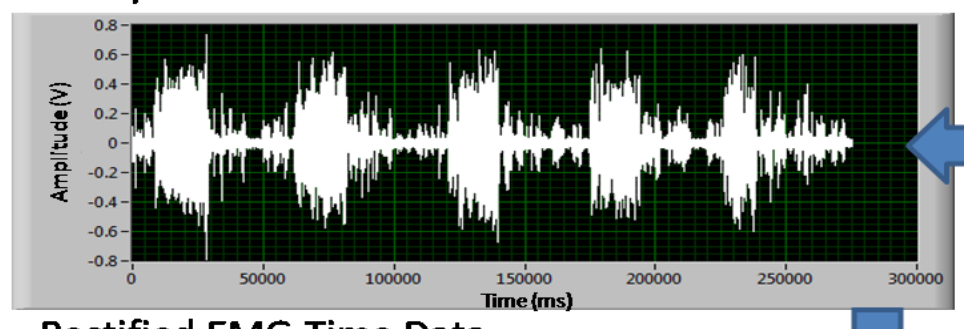

Bandpass \& Notch Filtered EMG Frequency Data
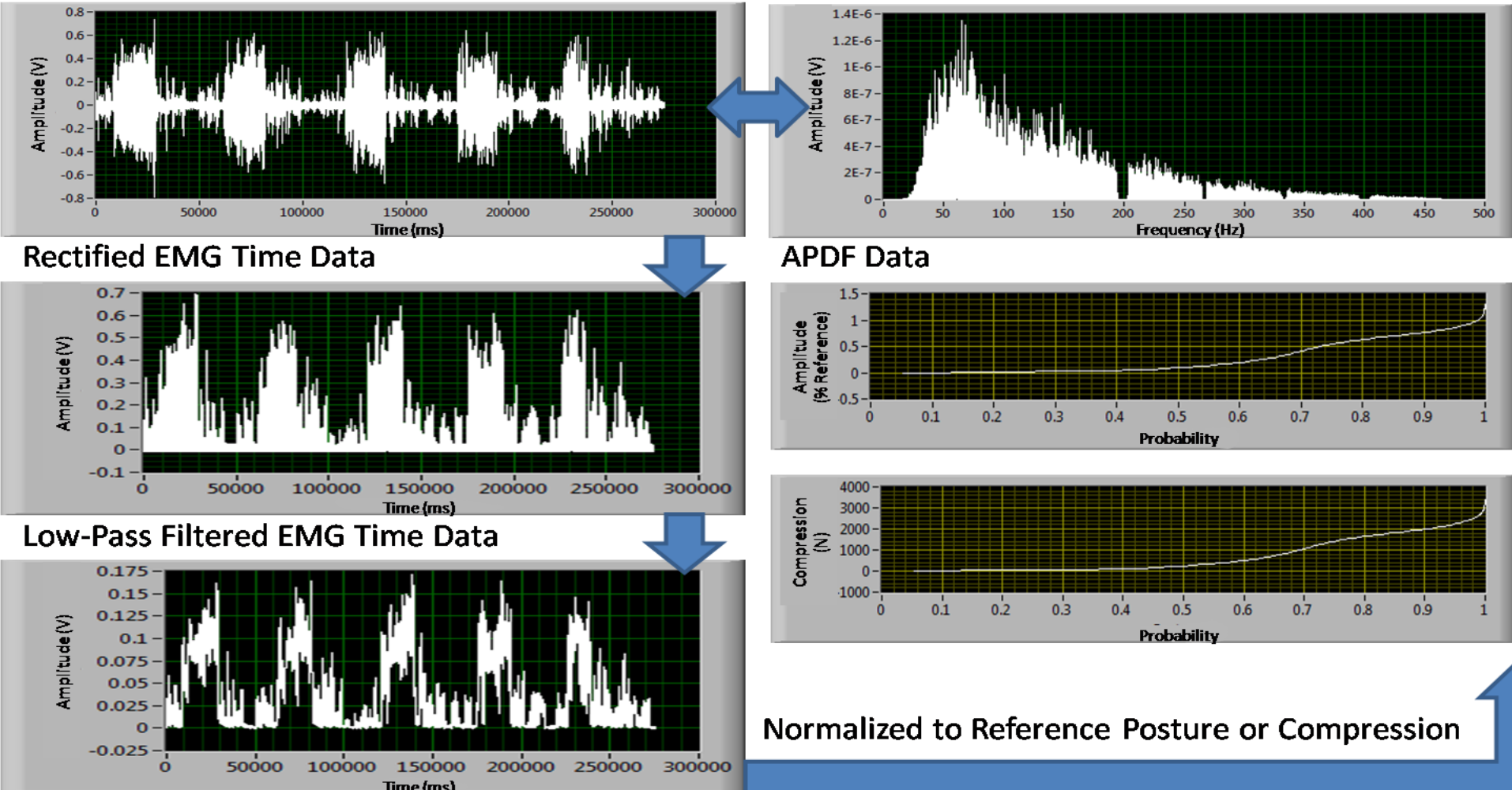

APDF Data
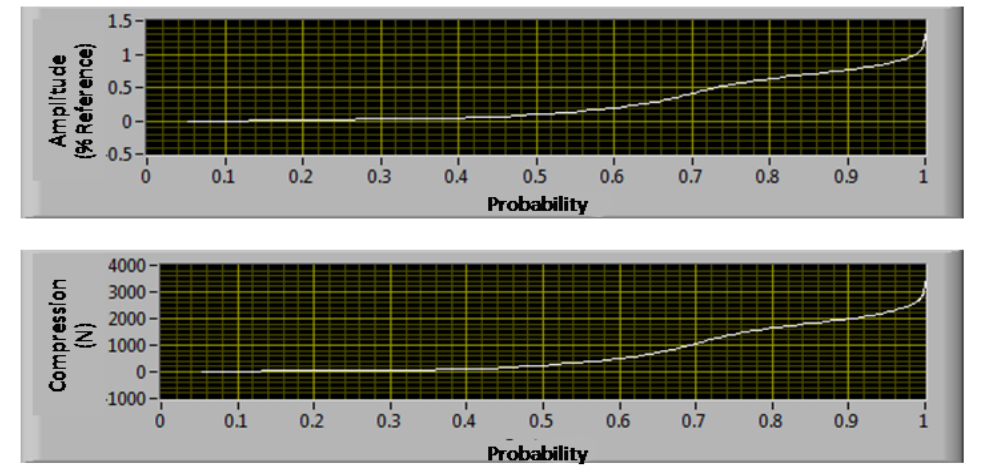

Normalized to Reference Posture or Compression

Figure 4.6. A flow chart of the electromyography (EMG) processing technique. 


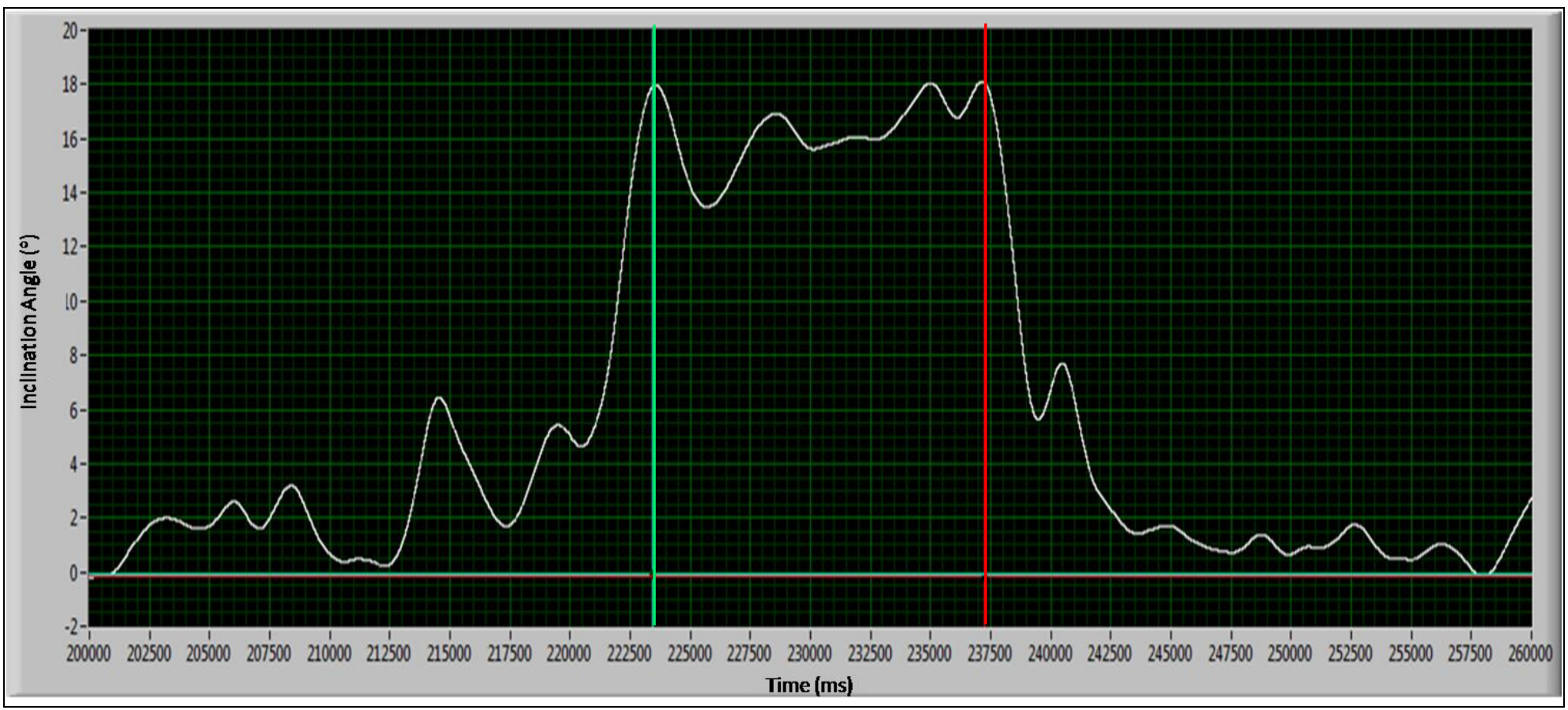

Figure 4.7. A trunk inclination angle versus time curve for one car during the automotive assembly task. (Note that the average angle was taken between the two cursors, which were the points when the subject bent into the car and then stood back up, respectively). 
The independent variables were the device (No PLAD/PLAD) condition and the side (Left/Right) condition; the dependent variables were EMG data for the TES, LES, and RA. Repeated measures ANOVAs were performed for each APDF level $\left(10^{\text {th }}, 50^{\text {th }}\right.$, and $\left.90^{\text {th }}\right)$ and were also used to test if there were significant differences in ratings of perceived exertion (RPE) and the trunk inclination angle between conditions. The significance level alpha $(\alpha)$ was set at 0.05 for all comparisons; this was the alpha level used when determining a priori sample size. Quantitative analyses in the form of descriptive statistics also occurred to assess the PLAD's user acceptability.

\subsection{Results}

All statistical results are summarized in Table 4.5; both objective and subjective results will be discussed in further detail below. When looking at the APDF results it must be noted that the $10^{\text {th }}$ percentile level (workers spend $10 \%$ of the work cycle at or below this amplitude) is approximately equal to standing at rest, the $50^{\text {th }}$ percentile amplitude is equal to the median activation across the entire cycle, and the $90^{\text {th }}$ percentile amplitude is approximately equal to when the subject is flexed into the car (Figure 4.8).

\subsubsection{Reference-Normalized EMG}

EMG signals in the low back (TES and LES) or abdominal (RA) regions did not increase with time at any APDF percentile (Figure 4.9). An example of the ANOVA results for the TES muscle can be found in Appendix H. As a result, EMG values for trials one through twelve were collapsed into one average value. The main effect of wearing the PLAD significantly reduced the reference posture normalized TES and LES muscle activity at the $10^{\text {th }}, 50^{\text {th }}$, and $90^{\text {th }}$ percentile levels $(\mathrm{p}<0.05)$, without any significant increases in rectus abdominus activity (Figure 4.10). Percent differences 
Table 4.5. Differences between the No-PLAD and PLAD conditions and results of the two-way repeated measures ANOVA.

\begin{tabular}{|c|c|c|c|c|c|c|c|c|c|}
\hline & & & \multicolumn{4}{|c|}{ Mean and Standard Deviation Results } & \multirow{2}{*}{\multicolumn{3}{|c|}{$\begin{array}{c}\text { ANOVA Results } \\
\text { P-Values } \\
\end{array}$}} \\
\hline & & & \multicolumn{2}{|c|}{ No PLAD } & \multicolumn{2}{|c|}{$\begin{array}{r}\text { PLAD } \\
\end{array}$} & & & \\
\hline & & & Right & Left & Right & Left & Device & Side & Interaction \\
\hline \multirow{9}{*}{ 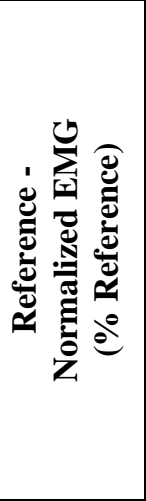 } & \multirow{3}{*}{ TES } & 10th & $3.4( \pm 2.5)$ & $2.6( \pm 1.7)$ & $2.1( \pm 1.4)$ & $1.3( \pm 1.1)$ & 0.011 & 0.093 & 0.949 \\
\hline & & 50th & $25.4( \pm 14.9)$ & $25.4( \pm 11.1)$ & $18.6( \pm 6.5)$ & $17.6( \pm 6.0)$ & 0.011 & 0.815 & 0.548 \\
\hline & & 90th & $79.6( \pm 23.9)$ & $88.2( \pm 17.5)$ & $66.8( \pm 12.6)$ & $73.6( \pm 9.6)$ & 0.008 & 0.157 & 0.758 \\
\hline & \multirow{3}{*}{ LES } & 10th & $5.1( \pm 4.1)$ & $4.5( \pm 4.5)$ & $3.4( \pm 3.5)$ & $3.6( \pm 2.7)$ & 0.018 & 0.724 & 0.337 \\
\hline & & 50th & $26.7( \pm 18.2)$ & $33.4( \pm 17.7)$ & $23.5( \pm 17.4)$ & $28.0( \pm 13.1)$ & 0.036 & 0.018 & 0.286 \\
\hline & & 90th & $77.3( \pm 16.8)$ & $90.5( \pm 12.6)$ & $69.1( \pm 19.4)$ & $79.6( \pm 7.5)$ & 0.004 & 0.021 & 0.569 \\
\hline & \multirow{3}{*}{$\mathbf{R A}$} & 10th & $27.0( \pm 15.6)$ & $27.6( \pm 23.2)$ & $26.3( \pm 18.5)$ & $17.6( \pm 14.6)$ & 0.328 & 0.493 & 0.396 \\
\hline & & 50th & $56.1( \pm 22.9)$ & $67.1( \pm 41.7)$ & $64.1( \pm 26.2)$ & $60.3( \pm 24.6)$ & 0.932 & 0.399 & 0.268 \\
\hline & & 90th & $120.2( \pm 52.4)$ & $156.6( \pm 91.3)$ & $159.1( \pm 79.1)$ & $154.4( \pm 65.2)$ & 0.353 & 0.306 & 0.058 \\
\hline \multirow{6}{*}{ 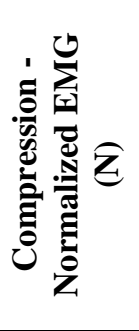 } & \multirow{3}{*}{ TES } & 10th & $473.96( \pm 106.96)$ & $450.01( \pm 62.93)$ & $437.03( \pm 50.64)$ & $417.84( \pm 67.67)$ & 0.011 & 0.090 & 0.879 \\
\hline & & 50th & $1048.97( \pm 440.41)$ & $1048.03( \pm 367.82)$ & $857.80( \pm 233.38)$ & $833.51( \pm 221.96)$ & 0.007 & 0.804 & 0.561 \\
\hline & & 90th & $2413.85( \pm 649.21)$ & $2624.26( \pm 505.99)$ & $2049.26( \pm 505.99)$ & $2215.17( \pm 339.75)$ & 0.004 & 0.167 & 0.737 \\
\hline & \multirow{3}{*}{ LES } & 10th & $516.49( \pm 151.75)$ & $501.49( \pm 151.75)$ & $473.45( \pm 127.20)$ & $478.30( \pm 103.76)$ & 0.019 & 0.725 & 0.363 \\
\hline & & 50th & $1093.56( \pm 591.95)$ & $1268.47( \pm 578.44)$ & $1002.13( \pm 573.85)$ & $1104.37( \pm 434.33)$ & 0.015 & 0.026 & 0.184 \\
\hline & & 90th & $2369.17( \pm 597.52)$ & $2694.34( \pm 485.59)$ & $2139.51( \pm 699.75)$ & $2371.29( \pm 381.63)$ & 0.000 & 0.021 & 0.435 \\
\hline \multicolumn{3}{|c|}{ RPE Borg Scale (6-20) } & \multicolumn{2}{|c|}{$9.7( \pm 2.79)$} & \multicolumn{2}{|c|}{$8.35( \pm 2.38)$} & 0.006 & & \\
\hline \multicolumn{3}{|c|}{ Inclination Angle $\left(^{\circ}\right)$} & \multicolumn{2}{|c|}{$29.90( \pm 8.68)$} & \multicolumn{2}{|c|}{$30.69( \pm 8.14)$} & 0.298 & & \\
\hline
\end{tabular}

$\mathrm{TES}=$ thoracic erector spinae, $\mathrm{LES}=$ lumbar erector spinae, $\mathrm{RA}=$ rectus abdominus; $\mathrm{EMG}=$ electromyography; $10^{\text {th }}, 50^{\text {th }}, 90^{\text {th }}=$ amplitude probability distribution function (APDF) percentiles 


\section{Trunk Inclination Angle}

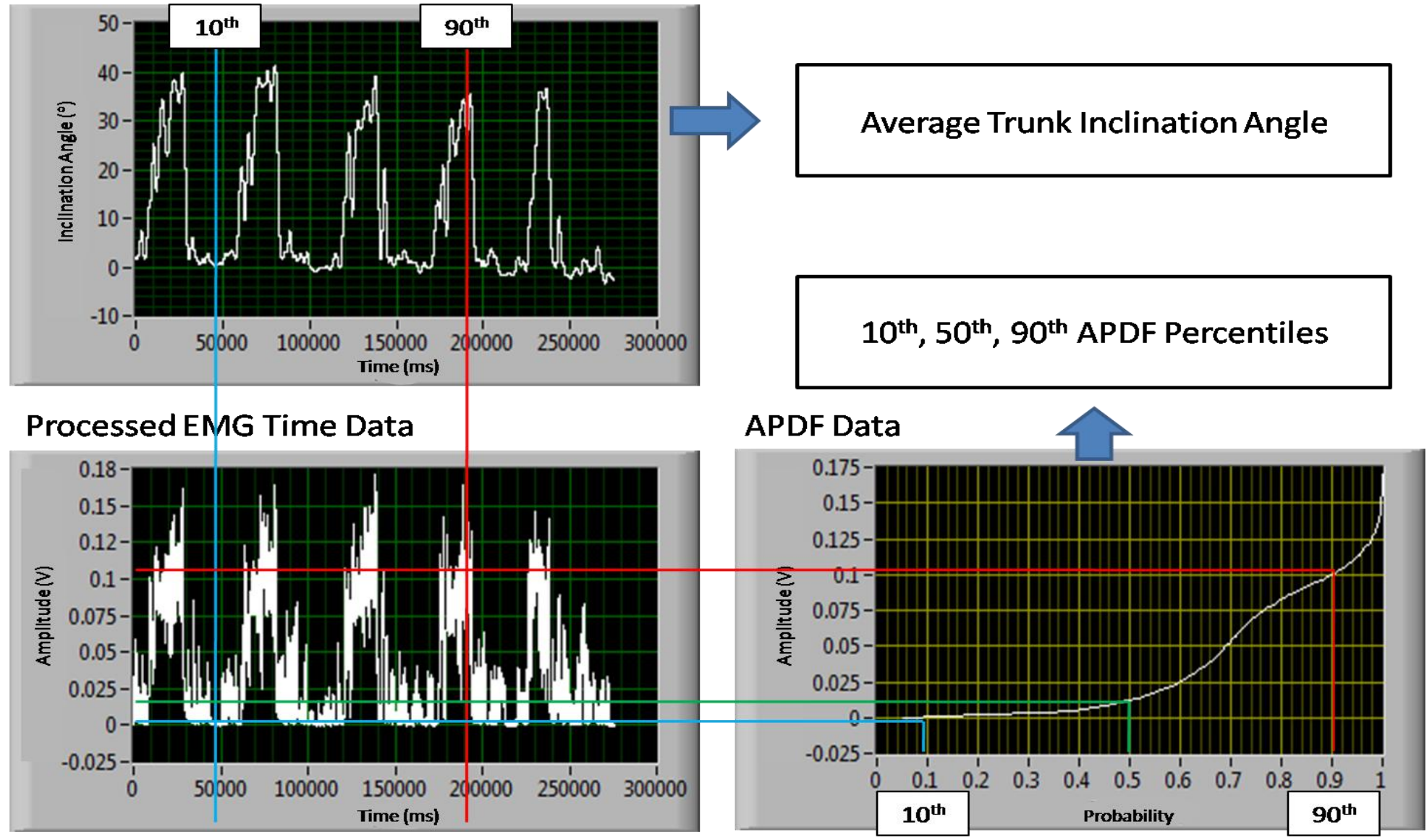

Figure 4.8. An example of the relationship between the trunk inclination angle and the amplitude probability distribution function (APDF) percentiles. (Notice the voltages for the $10^{\text {th }}$ percentile $(0.1$ probability) are equivalent to when the flexion angle is $0^{\circ}$ at standing (blue line), whereas the $90^{\text {th }}$ percentile $(0.9$ probability) voltages are equivalent to when the flexion angle is $30-40^{\circ}$ when the operators are fully flexed into the car (red line)). 


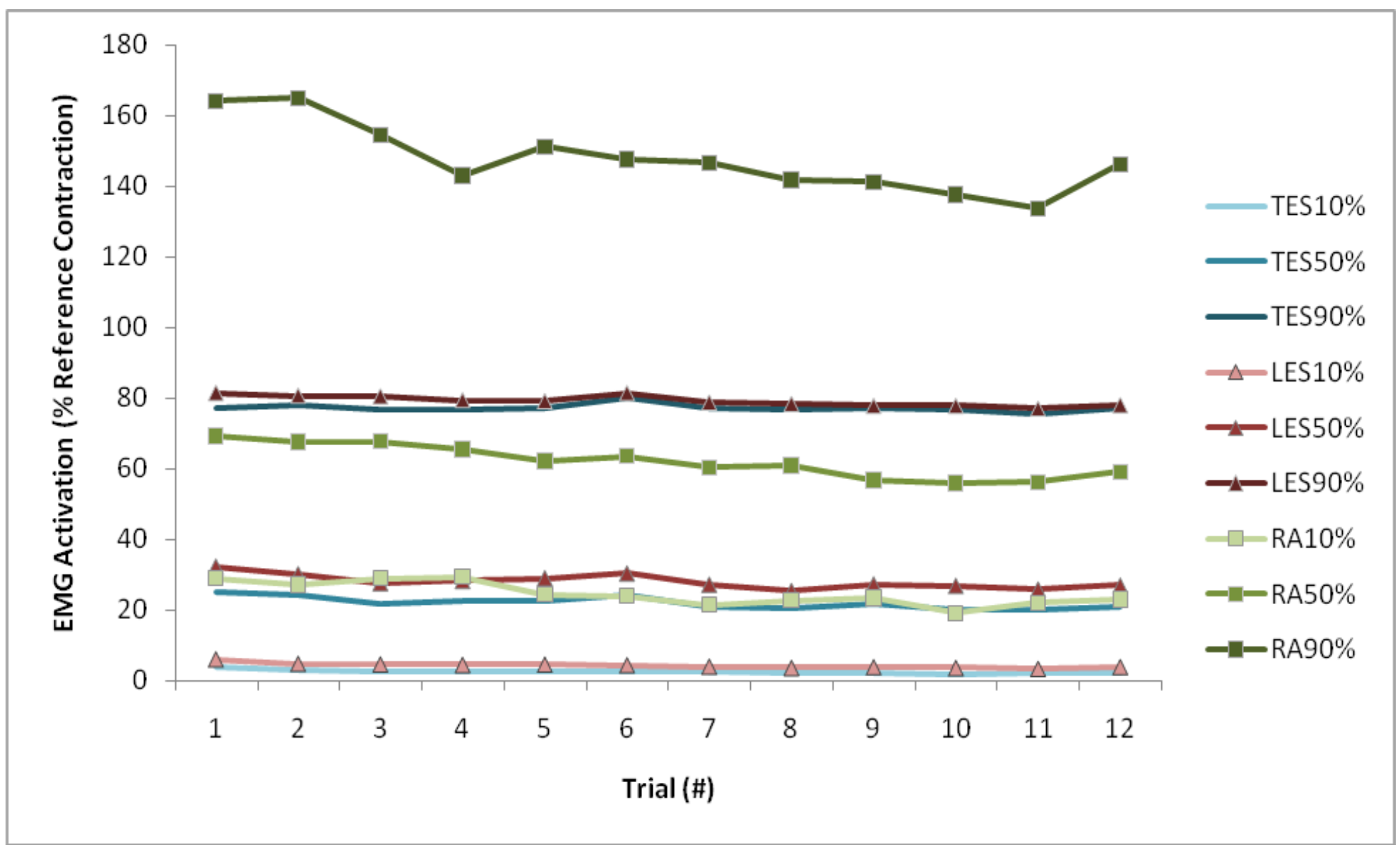

Figure 4.9. A time of sample versus reference-normalized electromyographical activation graph. (Notice that there were no activation increases for the thoracic or lumbar erector spinae (ES) or rectus abdominus (RA) at any amplitude probability distribution function (APDF) percentile). 


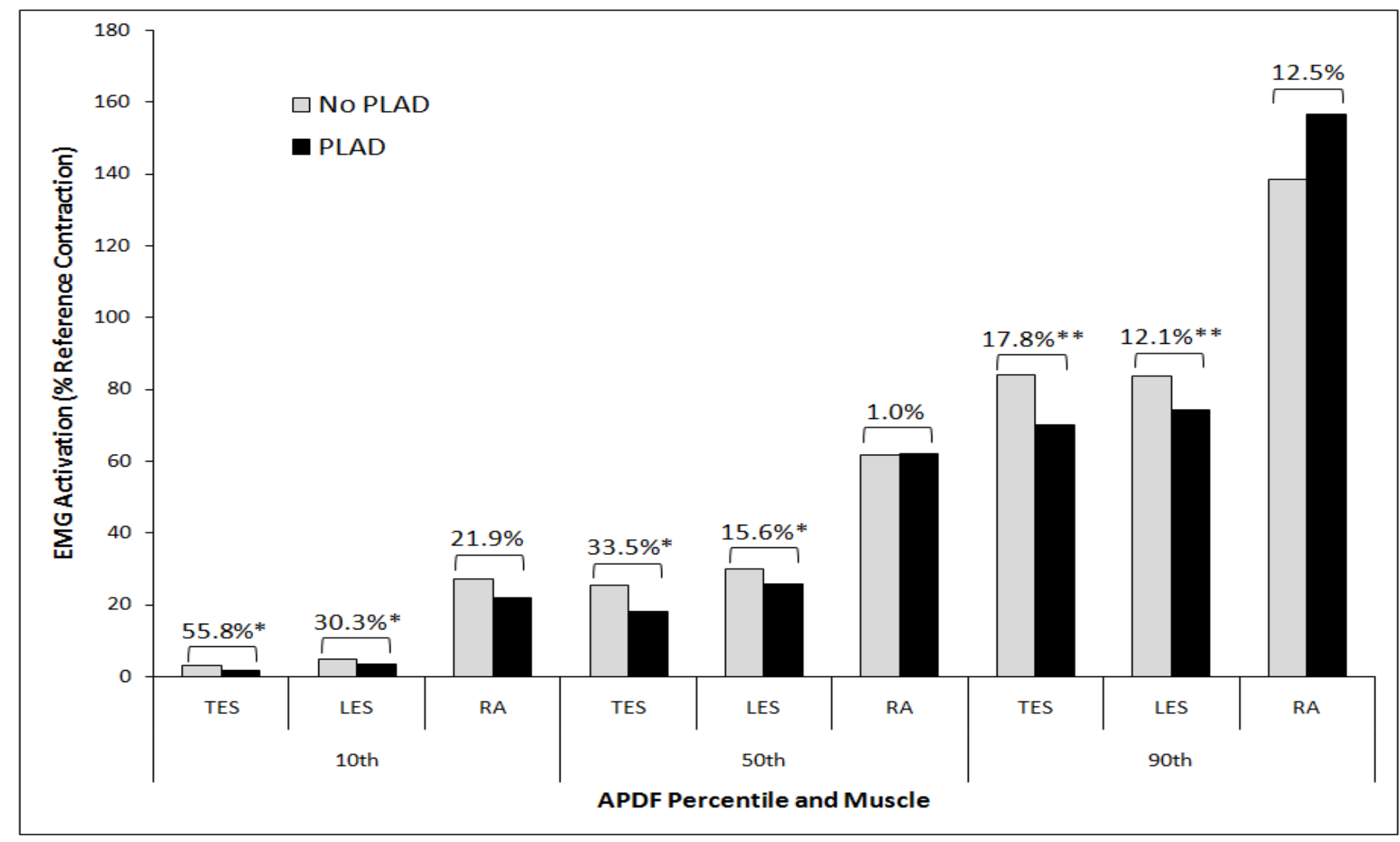

$*$ and $* *$ represent significant differences at $\mathrm{p}=0.05$ and $\mathrm{p}=0.01$, respectively

Figure 4.10. Electromyographical (EMG) activation as a percentage of reference contraction for thoracic (T) and lumbar (L) erector spinae (ES), and rectus abdominus (RA) at three amplitude probability distribution function (APDF) percentiles. Right and left muscle sides are collapsed. (Numbers above graphs represent percent differences between the No PLAD / PLAD conditions). 
between the device conditions for the low back muscles ranged from $12.1 \%\left(90^{\text {th }}\right.$ percentile activation LES) to $55.8 \%\left(10^{\text {th }}\right.$ percentile activation TES). The mean percentage reduction in EMG across the $10^{\text {th }}, 50^{\text {th }}$, and $90^{\text {th }}$ percentiles for TES and LES when wearing the PLAD was $27.52 \%$. This mean value was reasonably close to the $20 \%$ reduction in $\mathrm{L}_{4} / \mathrm{L}_{5}$ moment that was calculated for each individual. When considering each percentile separately, the $10^{\text {th }}$ percentile was $43.05 \%$ for combined LES and TES, the $50^{\text {th }}$ percentile was $24.55 \%$ and the $90^{\text {th }}$ percentile was $14.95 \%$. The main effect of side (Left>Right) significantly affected $(\mathrm{p}<0.05)$ reference-normalized EMG signals in the LES only at the $50^{\text {th }}$ and $90^{\text {th }}$ APDF activation levels. There were no significant interaction effects between the device and side.

\subsubsection{Compression-Normalized EMG (CNEMG)}

Similarly to when normalized to the reference posture, CNEMG values for trials one through twelve were collapsed into one average value. The main effect of wearing the PLAD significantly reduced the TES and LES EMG-predicted compression values at the $10^{\text {th }}, 50^{\text {th }}$, and $90^{\text {th }}$ APDF activation levels $(\mathrm{p}<0.05)$ (Figure 4.11). Percent differences using this approach ranged from the smallest difference $(6.7 \%)$ at the $10^{\text {th }}$ percentile of LES to the largest difference $(21.4 \%)$ at the $50^{\text {th }}$ percentile of the TES. Once again, the main effect of side (Left>Right) significantly affected $(\mathrm{p}<0.05)$ compression-normalized EMG signals in the LES only at the $50^{\text {th }}$ and $90^{\text {th }}$ APDF activation levels, and there were no significant interaction effects between the device and muscle side.

\subsubsection{Ratings of Perceived Exertion (RPE)}

Ratings of perceived exertion remained constant throughout the entire two-hour working shift for all individuals, indicating that subjects were not exhibiting signs of 


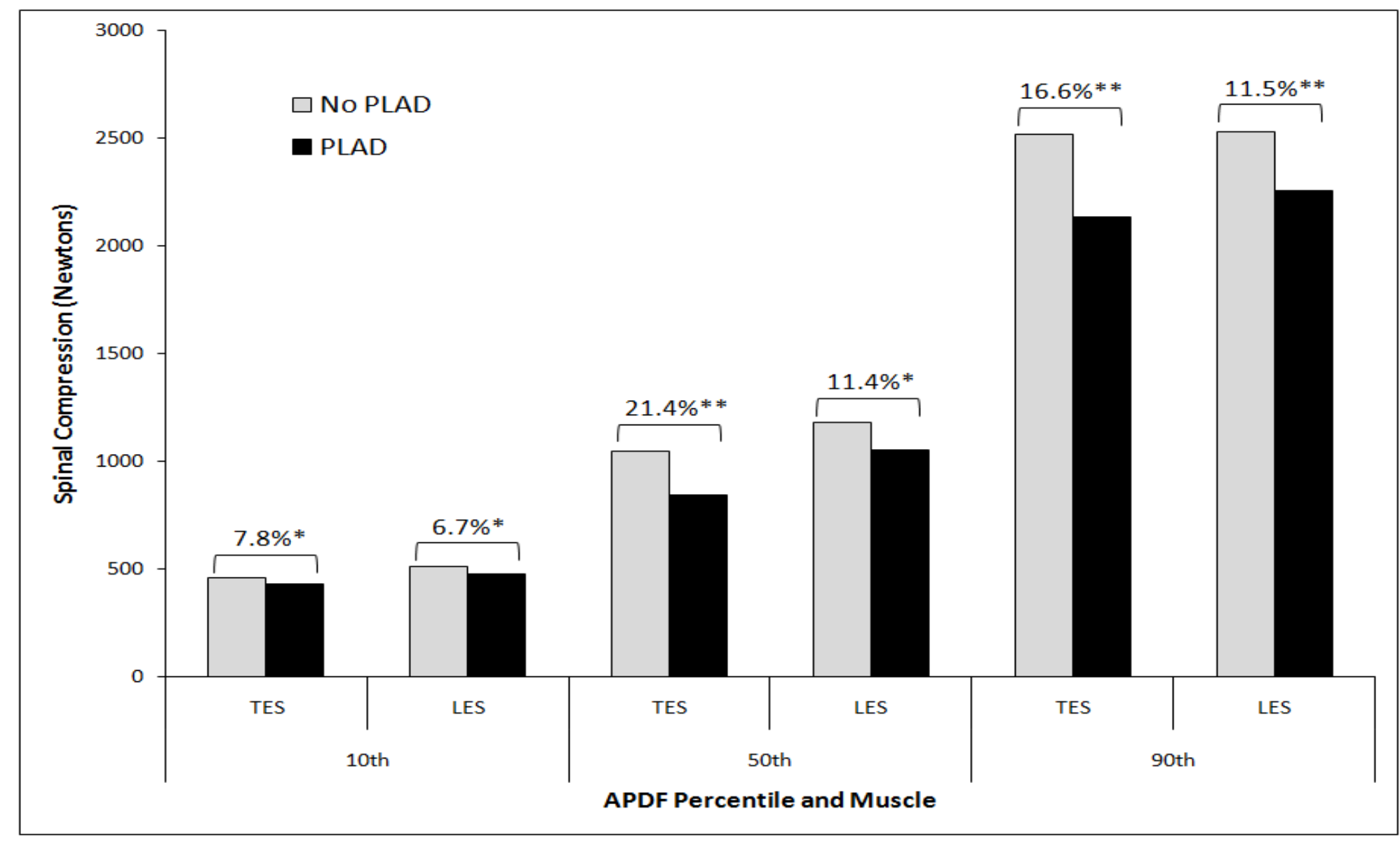

$*$ and $* *$ represent significant differences at $\mathrm{p}=0.05$ and $\mathrm{p}=0.01$, respectively

Figure 4.11. Compression-normalized electromyography (EMG) for thoracic (T) and lumbar (L) erector spinae (ES) at three amplitude probability distribution function (APDF) percentiles. Right and left muscle sides are collapsed. (Numbers above graphs represent percent differences between the No PLAD / PLAD conditions). 
fatigue. RPE scores were, however, significantly lower $(\mathrm{p}=0.006)$ when wearing the PLAD $($ mean $=8.35, \mathrm{SD}=2.38)$ than when not $($ mean $=9.7, \mathrm{SD}=2.79)$. Table 4.6 displays the RPE scores on both testing days; scores were lower when wearing the device for eight out of ten subjects, whereas, for the other two, they were identical.

\subsubsection{Trunk Inclination Angle}

The average trunk inclination angle for the ten operators was found to be very similar between the two testing days, indicating that there was no statistical difference ( $\mathrm{p}$ $=0.298$ ) between the two conditions when tested using a repeated measures ANOVA. The mean values for the No PLAD and PLAD conditions were 29.90 degrees $(\mathrm{SD}=8.68)$ and 30.69 degrees $(S D=8.14)$, respectively (Table 4.7). This result indicated that subjects did not significantly change their trunk postures when wearing the PLAD.

\subsubsection{Subjective Results}

The pre-test survey results (Table 4.8) revealed that mild to moderate low-back discomfort was very common among automotive assembly workers tested in this study, whereas flexibility and range of motion (ROM) were less problematic. Six out of ten workers had some form of low back discomfort, whereas only one had ROM problems in their hands and feet. Workers had been assigned to this specific assembly task for varying amounts of time, from 2 months to 5 years, and several of them found the job difficult due to extreme forward bending that strained their lower backs. Most subjects reported moderate fatigue $($ mean $=3.3$ out of 10 ) after a two-hour shift. Seven out of ten workers believed the PLAD would be beneficial and helpful in off-loading their low backs; however, some workers were concerned about comfort, effectiveness, and mobility when wearing the device. 
Table 4.6. Borg scale ratings of perceived exertion (RPE) for the 10 automotive operators under the two testing conditions.

\begin{tabular}{|c|c|c|}
\hline Subject \# & No PLAD (6-20) & PLAD (6-20) \\
\hline 1 & 7 & 7 \\
\hline 2 & 8 & 7 \\
\hline 3 & 10 & 8 \\
\hline 4 & 8 & 7 \\
\hline 5 & 12 & 10 \\
\hline 6 & 7 & 6 \\
\hline 7 & 10 & 10 \\
\hline 8 & 11 & 7 \\
\hline 9 & 8 & 7.5 \\
\hline 10 & 16 & 14 \\
\hline Average & $\mathbf{9 . 7}$ & $\mathbf{8 . 3 5}$ \\
\hline STDEV & $\mathbf{2 . 7 9}$ & $\mathbf{2 . 3 8}$ \\
\hline
\end{tabular}


Table 4.7. Trunk inclination angles (Degrees) for the 10 automotive operators under the two testing conditions.

\begin{tabular}{|c|c|c|}
\hline Subject \# & No PLAD $\left.^{(}{ }^{\circ}\right)$ & PLAD $^{(}{ }^{\circ}$ \\
\hline 1 & 46.42 & 45.54 \\
\hline 2 & 16.87 & 19.10 \\
\hline 3 & 35.15 & 36.53 \\
\hline 4 & 36.04 & 34.85 \\
\hline 5 & 31.41 & 29.50 \\
\hline 6 & 28.50 & 33.49 \\
\hline 7 & 21.88 & 22.10 \\
\hline 8 & 32.39 & 31.15 \\
\hline 9 & 30.19 & 33.78 \\
\hline 10 & 20.12 & 20.84 \\
\hline Average & $\mathbf{2 9 . 9 0}$ & $\mathbf{3 0 . 6 9}$ \\
\hline STDEV & $\mathbf{8 . 6 8}$ & $\mathbf{8 . 1 4}$ \\
\hline
\end{tabular}


Table 4.8. Pre-task baseline survey results for the 10 automotive operators.

\begin{tabular}{|c|c|c|c|c|c|c|c|}
\hline Subject \# & $\begin{array}{c}\text { Discomfort or } \\
\text { Pain? How Severe } \\
\text { (1-10)? }\end{array}$ & $\begin{array}{c}\text { Flexibility/ ROM } \\
\text { Problems? How Severe } \\
(\mathbf{1 - 1 0})\end{array}$ & $\begin{array}{c}\text { Time on } \\
\text { Task? }\end{array}$ & $\begin{array}{c}\text { Do you find the } \\
\text { task difficult? }\end{array}$ & $\begin{array}{c}\text { Fatigue after } \\
\text { 2hrs (1-10) }\end{array}$ & $\begin{array}{c}\text { Will the } \\
\text { PLAD Help? }\end{array}$ & PLAD Concerns? \\
\hline 1 & Low back (5) & No & 1 year & $\begin{array}{c}\text { Yes- Strain on } \\
\text { lower back }\end{array}$ & 6 & $\begin{array}{c}\text { Yes } \\
\text { Definitely }\end{array}$ & Does it work? \\
\hline 2 & Low back (5) & No & 5 years & No & 2 & Yes Slightly & No concerns at all \\
\hline 3 & No & No & N/A & $\begin{array}{c}\text { Yes- Bending into } \\
\text { car }\end{array}$ & Never done & $\begin{array}{c}\text { Yes Definitely } \\
\text { Is it uncomfortable? }\end{array}$ \\
\hline 4 & No (2) & No & 2 months & No & 2 & Yes Slightly & Will I be able to move? \\
\hline 5 & $\begin{array}{c}\text { Low back right } \\
\text { side (2) }\end{array}$ & No & 7 months & $\begin{array}{c}\text { No- Just back } \\
\text { tiring }\end{array}$ & 5 & Yes Slightly & Woes it work? / \\
Will I be able to move?
\end{tabular}


Table 4.9 displays the during-task questionnaire results for the ten automotive operators. When completing the assembly task without the PLAD, one subject reported progressive worsening in the legs and lower backs over the 2-hour shift, whereas another subject reported discomfort in the low back and wrist from supporting his/her body. When wearing the PLAD, pressure points (not pain) included the back of the legs and shoulders and areas of ROM restrictions included the shoulders when bending and reaching, and the feet and legs when walking. Subjects believed that the PLAD was offloading their low backs by an average of $52 \%$ even though only a $20 \%$ moment reduction was provided based on the predicted spring tension equations (Chapter 3), and average EMG reductions in the erector spinae across the duty cycle were $27.52 \%$.

Post-task subjective opinions were positive, with workers providing an average overall score of 4.2 out of 5 ( $\mathrm{SD}=1.03$ ) on a survey aimed at determining user acceptability (Table 4.10). This survey asked subjects to rank how PLAD affected several variables when compared to no device from 1 (poor) to 5 (excellent), and then asked them to describe user acceptability. Operators believed that the device was beneficial in reducing the back muscles' effort and strain, increasing one's personal safety, and preventing muscular strain injuries; however, some felt that it was slightly uncomfortable and restricting in the shoulders, legs, and feet. Several workers also believed the device was warm. Whether individuals wanted more or less support in the device was highly variable; however, 8 out of $10(80 \%)$ subjects said that the PLAD did not interfere with any aspect of the assembly task and that he/she would wear the device everyday (Table 4.11). One other subject said they would wear the device every second day. Workers 
Table 4.9. During-task questionnaire results for the 10 automotive operators.

\begin{tabular}{|c|c|c|c|}
\hline Subject \# & Measure & PLAD & No PLAD \\
\hline 1 & $\begin{array}{l}\text { Pressure points } \\
\text { ROM restrictions } \\
\text { \% help }\end{array}$ & $\begin{array}{c}\text { Back of the legs a little bit } \\
\text { Tension not restriction } \\
70-80 \%\end{array}$ & $\begin{array}{c}\text { Legs and lower back get worse as } \\
\text { quarter progresses } \\
- \\
-\end{array}$ \\
\hline 2 & $\begin{array}{l}\text { Pressure points } \\
\text { ROM restrictions } \\
\% \text { help }\end{array}$ & $\begin{array}{l}\text { None } \\
\text { None } \\
75 \%\end{array}$ & $\begin{array}{l}- \\
-\end{array}$ \\
\hline 3 & $\begin{array}{l}\text { Pressure points } \\
\text { ROM restrictions } \\
\% \text { help }\end{array}$ & $\begin{array}{l}\text { None } \\
\text { None } \\
75 \%\end{array}$ & $\begin{array}{l}- \\
-\end{array}$ \\
\hline 4 & $\begin{array}{l}\text { Pressure points } \\
\text { ROM restrictions } \\
\quad \% \text { help }\end{array}$ & $\begin{array}{c}\text { Shoulders } \\
\text { Shoulders a little bit } \\
70 \%\end{array}$ & $\begin{array}{l}- \\
-\end{array}$ \\
\hline 5 & $\begin{array}{l}\text { Pressure points } \\
\text { ROM restrictions } \\
\% \text { help }\end{array}$ & $\begin{array}{c}\text { Shoulders a little bit } \\
\text { Shoulders when reaching } \\
25 \%\end{array}$ & $\begin{array}{l}- \\
- \\
-\end{array}$ \\
\hline 6 & $\begin{array}{l}\text { Pressure points } \\
\text { ROM restrictions } \\
\% \text { help }\end{array}$ & $\begin{array}{c}\text { Shoulders a little bit } \\
\text { Leaning pulls feet up slightly } \\
25 \%\end{array}$ & $\begin{array}{l}- \\
-\end{array}$ \\
\hline 7 & $\begin{array}{l}\text { Pressure points } \\
\text { ROM restrictions } \\
\% \text { help }\end{array}$ & $\begin{array}{c}\text { Back of the legs } \\
\text { Leaning forward/ Shoulders } \\
20 \%\end{array}$ & $\begin{array}{c}\text { Back and wrist } \\
\text { (from supporting upper body) } \\
- \\
-\end{array}$ \\
\hline 8 & $\begin{array}{l}\text { Pressure points } \\
\text { ROM restrictions } \\
\% \text { help }\end{array}$ & $\begin{array}{l}\text { None } \\
\text { Slight restriction when } \\
\text { twisting } \\
75 \%\end{array}$ & $\begin{array}{l}- \\
- \\
-\end{array}$ \\
\hline 9 & $\begin{array}{l}\text { Pressure points } \\
\text { ROM restrictions } \\
\% \text { help }\end{array}$ & $\begin{array}{c}\text { Slight pressure all over } \\
\text { Bending/ Walking } \\
85 \%\end{array}$ & $\begin{array}{l}- \\
- \\
-\end{array}$ \\
\hline 10 & $\begin{array}{c}\text { Pressure points } \\
\text { ROM restrictions } \\
\% \text { help }\end{array}$ & $\begin{array}{l}\text { Right armpit } \\
\text { None } \\
20 \%\end{array}$ & $\begin{array}{l}- \\
-\end{array}$ \\
\hline Summary & $\begin{array}{l}\text { Pressure Points } \\
\text { ROM restrictions } \\
\text { \% help }\end{array}$ & \multicolumn{2}{|c|}{$\begin{array}{l}\text { Pressure points were observed at the shoulders and behind the legs } \\
\text { in some cases } \\
\text { Some workers felt slight restrictions when bending and felt } \\
\text { awkward when walking } \\
\text { Workers believed that the PLAD provided an average of } 52 \% \text { of } \\
\text { help }\end{array}$} \\
\hline
\end{tabular}


Table 4.10. Post-task PLAD user acceptability survey results for the 10 automotive operators. (Note that measures were ranked from 1 (poor) to 5 (excellent)).

\begin{tabular}{|c|c|c|c|c|c|c|c|c|c|c|}
\hline $\begin{array}{c}\text { Subject } \\
\#\end{array}$ & $\begin{array}{c}\text { Back } \\
\text { Muscles' } \\
\text { Effort } \\
\end{array}$ & $\begin{array}{c}\text { Leg } \\
\text { Muscles' } \\
\text { Effort } \\
\end{array}$ & $\begin{array}{l}\text { Personal } \\
\text { Safety }\end{array}$ & Balance & $\begin{array}{l}\text { ROM / } \\
\text { Flexibility }\end{array}$ & $\begin{array}{l}\text { Shoulder } \\
\text { Comfort }\end{array}$ & $\begin{array}{l}\text { Waist } \\
\text { Comfort }\end{array}$ & $\begin{array}{c}\text { Knee / Foot } \\
\text { Comfort }\end{array}$ & $\begin{array}{c}\text { Potential for } \\
\text { Preventing } \\
\text { MSIs } \\
\end{array}$ & $\begin{array}{c}\text { Overall } \\
\text { Opinion }\end{array}$ \\
\hline 1 & 5 & 3 & 5 & 5 & 3 & 4 & 5 & 5 & 5 & 5 \\
\hline 2 & 5 & 4 & 4 & 3 & 5 & 3 & 4 & 5 & 3 & 5 \\
\hline 3 & 4 & 4 & 5 & 4 & 4 & 4 & 4 & 4 & 4 & 5 \\
\hline 4 & 4 & 3 & 3 & 3 & 2 & 3 & 4 & 4 & 3 & 4 \\
\hline 5 & 4 & 3 & 3 & 3 & 2 & 2 & 3 & 3 & 2 & 3 \\
\hline 6 & 4 & 3 & 3 & 3 & 4 & 3 & 5 & 5 & 4 & 4 \\
\hline 7 & 2 & 1 & 2 & 3 & 2 & 2 & 4 & 2 & 3 & 2 \\
\hline 8 & 4 & 4 & 5 & 4 & 4 & 4 & 4 & 4 & 4 & 5 \\
\hline 9 & 4 & 4 & 4 & 5 & 4 & 3 & 4 & 5 & 4 & 5 \\
\hline 10 & 4 & 2 & 4 & 4 & 4 & 2 & 3 & 4 & 4 & 4 \\
\hline Average & 4 & 3.1 & 3.8 & 3.7 & 3.4 & 3 & 4 & 4.1 & 3.6 & 4.2 \\
\hline STDEV & 0.82 & 0.99 & 1.03 & 0.82 & 1.07 & 0.82 & 0.67 & 0.99 & 0.84 & 1.03 \\
\hline
\end{tabular}


Table 4.11. Post-task user acceptability responses (direct quotes) for the 10 automotive operators.

\begin{tabular}{|c|c|c|c|c|c|c|}
\hline Subject \# & $\begin{array}{l}\text { Did you want } \\
\text { more, less or } \\
\text { no support? } \\
\text { Why? }\end{array}$ & $\begin{array}{l}\text { Did the PLAD } \\
\text { interfere with any } \\
\text { aspect of task? }\end{array}$ & $\begin{array}{l}\text { Would you be } \\
\text { comfortable wearing the } \\
\text { PLAD every day? Why? }\end{array}$ & $\begin{array}{l}\text { Pressure/ } \\
\text { Discomfort? } \\
(1-10)\end{array}$ & $\begin{array}{l}\text { ROM } \\
\underset{(1-10)}{\text { limitations? }}\end{array}$ & Additional Comments/ Concerns? \\
\hline 1 & $\begin{array}{l}\text { More help- kept } \\
\text { strain off the low } \\
\text { back }\end{array}$ & No & Yes- decreases back strain & Shoulders (3) & $\begin{array}{l}\text { Shoulders, } \\
\text { Back of Legs } \\
\text { (3) }\end{array}$ & $\begin{array}{l}\text { PLAD would make it easier to work everyday } \\
\text { and it would be excellent }\end{array}$ \\
\hline 2 & $\begin{array}{l}\text { Same amount of } \\
\text { help }\end{array}$ & No & Yes- it helps my back & Shoulders (1) & None & $\begin{array}{l}\text { I believe the PLAD will reduce back discomfort } \\
\text { considerably }\end{array}$ \\
\hline 3 & $\begin{array}{l}\text { More help on the } \\
\text { way up }\end{array}$ & No & $\begin{array}{l}\text { Yes- It helps lower back } \\
\text { strain }\end{array}$ & None & None & $\begin{array}{l}\text { I think this will be a good thing for jobs on-line } \\
\text { to reduce lower back injuries }\end{array}$ \\
\hline 4 & $\begin{array}{l}\text { Same amount of } \\
\text { help }\end{array}$ & $\begin{array}{l}\text { Slightly affected } \\
\text { overall ROM }\end{array}$ & $\begin{array}{l}\text { Yes- Seems to help posture } \\
\text { which is very important in } \\
\text { reducing back problems }\end{array}$ & $\begin{array}{c}\text { Shoulders, } \\
\text { Legs, Feet (5) }\end{array}$ & $\begin{array}{l}\text { Shoulders, } \\
\text { Knees (5) }\end{array}$ & $\begin{array}{c}\text { Takes getting used to, but seems like a useful } \\
\text { device and could be beneficial to TMs comfort } \\
\text { and back health }\end{array}$ \\
\hline 5 & $\begin{array}{l}\text { Less help- } \\
\text { constricted in } \\
\text { shoulders }\end{array}$ & No & $\begin{array}{l}\text { Yes- as long as material was } \\
\text { lighter and less constricting in } \\
\text { shoulders }\end{array}$ & Armpits (4) & Shoulders (4) & None \\
\hline 6 & $\begin{array}{l}\text { Same amount of } \\
\text { help }\end{array}$ & No & $\begin{array}{l}\text { No- walking is awkward, suit } \\
\text { is a little warm (every other } \\
\text { day would be fine) }\end{array}$ & Shoulders (3) & $\begin{array}{l}\text { Back of Legs } \\
\text { (5) }\end{array}$ & $\begin{array}{l}\text { The suit did take the burden away from the } \\
\text { lower back }\end{array}$ \\
\hline 7 & $\begin{array}{l}\text { No device- felt } \\
\text { like it required } \\
\text { strength to bend } \\
\quad \text { forward }\end{array}$ & Bending forward & $\begin{array}{l}\text { No- felt like it required } \\
\text { strength to bend forward }\end{array}$ & $\begin{array}{l}\text { Shoulders, } \\
\text { Back of Legs, } \\
\text { Feet }(3,6,3)\end{array}$ & Shoulders (5) & Suit is heavy \\
\hline 8 & More help & $\begin{array}{l}\text { No- A little pulling } \\
\text { when twisting only }\end{array}$ & Yes- less strain on my back & None & $\begin{array}{c}\text { Right } \\
\text { shoulder (3) }\end{array}$ & None \\
\hline 9 & More help & No & Yes & Shoulders (6) & Low back (3) & None \\
\hline 10 & $\begin{array}{l}\text { To a point where } \\
\text { back muscles are } \\
\text { supported but still } \\
\text { have to work }\end{array}$ & No & $\begin{array}{l}\text { Yes- With a few } \\
\text { modifications would be } \\
\text { beneficial for me and } \\
\text { comfortable }\end{array}$ & $\begin{array}{l}\text { Right } \\
\text { shoulder (5) }\end{array}$ & Low back (4) & $\begin{array}{l}\text { PLAD is a good idea and would be beneficial. } \\
\text { Suggest changes to shoulder straps. Lighter } \\
\text { material. Let PLAD give } 15-20 \% \text { help }\end{array}$ \\
\hline Summary & $\begin{array}{l}\text { Dependent on } \\
\text { the person }\end{array}$ & $\begin{array}{l}\text { Overall }(8 / 10) \\
\text { PLAD did not } \\
\text { interfere with } \\
\text { anything }\end{array}$ & $\begin{array}{l}\text { 8/10 would wear PLAD } \\
\text { everyday, } 1 \text { would wear } \\
\text { every second day }\end{array}$ & $\begin{array}{l}\text { Shoulders, } \\
\text { Legs, Feet } \\
\text { are common }\end{array}$ & $\begin{array}{l}\text { Limited } \\
\text { when } \\
\text { bending }\end{array}$ & $\begin{array}{l}\text { A few modifications (shoulder support, } \\
\text { lighter material) would make the PLAD } \\
\text { comfortable for everyone. All individuals } \\
\text { could feel the PLAD helping their back. }\end{array}$ \\
\hline
\end{tabular}


believed that slight modifications to the shoulder support and PLAD material would make the device more comfortable for everyone. All workers could feel the PLAD offloading their low backs, and most believed it could reduce low back forces, discomfort, and injury rates in many industrial tasks that place excessive biomechanical loading on the low back.

\subsection{Discussion}

The main purpose of this study was to assess the effectiveness and user acceptability of a personal lift-assist device (PLAD) at an automotive manufacturing facility with operators who perform an assembly process requiring forward bending and static holds. The methodology was designed to assess device effectiveness by quantifying the electromyographical activity of the lower back and abdominal muscles, as well as ratings of perceived exertion and trunk inclination angles. User acceptability was assessed via a series of surveys and questionnaires administered to the automotive assembly workers prior to, during, and after the testing protocol.

\subsubsection{Reference-Normalized EMG}

Electromyographical data were normalized to a reference posture in this study because it was difficult to get a 'true' maximal contraction from the erector spinae musculature, especially when testing in an industrial setting (Potvin et al., 1996). As a result, we were unable to compare the APDF results directly to tolerance limit value standards to see if workers in the present study are at risk of becoming fatigued or developing a cumulative trauma disorder (Jonsson, 1982). Nevertheless, this method of EMG normalization did allow direct comparison between the No PLAD and PLAD conditions when workers carried out the assembly task, thus enabling the objective assessment of device effectiveness during static forward bending. 
There were no EMG increases found between the different time periods examined in this study, meaning fatigue probably did not have an effect. It is well known that, during prolonged static bending or repetitive motion, EMG amplitudes increase as individuals become fatigued (Basmajian \& Deluca, 1985; De Luca, 1984; Potvin \& Norman, 1993); this was not seen in the present study for any muscle at any APDF activation level. This may have occured as a result of the approximate 1:1 work-to-rest ratio in the analyzed assembly task since workers were in a static flexed forward position for approximately 30 seconds followed by a standing rest position for the remainder of the 55-second duty cycle. Courville et al. (2005) evaluated the effects of short rest periods after static lumbar flexion on the development of cumulative LBD in a feline model, and found that a short rest period of 2:1 load-to-rest ratio leads to a cumulative LBD, whereas a longer rest at 1:1 and 1:2 load-to-rest ratio is more favourable for preventing and attenuating injury progression. Subjective responses and RPE results support this theory as several individuals reported enjoying this specific task due to ample rest time built into the duty cycle.

Use of the PLAD as an engineering control significantly reduced the TES and LES reference-normalized EMG at the $10^{\text {th }}, 50^{\text {th }}$, and $90^{\text {th }}$ APDF levels by an average of $\sim 27 \%$ across the entire duty cycle, without significantly increasing RA activity. This indicates that workers spent 10,50 , and 90 percent of the work cycle at or below significantly lower low back muscle activation levels when wearing the device. This is very important as it has been shown that low back compression and shear, which have the potential to cause LBD, are primarily the result of tension in the vertically-oriented ES muscles caused by lifting or forward bending (Dolan et al., 1994; Kumar, 1999). It has 
also been shown in automotive assembly workers that prolonged trunk flexion can cause LBP (Punnett et al., 1991), and that cumulative lumbar disc compression and shear were significantly greater in LBP cases than non-cases (Kerr et al., 2001; Norman et al., 1998).

The present results are similar to previous PLAD results obtained in a laboratory setting (Abdoli-E et al., 2006) and comparable to results obtained by other researchers with other on-body weight transfer devices (Barrett \& Fathallah, 2001). Abdoli et al. (2006) found that during laboratory simulated lifting the PLAD significantly reduced the integrated EMG activity of the LES and TES by $14.4 \%$ and $27.6 \%$ respectively, without significantly increasing RA or external oblique activity. Futhermore, Barrett and Fathallah (2001) compared three different on-body material handling devices: The Happyback (ErgoAg Company, Aptos, CA), The Bendezy (Bendezy LiteTop Company, Mount Barker, Australia), and The Bending Non-Demand Return (BNDR) (Limbic Systems Inc., Ventura, CA) and found that they reduced the EMG activity of the ES muscles by $23 \%, 21 \%$, and $31 \%$, respectively.

The main effect of side (Left> Right) was different for the LES muscle only at the $50^{\text {th }}$ and $90^{\text {th }}$ APDF percentiles, indicating that the left and right side LES muscles were differentially recruited when carrying out the assembly task. This finding made intuitive sense as workers were forced to bend sagitally into the car and then twist to the left side in order to carry out work on the dash of the car. This finding is significant because it has been shown that torsion significantly reduces the compressive strength of the spine (Aultman et al., 2004), which is of particular importance since these workers are forward bent and twisted at the same time. Twisting also has the potential to cause fractures to the facet joints, laminae and vertebral bodies, as well as cause tears in the joint capsules and 
intervertebral discs (Bogduk, 2004). There were no interaction effects between muscle side and device, showing the the PLAD's effectiveness was independent from any differences that may have been observed in the left and right side of the body. This may be because the PLAD has also been shown to be effective at significantly reducing TES (24.4\%) and LES (23.9\%) EMG activity and 3-D dynamic moments during asymetrical freestyle lifting (Abdoli-E \& Stevenson, 2008).

\subsubsection{Compression-Normalized EMG (CNEMG)}

Erector spinae EMG data were also normalized to compression in the present study, as per the protocol of Potvin et al. (1990), in order to compare PLAD's effect on reducing this LBD risk factor. It has been shown that the exposure time at a specific level of compression calculated using CNEMG was, on average, within $6.5 \%$ of the time calculated by a biomechanical model (Mientjes et al., 1999), showing that it is a fieldacceptable method of estimating spinal compression over time. CNEMG was also collapsed across time samples because amplitudes did not increase with time. The main effect of the PLAD condition did significantly reduce thoracic and lumbar EMGpredicted compression at all three APDF percentile levels $(\mathrm{p}<0.05)$, whereas the main effect of side was only significant for the $50^{\text {th }}$ and $90^{\text {th }}$ APDF percentiles of the LES muscle. Once again, there were no significant interaction effects between the device and side. Compression and reference-normalized EMG possessed excellent agreement across all back muscles. It is important to note, however, that percent differences for the TES and LES muscles at the $10^{\text {th }}$ percentile APDF activation were much lower when normalized to compression because the actual activation levels were extremely small; going from $2 \%$ to $1 \%$ maximum voluntary contraction would translate into a $50 \%$ 
difference in reference-normalized EMG, but would only translate to a small difference in compression. The percent differences in compression were also lower than those observed when looking at reference-normalized EMG, due to the $1 / 2$ body weight offset that was applied during the EMG-compression normalization process.

The ability to reduce workers' exposure to spinal compression is very important as prolonged or repetitive exposure to spinal compression can cause end plate fractures and trabecular damage (Gunning et al., 2001), disc degeneration, and altered cell metabolism (Lotz \& Chin, 2000), as well as disc herniation (Marras, 2000). Off-body materials handling devices have been shown to reduce awkward postures, back muscular activity, and spinal compression under many automotive and industrial assembly situations (Chaffin et al., 1999; Hermans et al., 1999). The ability of an on-body device to provide similar assistance is very promising as these devices are negligible in cost, are easy to incorporate into the workplace, and are small and manoeuvrable. PLAD was estimated mathematically, and validated empirically, to reduce low back moments by 23-36 Nm resulting in reductions in compression and shear forces (Abdoli-E et al., 2007), and the present study has shown that PLAD is also effective at reducing low back compression during an automotive assembly task.

\subsubsection{Ratings of Perceived Exertion (RPE)}

In this study, RPE was used as an indicator of how hard automotive operators believed they were working both with and without the PLAD. A significant effect of the device on RPE Borg scale scores $(\mathrm{p}=0.006)$ suggested that subjects perceived the task to be less strenuous when the PLAD was worn. These results were similar to those found by 
Lotz et al. (2008), where the PLAD was effective in significantly reducing muscular fatigue and RPE in men during a 45-minute continuous lifting task.

\subsubsection{Trunk Inclination Angle}

The trunk inclination angle was found to be statistically similar $(\mathrm{p}=0.298)$ between the two testing conditions which would suggest that workers' trunk postures had not changed between the PLAD and No PLAD days. These results support the claim that all reference and compression-normalized EMG differences between conditions were a result of wearing the PLAD, and not due to the confounding effects of trunk inclination.

\subsubsection{Subjective Results}

Mild to moderate low-back discomfort was common in the operators tested within the present study. Six out of $10(60 \%)$ subjects reported low back discomfort, and only one person who had been working on the task for greater than 7 months did not report any form of low back discomfort or pain. These findings are consistent with those reported by Veiersted et al. (1993), who reported that musculoskeletal pain usually appears within workers after exposure times of 6-12 months. Several workers found the assembly task to be difficult due to the static forward bends that are assumed by many automobile assembly workers (Punnett et al., 1991), and most workers reported mild to moderate fatigue after a two-hour shift. Others reported little to no fatigue after two hours, which might be the reason for no observed EMG differences with time.

Test questionnaires revealed that pressure points when working included the shoulders and the back of the legs. The reason for these pressure points is that on-body materials handling devices, also known as weight transfer devices, function by 
transferring the loads on the lower back to the shoulders, hips, and lower limbs (Barrett \& Fathallah, 2001). Abdoli-E et al. (2007) found that resultant contact forces applied to each shoulder, the lower leg attachment points, and the pelvic girdle ranged from $75-90 \mathrm{~N}$, 125.6-178.3, and 221.3-468.5 Newtons, respectively. It was also reported that these forces all fall below acceptable limits (Abdoli-E et al., 2007). Although it appeared that the pressure points caused by PLAD were acceptable side effects for reducing low back discomfort, increased padding in these regions might be beneficial in increasing user acceptability and comfort. Several workers also reported that the device was somewhat hot, which had the potential to cause heat strain and reduced productivity with prolonged exposure (Werner, 2005). A lighter material with vents would go a long way in increasing user comfort. Some subjects also reported slight range of motion restrictions in the shoulders when bending, and in the feet and legs when walking; with time, subjects became accustomed to these feelings, and device use became more natural. One subject did report less wrist pain when using the PLAD because less hand support was required to support the upper body during the task; using less hand support could have been a confounding effect in the EMG data recorded for this subject.

The PLAD wearers believed the device was assisting them, on average, by $52 \%$ even though approximately $20 \%$ moment reduction was provided to each person. The hypothetical rationale for this finding is that effort is perceived, and workers' perceptive abilities are non-linearly related to physical work rate; this is known as Stevens' psychophysical power law (Stevens, 1957). Stevens' power law describes perceptual continua on which the subjective magnitude is the power function of the physical stimulus magnitude (Karwowski et al., 1999). That is, the relationship between the 
subjective sensation $(\mathrm{N})$ and the intensity of the physical stimulus $(\mathrm{X})$ can be defined by the power function: $\mathrm{N}=\mathrm{aX}{ }^{\beta}$, where a is a constant, and $\beta$ is the slope of the line that represents the power function when plotted on log-log coordinates. In the present case, the subjective sensation was how much workers perceived the PLAD do be doing, whereas the physical stimulus was the $20 \%$ help the PLAD actually provided. Previous research has shown that 1.6 is the slope $(\beta)$ that researchers have come up with that links demand to effort (Borg, 1962; Snook, 1978), but in the present study only one point along the continua (20\%) was tested. This was deemed acceptable because the scale is being used simply as a basis of comparison and not to establish relationships across effort levels. In the present case 1.3 is the exponent that was discovered: $\left(20^{1.3}\right) \%$ subjective $=$ $\sim 50 \%$ objective; this is relatively close to the 1.6 that has been put forth in previous research. However, the observed trend cannot be confirmed based on this law unless the subjective responses are tested at multiple levels of PLAD support.

Post task subjective opinions were positive, with workers providing an overall score of 4.2 out of 5 on a survey aimed at determining user acceptability. Eight out of ten subjects were pleased with the device and said they would wear the PLAD every day to carry out their on-line work duties, whereas one other said they would wear the PLAD every second day. These findings will be helpful in determining where design iterations need to be improved to: reduce restricted motions, improve safety, increase comfort, and other deterrents that might reduce user acceptability. Overall, the operators in this study were pleased with and would wear the current PLAD to prevent low back discomfort. With slight alterations to the shoulder support and device material, PLAD has the 
potential to be beneficial at reducing low back forces and discomfort in a variety of industrial tasks that place excessive biomechanical loading on the low back.

\subsubsection{Limitations}

Although it appears that the PLAD was effective in reducing low back EMG activity and predicted-compression in an automotive industrial setting and had high user acceptability, these findings are not stated without an understanding of the limitations of the current study. The reference posture used to normalize the electromyographical data could have resulted in errors if the posture was not identical between trials and testing days. If the trunk or hip were flexed to a different degree, then the reference data would be distorted in one situation, which would alter the normalized EMG. Similarly, if the shoulders were more or less protracted on one day, there could have been greater involvement of the TES versus LES, or vice versa. All attempts were made to ensure this did not happen, as all subjects were required to stand on the same line and a goniometer was used to measure the trunk angle. In addition, EMG data were normalized to compression by digitizing photographs; any severe differences would have been accounted for in this case. Because the two methods of normalization had good agreement, as significance was found in the same places, it can be assumed that the reference postures were close to identical between days.

Secondly, we were unable to separate trunk from hip flexion in the current study as posture was analyzed by assessing trunk inclination. Although trunk inclination was not statistically different between testing conditions, it is possible that these inclinations were achieved with differing contributions from the hip versus spine. Future studies will attempt to separate these using a combination of inclinometers to ensure present findings. 
Thirdly, the only abdominal muscle analyzed was the rectus abdominus. The RA muscle was chosen over the oblique muscles because we wanted to see if additional abdominal effort was required to overcome the element stiffness, and because the location of oblique electrodes would have been pushing against the car and could have rubbed off. However, it is known that the internal (IO) and external (EO) oblique muscles are major co-contractors with the ES muscles during forward bending and lifting (Granata et al., 2005). It is possible that either EO or IO muscle activation would have significantly increased when wearing the PLAD. Abdoli-E et al. (2006) found that neither EO nor RA activity increased during lifting when wearing the device, and thus it is probable that similar results would have been seen here.

Next, it is acknowledged that the Borg RPE scale may not have been ideal for determining how hard individuals believed they were working between situations. The RPE-20 scale is built to reflect cardiovascular effort and not physical strength (Borg, 1998). Because the task was not extremely demanding from a cardiovascular point of view (RPE scores remained constant throughout the shift), it may have been beneficial to use the Borg CR-10 scale, which possesses verbal anchors to linearize perception of work (strength). There are more numbers at the high end of the CR-10 scale to take into account the 1.6 exponent found within Stevens' Power Law. The RPE score was still able to assess differences between days, and thus it is likely that the use of the Borg scale was adequate for the current research need. Further research is recommended to ascertain whether the differences between subjective opinions of PLAD support and objective measurements of PLAD support are valid. 
The PLAD prototype used also introduced some limiting factors into the research. Although three PLAD sizes were used for the current study (small, medium, large), the device did fit some individuals better than others. If the PLAD is implemented as an ergonomic tool in industry, it may be beneficial for each worker to have a device tailored to fit his/her anthropometry. It was possible, however, to tackle some of the limitations addressed by previous PLAD researchers by providing operators with individualized amounts of support and by testing the device on actual experienced workers performing on-line industrial tasks.

Finally, this study involved primarily forward bending and static holding with minor amounts of walking between cars. Although initial studies involved lifting tasks in a laboratory, more field research is needed to confirm which tasks are most appropriate to recommending the PLAD.

\subsection{Conclusion}

The present study was successful at displaying the effectiveness and user acceptability of the PLAD Version 6 at an automotive manufacturing facility, using operators who perform an assembly process requiring forward bending and static holds. The PLAD was able to significantly reduce low back muscular activity, EMG-predicted compression, and ratings of perceived exertion, without significantly changing abdominal activity or trunk inclination. Workers had positive responses about the PLAD, and 80\% said they would wear the device everyday on-line. It appears that with slight modifications the PLAD can be beneficial in reducing low back forces and discomfort in various industrial tasks that place excessive physical demands on the low back. 


\subsection{References}

Abdoli-E, M., \& Stevenson, J. (2008). The effect of on-body lift assistive device on the lumbar 3-D dynamic moments and EMG during assymetric freestyle lifting. Clinical Biomechanics , 23, 372-380.

Abdoli-E, M., Agnew, M., \& Stevenson, J. (2006). An on-body personal lift augmentation device (PLAD) reduces EMG amplitude of erector spinae during lifting tasks. Clinical Biomechanics , 21, 456-465.

Abdoli-E, M., Stevenson, J., Reid, S., \& Bryant, T. (2007). Mathematical and empirical proof of principle for an on-body personal lift augmentation device. Journal of Biomechanics , 40, 1694-1700.

Aultman, C., Drake, J., Callaghan, J., \& McGill, S. (2004). The effect of static torsion on the compressive strength of spines: An in vitro analysis using a porcine spine model. Spine , 29 (15), E304-309.

Barrett, A., \& Fathallah, F. (2001). Evaluation of four weight transfer devices for reducing loads on the lower back during agricultural stoop labor. ASAE Annual International Meeting Paper Number: 01-8056 (pp. 1-8). Sacramento, CA: ASAE. Basmajian, J. V., \& Deluca, C. J. (1985). Muscles alive: their functions revealed by electromyography (5th ed.). Baltimore: Williams and Wilkins.

Bogduk, N. (2004). Clinical Anatomy of the Lumbar Spine and Sacrum (4th ed.). Philadelphia: Elsevier- Churchill Livingstone.

Borg, G. (1998). Borg's perceived exertion and pain scales. Stockholm: Human Kinetics. Borg, G. (1962). Physical performance and perceived exertion. Gleerup, Lund.

Chaffin, D., Stump, B., Nussbaum, M., \& Baker, G. (1999). Low-back stresses when learning to use a materials handling device. Ergonomics , 42 (1), 94-110.

Courville, A., Sbriccoli, P., Zhou, B.-H., Solomonow, M., Lu, Y., \& Burger, E. (2005). Short rest periods after static lumbar flexion are a risk factor for cumulative low back disorder. Journal of Electromyography and Kinesiology , 15, 37-52.

De Luca, C. (1984). Myoelectrical manifestations of localized muscular fatigue in humans. Critical Reviews in Biomedical Engineering , 11, 251-279.

Dolan, P., Earley, M., \& Adams, M. (1994). Bending and compressive stresses acting on the lumbar spine during lifting activities. Journal of Biomechanics , 27 (10), 1237-1248. 
Drake, J. D., \& Callaghan, J. P. (2006). Elimination of electrocardiogram contamination from electromyogram signals: An evaluation of currently used removal techniques. Journal of Electromyography and Kinesiology, 16, 175-187.

Genaidy, A., \& Karwowski, W. (1993). The effects of neutral posture deviations on perceived joint discomfort ratings in sitting and standing postures. Ergonomics , 36 (7), 785-792.

Granata, K. P., Lee, P. E., \& Franklin, T. C. (2005). Co-contraction recruitment and spinal load during isometric trunk flexion and extension. Clinical Biomechanics , 20 (10), 1029-1037.

Gunning, J., Callaghan, J., \& McGill, S. (2001). The role of prior loading history and spinal posture on the compressive tolerance and type of failure in the spine using a porcine trauma model. Clinical Biomechanics , 16 (6), 471-480.

Hansson, G., Asterland, P., Holmer, N.-G., \& Skerfving, S. (2001). Validity and reliability of triaxial accelerometers for inclinometry in posture analysis. Medical and Biological Engineering and Computing , 39 (4), 405-413.

Hermans, V., Hautekiet, M., Spaepen, A., Cobbaut, L., \& De Clerq, J. (1999). Influence of material handling devices on the physical load during the end assembly of cars. International Journal of Industrial Ergonomics , 24, 657-664.

Jonsson, B. (1982). Measurement and evaluation of local muscular strain in the shoulder during constrained work. Journal of Human Ergology , 11, 73-88.

Karwowski, W., WookGee, L., Jamaldin, B., Gaddie, P., Jang, R.-L., \& Alqesaimi, K. K. (1999). Beyond psychophysics: the need for a cognitive engineering approach to setting limits in manual lifting tasks. Ergonomics , 42 (1), 40-60.

Kerr, M., Frank, J., Shannon, H., Norman, R., Wells, R., Neumann, W., \& Bombardier, C. (2001). Biomechanical and Psychosocial Risk Factors for Low Back Pain at Work. American Journal of Public Health , 91 (7), 1069-1075.

Kumar, S. (1999). Biomechanics in Ergonomics (1st ed.). London: Taylor and Francis. Landsbergis, P. A., Cahill, J., \& Schnall, P. (1999). The impact of lean production and related new systems of work organization on worker health. Journal of Occupational Health Psychology, 4 (2), 108-130.

Lotz, C., Agnew, M., Godwin, A., \& Stevenson, J. (2008). The effect of an on-body personal lift-assist device (PLAD) on fatigue during a repetitive lifting task. Journal of Electromyography and Kinesiology, In Press. 
Lotz, J., \& Chin, J. (2000). Intervertebral disc cell death is dependent on the magnitude and duration of spinal loading. Spine , 25 (12), 1477-1483.

Marras, W. (2000). Occupational low back disorder causation and control. Ergonomics, 43 (7), 880-902.

McGill, S., Hughson, R., \& Parks, K. (2000). Lumbar erector spinae oxygenation during proloned contractions: implications for prolonged work. Ergonomics , 43 (4), 486-493.

Mientjes, M., Norman, R., Wells, R., \& McGill, S. (1999). Assessment of an EMG-based method for continuous estimates of low back compression during asymmetrical occupational tasks. Ergonomics , 42 (6), 868-879.

Potvin, J., \& Norman, R. (1993). Quantification of erector spinae muscle fatigue during prolonged, dynamic lifting tasks. European Journal of Applied Physiology, 67, 554-562.

Potvin, J., Norman, R., \& McGill, S. (1996). Mechanically corrected EMG for the continuous estimation of erector spinae muscle loading during repetitive lifting. European Journal of Applied Physiology, 74 (1-2), 119-132.

Potvin, J., Norman, R., \& Wells, R. (1990). A field method for continuous estimation of dynamic compressive forces on the L4/L5 disc during the performance of repetitive tasks. 23rd Annual Conference of the Human Factors Association of Canada. Ottawa, ON, Canada.

Punnett, L., Fine, L., Keyserling, W., Herrin, G., \& Chaffin, D. (1991). Back disorders and nonneutral trunk postures of automobile assembly workers. Scandinavian Journal of Work and Environmental Health, 17, 337-346.

Punnett, L., Pruss-Ustun, A., Imel Nelson, D., Fingerhut, M., Leigh, J., Tak, S., \& Phillips, S. (2005). Estimating the global burden of low back pain attributable to combined occupational exposures. American Journal of Industrial Medicine , 48, 459469.

Resnick, M., \& Chaffin, D. (1997). An ergonomic evaluation of three classes of material handling devices (MHD). International Journal of Industrial Ergonomics , 19 (3), 217229.

Sakamoto, K., \& Swie, Y. (2003). EMG characteristics of low back and lower limb muscles during forward bending posture. Electromyography and Clinical Neurophysiology , 43 (6), 335-347.

Seroussi, R., \& Pope, M. (1987). The relationship between trunk muscle electromyography and lifting moments in the sagittal and frontal planes. Journal of Biomechanics, 20 (2), 135-146. 
Snook, S. (1978). The design of manual handling tasks tasks. Ergonomics , 21, 963-985.

Stevens, S. S. (1957). On the psychophysical law. Psychological Review, 64, 153-181.

Sundin, A., Christmansson, M., \& Larsson, M. (2004). A different perspective in participatory ergonomics in product development improves assembly work in the automotive industry. International Journal of Industrial Ergonomics , 33, 1-14.

(2005). Surface ElectroMyoGraphy for the Non-Invasive Assessment of Muscles (SENIAM). The Netherlands: Roessingh Research and Development.

Veiersted, K., Westgaard, R., \& Andersen, P. (1993). Electromyographic evaluation of muscular work pattern as a predictor of trapezius myalgia. Scandinavian Journal of Work and Environmental Health, 1993, 284-290.

Werner, J. (2005). Regulatory processes of the human body during thermal and work strain. Environmental Ergonomics - The Ergonomics of Human Comfort, Health and Performance in the Thermal Environment , 3, 3-9.

Woldstad, J., \& Chaffin, D. (1994). Dynamic push and pull forces while using a manual material handling assist device. IIE Transactions , 26 (3), 77-88.

Woolf, A., \& Pfleger, B. (2003). Burden of major musculoskeletal conditions. Bulletin of the World Health Organization , 81 (9), 646-656. 


\section{CHAPTER 5.0}

\section{GENERAL DISCUSSION}

\subsection{Overview of Findings}

The overall objectives of the present research studies were to: 1) develop "sizing" equations to control for spring support based on body posture and anthropometry, and 2) to test PLAD's (Version 6) effectiveness and user acceptability during static forward bending in an automotive assembly plant. In order to achieve these objectives, both a laboratory and a field study were required. Major findings are stated below.

Study 1, which took place in a laboratory setting, resulted in a model that was able to successfully determine the PLAD's spring excursion based on one's height, weight and gender, as well as trunk inclination and knee angles in a working posture $\left(\mathrm{R}^{2}=0.885, \mathrm{SE}\right.$ $=2.873)$. This model was validated $\left(\mathrm{R}^{2}=0.923, \mathrm{RMS}\right.$ Error $\left.=2.124\right)$ and incorporated into a larger computerized model that was used to calculate a required overall spring stiffness for offsetting a given proportion of a worker's $\mathrm{L}_{4} / \mathrm{L}_{5}$ moment. This work was crucial as it was then possible to provide the automotive assembly workers in Study 2 with a known amount of PLAD support, which was used as a further validation for the model and is discussed below.

Study 2 involved field testing the PLAD at an automotive assembly plant, using operators who perform an assembly process requiring forward bending and static holds. The PLAD was able to significantly reduce low back muscular activity, predictedcompression, and ratings of perceived exertion, without significantly altering abdominal muscle activity or trunk inclination. These findings are similar to those found in previous 
research studies (Abdoli-E \& Stevenson, 2008; Abdoli-E et al., 2006; Lotz et al., 2008), but are novel as this research displayed the PLAD's effectiveness both during static holding tasks and in an industrial style setting. These findings are also significant as they showed that the new PLAD Version 6, which possessed several crucial design changes, was still effective in reducing low back loading without compromising trunk posture or abdominal activity. Most importantly, the PLAD was accepted by automotive assembly workers; most said they would wear the device, with slight alterations, everyday.

One further difference between the present and previous research regarding the PLAD is that it was possible to provide each operator with a similar amount of support ( $20 \%$ of the $\mathrm{L}_{4} / \mathrm{L}_{5}$ moment) using customized sizing equations that were developed in Chapter 3. Previous studies were unable to control for element stiffness based on anthropometry and posture (Abdoli-E et al., 2006; Abdoli \& Stevenson, 2008) Lotz et al., 2008), leading to larger variations in how the device functioned across individuals; moreover, it was impossible in these cases to predict how much help the device would be providing. In study 2 , when the $10^{\text {th }}$ (static), 50 ${ }^{\text {th }}$ (median), and $90^{\text {th }}$ (peak) APDF percentiles for the TES and LES were averaged, the percent difference between the PLAD and No PLAD conditions was $27.52 \%$. This was slightly larger than the $20 \%$ given due to the high $10^{\text {th }}$ percentile average differences, which were the result of extremely small activation levels. If only the median and peak APDF values are considered, the difference drops to an average of $19.75 \%$ for the ES muscles. This is almost identical to the calculated $20 \%$ in moment that was provided to each operator, and is feasible since static low back moments and ES EMG activity are linearly-related (Seroussi \& Pope, 1987). It is important to note that some error may have been the result of the $3 \%$ 
difference in what overall stiffness was desired, and what could be provided to each worker due to limitations in individual spring stiffnesses and the amount that could fit in the device. Moreover, although the low-back moment and ES EMG activity are linearly related in static postures, this does not ensure a 1:1 ratio between the two. Nevertheless, these data indicate that the equations and computer program developed in Chapter 3 can be used to select the desired spring stiffness required for offsetting a known percentage of the low back bending moment, for a given individual in a given posture, thereby further validating the model. This is critical to future PLAD research, as this result would indicate that it is possible to have better control over the amount of support provided by the PLAD. In this way, researchers and wearers can identify an optimal tension that the PLAD should provide based on variables, such as: spinal stability, comfort, and the type of task being executed.

\subsection{Relevance to Industry}

The results from the present work are directly relevant to the automotive industry where LBD as a result of occupational RF such as lifting, static holding, and forward bending are very common (Norman et al., 1998; Punnett et al., 1991). However, the findings are also relevant and generalizable to many other industries that possess similar manual materials handling exposures. The PLAD has been shown effective in reducing low back muscular activity and loading during sagittal lifting (Abdoli-E et al., 2006), asymmetrical lifting (Abdoli-E \& Stevenson, 2008), repetitive lifting (Lotz et al., 2008), and now static holding and forward bending; these are some of the most common and costly ergonomic issues observed in industrial settings (Bernard, 1997; Bigos et al., 1986; Marras et al., 1995; Norman et al., 1998; Punnett et al., 1991). Nearly every industrial 
task involves some form or degree of each of these RF, and thus the ability to reduce workers' acute or cumulative exposure is crucial to attenuating LBD risk and the associated costs. If the PLAD were to be implemented as an ergonomic on-body materials handling device in industry for reducing low back loading, it is likely that it would be effective in reducing injury rates and some of the associated costs that follow (Punnett et al., 2005). The present results have displayed that workers will wear the device, and that it is possible to provide an accurate amount of support to wearers. From these results, longer-term implementation in industry is a feasible option that could occur in the future.

\subsection{Other Areas Where the PLAD May be Useful}

Although implementation of the PLAD as a materials handling device is a logical use for the device, there are other possible applications or fields where the PLAD could be useful. One such area is in rehabilitation clinics as a return-to-work tool. It is possible that the PLAD would reduce the demands on the erector spinae during rehabilitation and the early stages of the return-to-work process, which could help workers return to their jobs more quickly after an acute LBP episode. Moreover, as the rehabilitation process progresses, it would be possible to wean subjects off the device using the customized software developed in Chapter 3. By providing subjects with a greater amount of support post-injury, then slowly providing less and less, it may be possible that workers could rehabilitate faster and with less chance of a relapse than workers who are rehabilitated without the help of the device.

\subsection{Future Research}

While the PLAD is effective in reducing several occupational LBD risk factors including low back muscular activity and spinal compression, further research is required 
before recommending the device for long-term use in any setting. All results observed to this date have been during short-term testing sessions; no long-term studies have taken place. It is crucial that testing is done regarding how the device affects spinal stability and muscle deconditioning before device use is recommended.

Analyzing the effect of external spring elements on the stability of the spine could be achieved using EMG and a 3-D biomechanical model (Cholewicki et al., 2000; Granata \& Wilson, 2001; Potvin \& Brown, 2005). If research were to be carried out analyzing the effect of the device on spinal stability, it may be possible to come up with an 'ideal' stiffness that would provide the greatest amount of support without significantly compromising lumbar spine stability. Carrying out research of this nature would also allow discrete conclusions regarding how an on-body materials handling device, such as the PLAD or those discussed in Barrett and Fathallah (2001), affects the natural balance and stability that is maintained by the anatomy of the lumbar spine. These findings would be very beneficial when recommending PLAD use for long periods of time.

A longitudinal study that analyzes how PLAD use affects the strength of the erector spinae as well as other back and leg muscles would also be very helpful in making final decisions regarding long-term use. Back belts were instituted as an ergonomic tool in industry before sufficient research took place, and it has since been discovered that back belt use can decrease erector spinae muscle activity, which could lead to muscle deconditioning (Bauer et al., 1999). Furthermore, wearing back belts for greater than four years can actually increase one's risk of obtaining a LBD by $27 \%$ (Kraus et al., 1996). A similar fate is not desired for the PLAD, and thus adequate research is required before the 
device is placed in industry or rehabilitation clinics as an ergonomic aid. If the PLAD were to be worn by a group of individuals who were tested constantly over a period of time for back extension strength (among other things), it would be possible to see how strength, and thus deconditioning, are affected by longer term use. The present study provided a $20 \%$ reduction in moment in order to not provide too much help and possibly compromise spinal stability; however, research is required in order to determine whether PLAD use can cause deconditioning, and how much support can be provided before deconditioning does occur.

The present study was also helpful at displaying the user acceptability of the PLAD during one industrial task. Further studies could also be helpful in further assessing what people like and do not like about the PLAD. A psychophysical study that would be interesting to look at would be how different individuals perceive differing amounts of back support by the device. The present study looked at one level of support (20\%), and thus it was not possible to make generalizations with respect to Stevens' Power Law. A future study that provides individuals with varying amounts of support during different tasks and asks them how much they believe the device is helping may be effective in fitting a power curve and assessing the exponent that relates wearers' perceptions to their actual physical work rate. An objective measure of wearer's perception could be found by adding a strain gauge in series with the elastic elements. Another user acceptability study could involve providing users with a variety of spring stiffnesses and letting them choose what they feel is the most helpful and comfortable when working. By blinding subjects to the stiffness level and asking them to rank the springs based on comfort and user acceptability, it may be possible to get an even better idea as to what type of stiffness 
PLAD wearer's desire when completing a variety of tasks. At this point it may also be feasible to match what individuals perceive to be the most beneficial with what is best from a safety point of view; this would advance future research involving the PLAD.

It is also important to note that PLAD design iterations are still changing. Future work will be done to make the device more comfortable and less warm, and the pelvic spacers may also be widened to increase the PLAD's mechanical advantage. Regardless of changes that have been made to the PLAD over time, findings have shown that the device does reduce the physical demands of the low-back and the present findings also show that workers will wear the device when working in industry. 


\subsection{References}

Abdoli-E, M., \& Stevenson, J. (2008). The effect of on-body lift assistive device on the lumbar 3-D dynamic moments and EMG during assymetric freestyle lifting. Clinical Biomechanics , 23, 372-380.

Abdoli-E, M., Agnew, M., \& Stevenson, J. (2006). An on-body personal lift augmentation device (PLAD) reduces EMG amplitude of erector spinae during lifting tasks. Clinical Biomechanics , 21, 456-465.

Barrett, A., \& Fathallah, F. (2001). Evaluation of four weight transfer devices for reducing loads on the lower back during agricultural stoop labor. ASAE Annual International Meeting Paper Number: 01-8056 (pp. 1-8). Sacramento, CA: ASAE.

Bauer, J., Fry, A., \& Carter, C. (1999). The use of lumbar-supporting weight belts while performing squats: erector spinae electromyographic activity. Journal of Strength and Conditioning Research, 13, 384-388.

Bernard, B. (1997). Musculoskeletal disorders and workplace factors: A critical review of epidemiologic evidence for work-related musculoskeletal disorders of the neck, upper extremity, and low back. Cincinatti, OH: Department of Health and Human Services, National Institute for Occupational Health and Safety.

Bigos, S., Spengler, D., Martin, N., Zeh, J., Fisher, L., Nachemson, A., \& Wang, M.H. (1986). Back Injuries in Industry: A retrospective Study II: Injury Factors. Spine , 11 (3), 246-251.

Cholewicki, J., Simons, A., \& Radebold, A. (2000). Effects of external trunk loads on lumbar spine stability. Journal of Biomechanics , 33, 1377-1385.

Granata, K., \& Wilson, S. (2001). Trunk posture and spinal stability. Clinical Biomechanics , 16, 650-659.

Kraus, J., Brown, K., McArthur, D., Peek-Asa, C., Samaniego, L., \& Kraus, C. (1996). Reduction of acute low back injuries by use of back supports. Journal of Occupational and Environmental Health, 2, 264-273

Lotz, C., Agnew, M., Godwin, A., \& Stevenson, J. (2008). The effect of an on-body personal lift-assist device (PLAD) on fatigue during a repetitive lifting task. Journal of Electromyography and Kinesiology, In Press.

Marras, W., Lavender, S., Leurgans, S., Fathallah, F., Ferguson, S., Allread, W., \& Rajulu, S.L. (1995). Biomechanical risk factors for occupationally related low back disorders. Ergonomics , 38 (2), 377-410. 
Norman, R., Wells, R., Neumann, P., Frank, P., Shannon, H., \& Kerr, M. (1998). A comparison of peak vs cumulative physical work exposure risk factors for the reporting of low back pain in the automotive industry. Clinical Biomechanics , 13, 561-573.

Potvin, J., \& Brown, S. (2005). An equation to calculate individual muscle contributions to joint stability. Journal of Biomechanics, 38(5), 973-980.

Punnett, L., Fine, L., Keyserling, W., Herrin, G., \& Chaffin, D. (1991). Back disorders and nonneutral trunk postures of automobile assembly workers. Scandinavian Journal of Work and Environmental Health, 17, 337-346.

Punnett, L., Pruss-Ustun, A., Imel Nelson, D., Fingerhut, M., Leigh, J., Tak, S., \& Phillips, S. (2005). Estimating the global burden of low back pain attributable to combined occupational exposures. American Journal of Industrial Medicine , 48, 459469. 
APPENDICES 


\section{APPENDIX A}

Ethics Approval 


\section{Study 1}

September 5, 2007

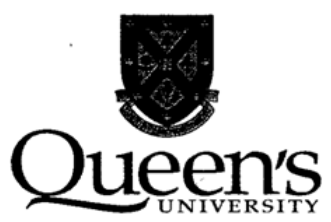

OFFICE OF RESEARCH SERVICES

Fleming Hall, Jemmett Wing

Queen's University

Kingston, Ontario, Canada K7L. 3N6

Tel 613 533-6081

Fax 613 533-6806

ors@post.queensu.ca

Dr. Joan Stevenson

www.queensu.ca/vpr/

School of Kinesiology and Health Studies

Queen's University

\section{Re: "Design and Evaluation of a Mechanical Lift Assist Device (PLAD)"} PHE-047-03

Dear Dr. Stevenson,

I am writing to acknowledge receipt of your email dated Tue. 04 Sep 2007 which requested approval for some changes to the above-named study. I have reviewed these changes:

- Addition of Ryan Graham, Research Assistant and Master's Student to the project

- Request to collect data on the actual excursion (in $\mathrm{cm}$ ) when men and women of different statures and body weights lift under different lifting conditions

- Consent form (Study \#1 - Lab Pilot Study)

and hereby give my approval. These amendments will be reported to the Research Ethics Board.

Yours sincerely,

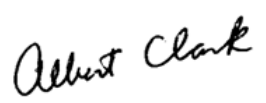

Albert Clark, Ph.D.

Chair

Research Ethics Board

$\mathrm{AFC} / \mathrm{kr}$

c.c.: Mr. Ryan Graham, School of Kinesiology and Health Studies

think Research

think Queen's

E P A R I N G L E A D E R S A N D C I T I Z E N S F O R A G L O B A L S O C C I E T Y 
Study 2

October 26, 2007

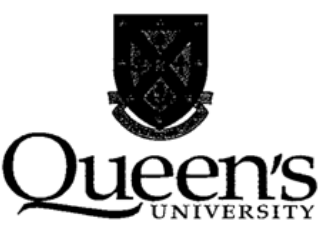

OFFICE OF RESEARCH SERVICES

Fleming Hall, Jemmett Wing

Queen's University

Kingston, Ontario, Canada K7L 3N6

Tel 613 533-6081

Fax 613 533-6806

ors@post.queensu.ca

Dr. Joan Stevenson

www.queensu.ca/vpr/

School of Kinesiology and Health Studies

Queen's University

\section{Re: "Design and Evaluation of a Mechanical Lift Assist Device (PLAD)" PHE-047-03}

Dear Dr. Stevenson,

I am writing to acknowledge receipt of your email dated Wed. 24 Oct. 2007

which requested approval for an addendum to the above-named study. I have reviewed the following documents:

- Cover letter of explanation

- Notification that Ryan Graham is an investigator on the study

- Information/Consent Form for the Pilot Study at Queen's

- Information/Consent Form for the TMMC Study

- A copy of the Pre-Task PLAD Survey

- A copy of the Post-Task PLAD Survey

and hereby give my approval. Receipt of these documents will be reported to the Research Ethics Board.

Yours sincerely,

$$
\text { Qubent Clank }
$$

Albert Clark, Ph.D.

Chair

Research Ethics Board

$\mathrm{AFC} / \mathrm{kr}$

c.c.: Mr. Ryan Graham, School of Kinesiology and Health Studies 
APPENDIX B

$\underline{\text { Written Consent }}$ 


\section{Ethics Consent Form}

\section{Study 1: Lab Pilot Study}

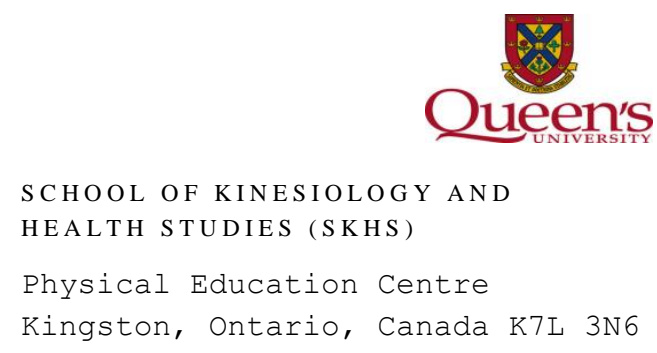

Physical Education Centre

Kingston, Ontario, Canada K7L 3N6

\section{Determining Changes in Spring Excursion and PLAD's Moment Arm with Varying Degrees of Trunk and Knee Flexion}

Dear Participant,

We would like to invite you to participate in a research study at Queen's University where we are developing an on-body ergonomic aid for lifting and static holding tasks. This ergonomic aid is called a Personal Lift-Assist Device (PLAD) and is design to be worn during manual materials handling tasks.

We will read through this consent form with you and describe the procedures in detail. You will be given time to read about it yourself and we are encouraged to ask questions at any time.

\section{Aims and Purposes of the Study:}

The PLAD is made up of a modified back-pack, a waist belt with pelvic spacers and knee pads with a cable and steel springs connecting all three items. The springs are stretched when you bend forward and they help you return to standing posture during lifting or counter your body weight when leaning forward. The goal of this research is to assess changes in spring excursion and PLAD's moment arm as a result of varying degrees of trunk and knee flexion. We will use your feedback to improve the effectiveness of the PLAD; the findings from the present study will be used at a later date to determine spring requirements for offsetting $20 \%$ to $100 \%$ of the low back forces and moment in a variety of postures, for individuals of varying heights and weights.

\section{Methodology:}

Personal Information: For your personal safety, we will exclude you from the study if you are currently suffering from low back pain. After you have been cleared to take part in the study, we will record your height $(\mathrm{m})$, weight $(\mathrm{kg})$, and various anthropometric dimensions $(\mathrm{m})$.

Wearing PLAD: PLAD is worn like a backpack. It will be fitted to you by tightening straps around the shoulders, waist and knees. It can be worn over most types of clothing apparel. However, we would like you to wear comfortable street shoes or gym shoes (not sandals). We will help adjust the PLAD until it is comfortable and you are willing to proceed with the study. 
We will not use the springs in the PLAD because we only wish to know the length (excursion) of the cable needed as you bend forward or execute different lifting tasks.

Instrumentation: To measure your trunk and knee angles, we will use a Fastrak $^{\mathrm{TM}}$ electromagnetic tracking system by Polhemus (Cochester, VT, USA). Three small motion sensors will be attached to your body at the sternum, thigh and shank, and will be mounted securely using Tufskin $^{\circledR}$ spray followed by stretchy fabric-based adhesive tape. To measure the length needed for the cable and spring, a displacement transducer by Celesco (Chatsworth, CA, USA) will be used. It will be attached in-line with the PLAD, as per Figure 1, and will record a displacement when your trunk or knees are flexed.

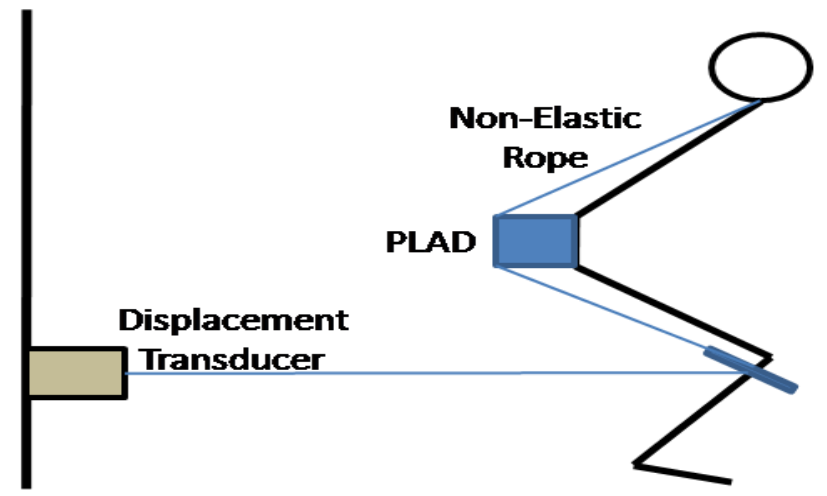

Trial Protocol: In this lab-based study, you will be asked to carry out a protocol that simulates unloaded stoop, squat and freestyle lifting. We will outfit you with the PLAD and asked you to perform a few practice trials after connecting the PLAD to the displacement gauge. The task will begin with you standing upright in a 'soldier position' so that we can zero (calibrate) the Fastrak system and displacement transducer.

You will be asked to bend only your trunk as far forward as possible without moving your feet or flexing your knees (stoop). Next, you will be asked to flex only your knees, while retaining an upright trunk (squat). Lastly, you will be asked to combine both trunk and knee flexion (freestyle). The entire study should take no more than 30 minutes.

\section{Risks and Benefits of Participation:}

To protect you as much as possible from this risk, we encourage you to quit at any point if you are experiencing more pain or discomfort than you would anticipate with this task. Exercising muscles that are not used often may leave you with a sore feeling for a couple of days after the study. If you have soreness or pain, please call us and we will assist you in contacting your preferred health care professional.

There are no direct personal benefits from the study. You will have an opportunity to contribute to the improvement of a new on-body personal lift-assist device that may aid workers in reducing the risk of low back pain. 
By signing this consent form, you do not waive your legal rights nor release the investigators from their legal and professional responsibilities.

\section{Confidentiality:}

All information obtained during the course of this study is strictly confidential and your anonymity will be protected at all times. Your identity is only recorded at the time of filing the consent forms. You will be assigned a study number that will link your information to this file. All data recorded in computer files will be locked and only the principal researcher and research assistants will be granted access. In all cases of publication, only summary data are used so that no individual can be identified.

We are interested in collecting video and digital photographs for use in future research, presentations and publications. If you are willing to have your photograph taken, we will ask you to sign the section at the bottom of this form pertaining to this information.

\section{Voluntary Nature of the Study:}

As a participant, you are a volunteer who may withdraw from the study at any time without coercion or penalty. You may withdraw after hearing about the details of the study. You may also withdraw at any point during the study with no coercion or penalty. If you choose to withdraw, we will ask you if you would like us to remove all of your data from the database.

\section{Contacts:}

If at any time you have further questions, problems or adverse events, you can contact:

Dr. Joan Stevenson (School of Kinesiology and Health Studies)

(613) 533-6288

Dr. Jean Cote (School of Kinesiology and Health Studies)

If you have any questions regarding your rights as a research participant, you can contact:

Dr. Albert Clark (Research Ethics Board, Chair)

(613) 533-6081

\section{What Does My Signature Mean?:}

By signing below, I am indicating that:

- I have read the letter of information

- I am aware that the purpose of the study is to assess a personal lifting assistive device (PLAD)

- I realize I can withdraw at any time without penalty or coercion

- I can contact any of the people identified in this letter if I have questions, concerns, or complaints 
- I realize that my data will be kept confidential. Only if I sign a second time below will additional photos or video be taken for possible use in presentations or publications

- By signing this consent form, I do not waive my legal rights nor release the investigator(s) and sponsors from their legal and professional responsibilities. 


\section{$\underline{\text { Subject's Copy }}$}

Signature Page (Sign two times, one for yourself and one for the investigator):

Signature of Participant

Date

\section{Statement of Investigator:}

I have carefully explained the nature of the above research study. I certify that, to the best of my knowledge, the participant understands clearly the nature of the study and demands, benefits, and risks involved to participants in this study.

Signature of Investigator

Date

\section{Consent for Photographs:}

By signing below, I am indicating my willingness to be photographed for presentations or publications. I realize my identity will be blocked from view in these images.

Signature of Participant

Date 


\section{$\underline{\text { Investigator's Copy }}$}

Signature Page (Sign two times, one for yourself and one for the investigator):

Signature of Participant

Date

\section{Statement of Investigator:}

I have carefully explained the nature of the above research study. I certify that, to the best of my knowledge, the participant understands clearly the nature of the study and demands, benefits, and risks involved to participants in this study.

Signature of Investigator

Date

\section{Consent for Photographs:}

By signing below, I am indicating my willingness to be photographed for presentations or publications. I realize my identity will be blocked from view in these images.

Signature of Participant

Date 


\section{Ethics Consent Form \\ for Research \\ Study 2 entitled:}

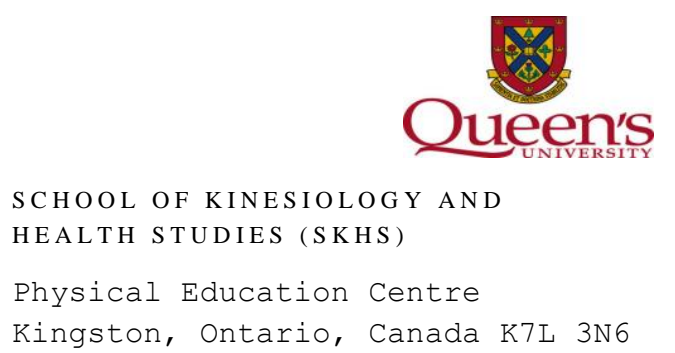

\section{User Acceptability of a Personal Lift- Assist Device (PLAD) at an Automotive Manufacturing Company}

Dear Team Member,

We are researchers in the area of Ergonomics from Queen's University and Ryerson University. You are invited to participate in a research study to examine the user acceptability and effectiveness of a Personal Lift-Assist Device (PLAD). The PLAD is designed to assist you during lifting tasks and static holding tasks. In a group presentation, we have provided a detailed description of the PLAD's design and how it works as well as details about this research study. This Ethics Consent letter will present key information again so you can read about the study and decide whether you wish to become a participant. If you wish to participate, you will be asked to sign this letter and leave a copy of the last page with the researcher.

\section{Aims and Purposes of the Study:}

The goal of this research is to assess user acceptability of the Personal Lift-Assist Device or PLAD. We wish to know whether you are comfortable and find the PLAD effective during specific manual materials handling tasks. We will use your feedback to improve the design of the PLAD and to determine if it is effective for the analyzed assembly tasks. Management will use your opinions and the test results to decide if they wish to pursue this ergonomic intervention further for specific jobs.

\section{Methodology:}

Personal Information: For your personal safety, we wish to exclude you from the study if you are currently suffering from shoulder or low back pain. After you qualify to take part in the study, we will record your name and work shift so that we can keep track of your timetable. We will use a code number instead of your name on all paperwork used in the study. Your name and assigned code number will be kept as well but retained in a separate password-protected file.

Wearing the PLAD: The PLAD has three main parts with an adjustable cable joining them: pants with a strap under your shoes, a waist belt with two spacers at buttocks height and an upper part that is worn like a backpack. It is important that the PLAD is well-fitted to each worker's body size. Therefore, the first step will be for a professional tailor to measure various body dimensions (e.g., leg length, shoulder width, waist girth, height, weight, etc). Once we have made the PLAD suits, we will return before scientific testing to make any final adjustments. At that time, you will be able to try on the PLAD and see how it feels. 


\section{The Tasks}

We wish to challenge the PLAD using a task that involves lifting and carrying and a task that involves a lot of forward trunk lean. To scientifically test the PLAD, we must compare your usual work with and without wearing the on-body ergonomic aid. This means we must collect data from each worker over two days.

During both sessions (regular work and PLAD-assisted work) we will collect two types of information over your two hour shift:

A) Your subjective opinion throughout the task. We will ask a number of questions before, during and after your job rotation about regions of discomfort, mobility, balance and fatigue. This information will serve as a baseline for regular work and feedback on the PLAD design during ergonomic-assisted work.

B) Muscle signals from your trunk muscles. One way to examine the PLAD's effectiveness is to see how hard your trunk muscles are working during regular work and PLAD-assisted work. We will monitor your muscles using a portable electromyographic system called an EMG system. Small electrodes will be attached to your skin with double-sided adhesive tape and covered with a bandage over a couple of your back and stomach muscles. In order for the sensors to stick to your skin, I will clean it with rubbing alcohol using a cotton pad. EMG lead wires will be held down with athletic tape. The EMG system will be attached to the back of your shirt with safety pins or to the back or side of your waist belt.

Once the EMG system is in place, we will ask you to hold a ten pound weight in front of your chest for 10 seconds. Then, we will ask you for three maximal flexion and extension contractions against an immovable stand. These tests will allow us to compare your data across the two different days and across the other Team Members. The preparations will take about 15 minutes. Once you begin your job, there will be minimal interruptions for your subjective feedback.

\section{$\underline{\text { Risks and Benefits of Participation: }}$}

Research has shown that manual materials handling tasks have higher risks of musculoskeletal injuries, especially low back pain. To protect you as much as possible from this risk, we will encourage you to quit at any point if you are experiencing more pain or discomfort than you would anticipate with this task. If you feel extended soreness or pain, please go to the medical centre for assistance or contact your preferred health care professional. For your information, no one has hurt themselves when wearing the PLAD.

Some individuals may have sensitive skin resulting in skin irritation from rubbing alcohol or adhesive tape. Normally this irritation disappears shortly after the tape is removed. If it does not disappear within a couple of hours, please go to the medical centre for assistance.

In terms of the benefits of the study, there are no direct personal benefits expected. However, your feedback will contribute to improvements in the PLAD design and possible future use of the PLAD in industry.

By signing this consent form, you do not waive your legal rights nor release the investigators from their legal and professional responsibilities. 


\section{Confidentiality:}

All information obtained during the course of this study is strictly confidential and your anonymity will be protected at all times. Your identity is only recorded to make body-size measurements for PLAD fittings and to assign a code number for your file. All data recorded in computer files will be locked and only the principal researcher and research assistants will be granted access. In all cases of publication, only summary data are used and this is done in such a way that no individual can be identified.

Photography from outsiders is not permitted in the manufacturing plant nor do we need photographs for this research. However, it is helpful to show the task and setup in research presentations and publications. If granted permission, are you willing to have personnel take photographs during data collection? Only two participants will be asked for permission during data collection.

\section{Voluntary Nature of the Study:}

As a participant, you are a volunteer who may withdraw from the study at any time without coercion or penalty. You may withdraw after hearing about the details of the study or you may also withdraw at any point during the study with no penalty.

\section{Contacts:}

If at any time you have further questions, problems or adverse events, you can contact:

Dr. Joan Stevenson (School of Kinesiology and Health Studies)

(613) 533-6288

Dr. Jean Cote (School of Kinesiology and Health Studies)

If you have any questions regarding your rights as a research participant, you can contact:

Dr. Albert Clark (Research Ethics Board, Chair)

(613) 533-6081

\section{What Does My Signature Mean?}

I am being asked to sign below. My signature indicates that:

- I have read the letter of information

- I am aware that the purpose of the study is to assess a personal lifting assistive device (PLAD)

- I realize I can withdraw at any time without penalty or coercion

- I can contact any of the people identified in this letter if I have questions, concerns, or complaints

- I realize that my data will be kept confidential.

- By signing this consent form, I do not waive my legal rights nor release the investigator(s) and sponsors from their legal and professional responsibilities. 


\section{Participant's Copy}

(Please sign and keep this Ethics Consent letter for your records). 
Researcher's Copy

Ethics Consent Study 2

\section{User acceptability of a Personal Lift-Assist Device (PLAD) at an Automotive Manufacturing Company}

This page is for the researchers to verify that you are willing to participate in the above study. By signing this page you are declaring the following:

- You were given a verbal presentation about the above-mentioned research study

- You were given an Ethics Consent letter of information to read and keep

- You are aware that the purpose of the study is to assess a personal lifting assistive device (PLAD) based on your subjective opinion and objective signals from your trunk muscles

- You realize that you can withdraw at any time without penalty or coercion

- You know that you can contact any of the people identified in the Ethics Consent letter if you have questions, concerns, or complaints

- You realize that your data will be kept confidential

- By signing this consent form, you realize that you do not waive your legal rights nor release the investigator(s) and sponsors from their legal and professional responsibilities.

(Please sign and return this page ONLY to the researchers or manager in charge)

Print your Name

Date

Signature of Participant

Witness

Date 


\section{APPENDIX C}

$\underline{\text { Automotive Assembly Job Task Details }}$

8/21/2007 11:09 AN

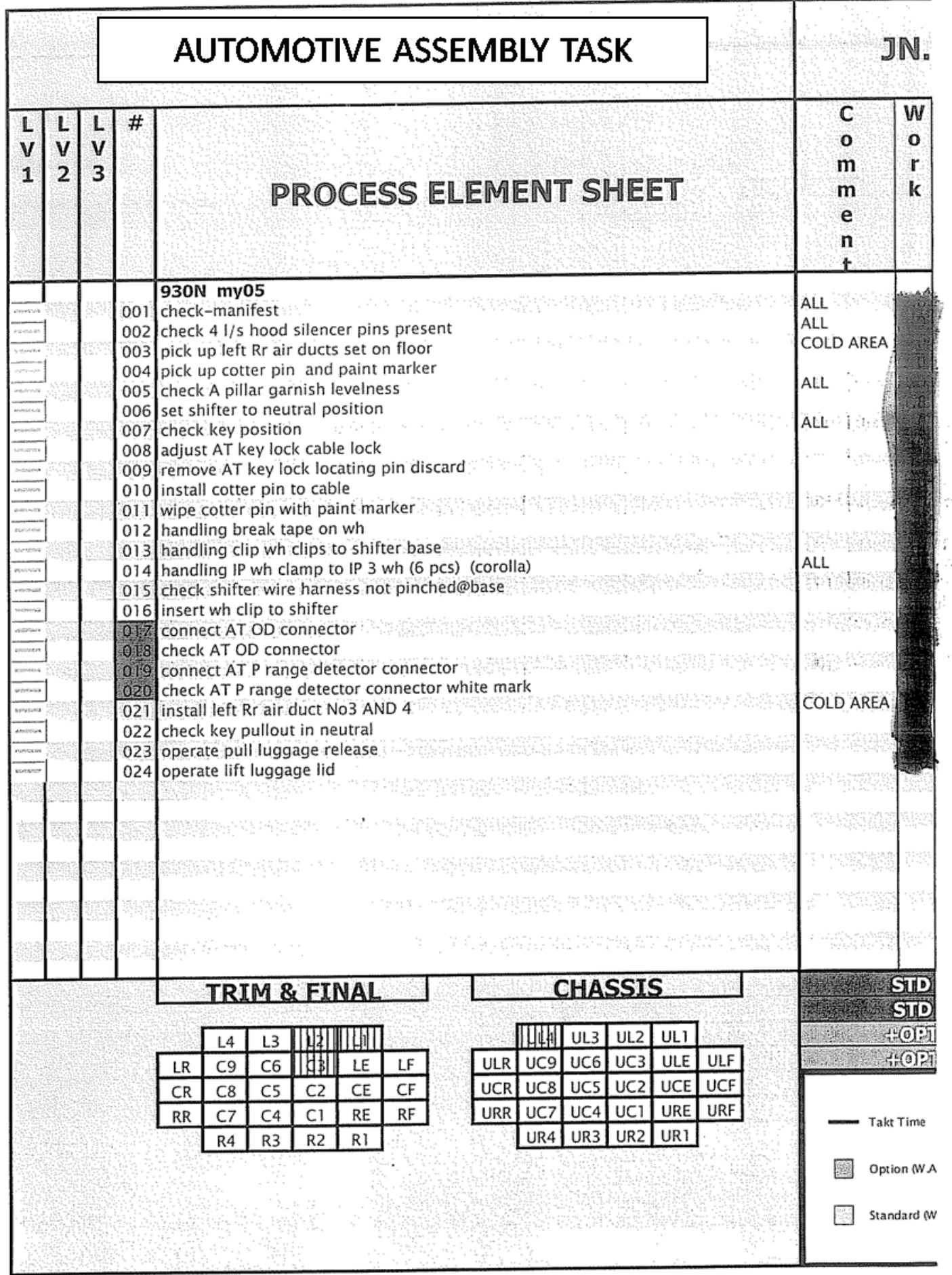




\section{APPENDIX D}

Sample Size Power Calculation

$\underline{\text { Mean EMG for LES from Abdoli-E et al. (2006) }}$

\begin{tabular}{|c|c|c|}
\hline & No-PLAD & PLAD \\
\hline Mean $(\boldsymbol{\mu})$ & 22.282 & 19.105 \\
\hline $\begin{array}{c}\text { Standard Deviation }(\boldsymbol{\sigma}) \\
\begin{array}{c}\text { Coefficient of Variation } \\
(\boldsymbol{\sigma} / \boldsymbol{\mu})\end{array}\end{array}$ & 5.837 & 4.729 \\
\hline
\end{tabular}

For the $20 \%$ reduction in the $\mathrm{L}_{4} / \mathrm{L}_{5}$ moment, arbitrary means are chosen:

\begin{tabular}{|c|c|c|}
\hline & No-PLAD & PLAD \\
\hline Mean $(\boldsymbol{\mu})$ & 20.000 & 16.000 \\
\hline $\begin{array}{c}\text { Coefficient of Variation } \\
(\boldsymbol{\sigma} / \boldsymbol{\mu})\end{array}$ & 0.262 & 0.248 \\
\hline Standard Deviation $(\boldsymbol{\sigma})$ & & 3.96 \\
\hline
\end{tabular}

$$
\begin{gathered}
\text { Effect Size }(d)=\frac{\text { mean } 1-\text { mean } 2}{\sqrt{\left(S D 1^{2}\right)+\left(S D 2^{2}\right) / 2}} \\
\text { Effect Size }(d)=\frac{20-16}{\sqrt{\left(5.24^{2}\right)+\left(3.96^{2}\right) / 2}} \\
\text { Effect Size }(d)=\mathbf{0 . 8 6}
\end{gathered}
$$

Thus for power $=0.8$ and $\alpha=0.05$ [From Stephens (1999) Table C1]:

$$
n=8
$$

\section{References:}

Abdoli-E, M., Agnew, M., \& Stevenson, J. (2006). An on-body personal lift augmentation device (PLAD) reduces EMG amplitude of erector spinae during lifting tasks. Clinical Biomechanics , 21, 456-465.

Stevens, J. (1999). A modern approach to intermediate statistics (2nd ed.). New Jersey, USA: Lawrence Erlbaum Associates. 


\section{APPENDIX E}

$\underline{\text { Computer Programs }}$ 


\section{Labview 8.0 Electromyography (EMG) Processing Program}
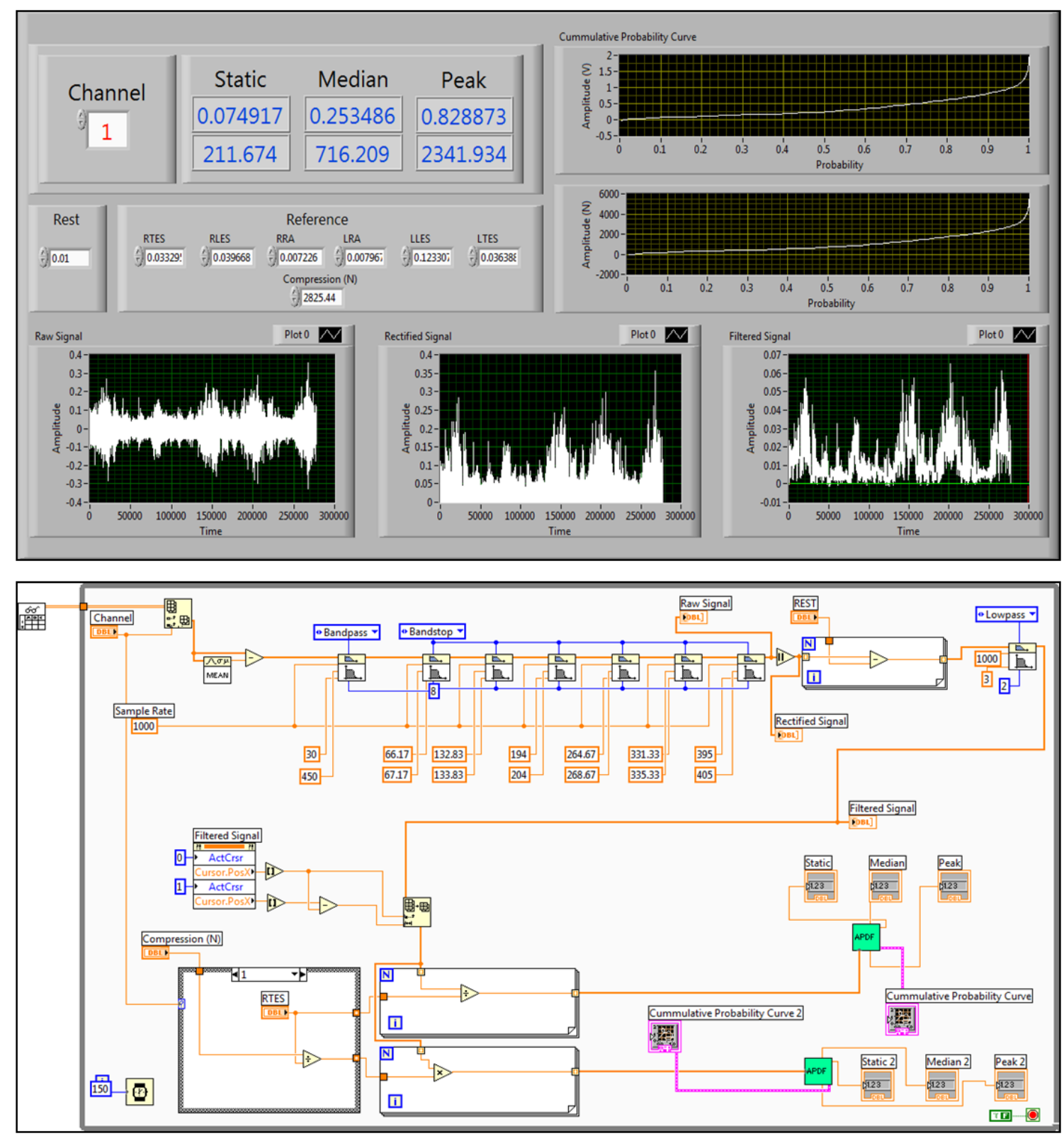


\section{Labview 8.0 Angle Processing Program}
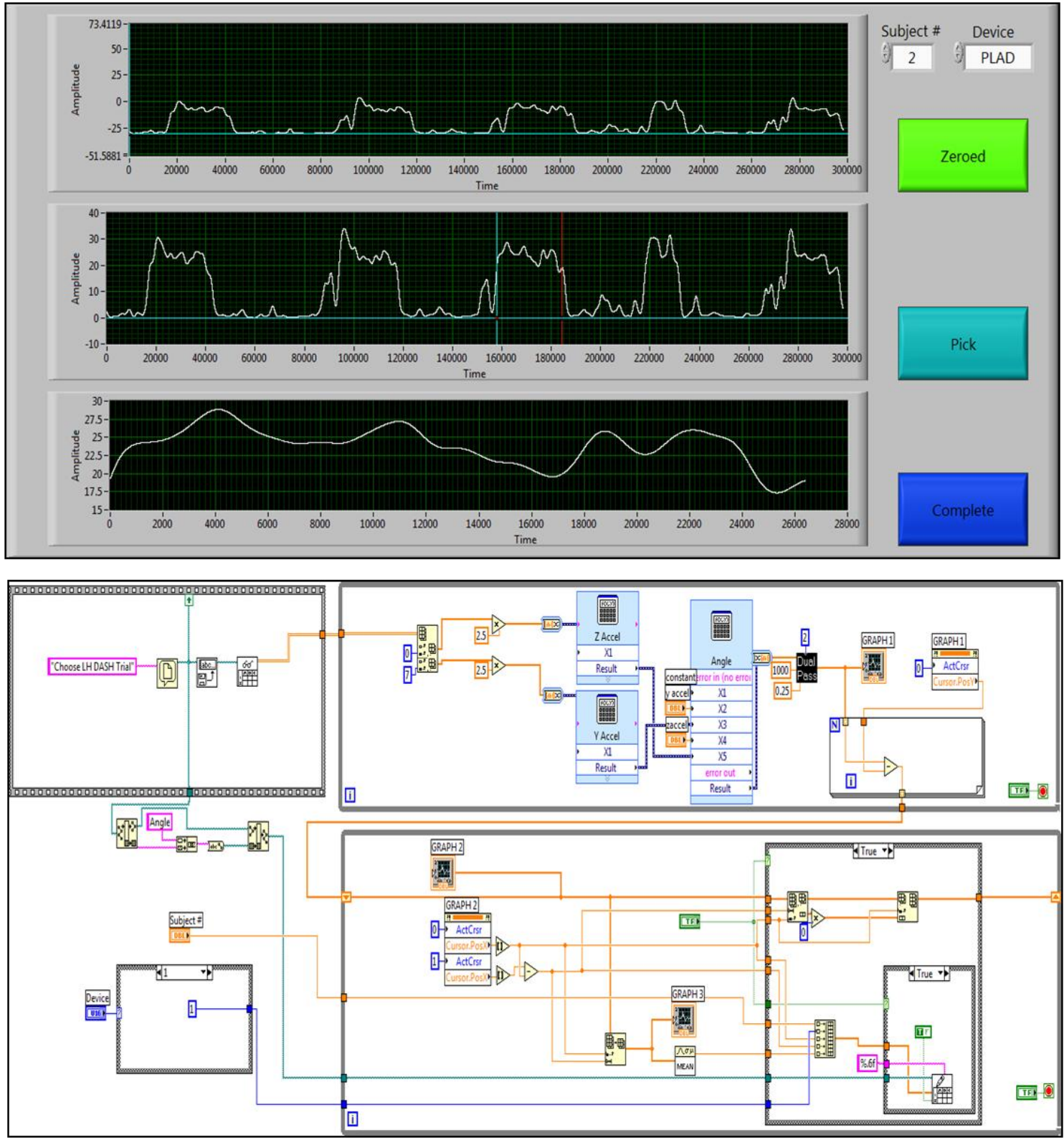


\section{Matlab R2007a Spring Optimization Program}

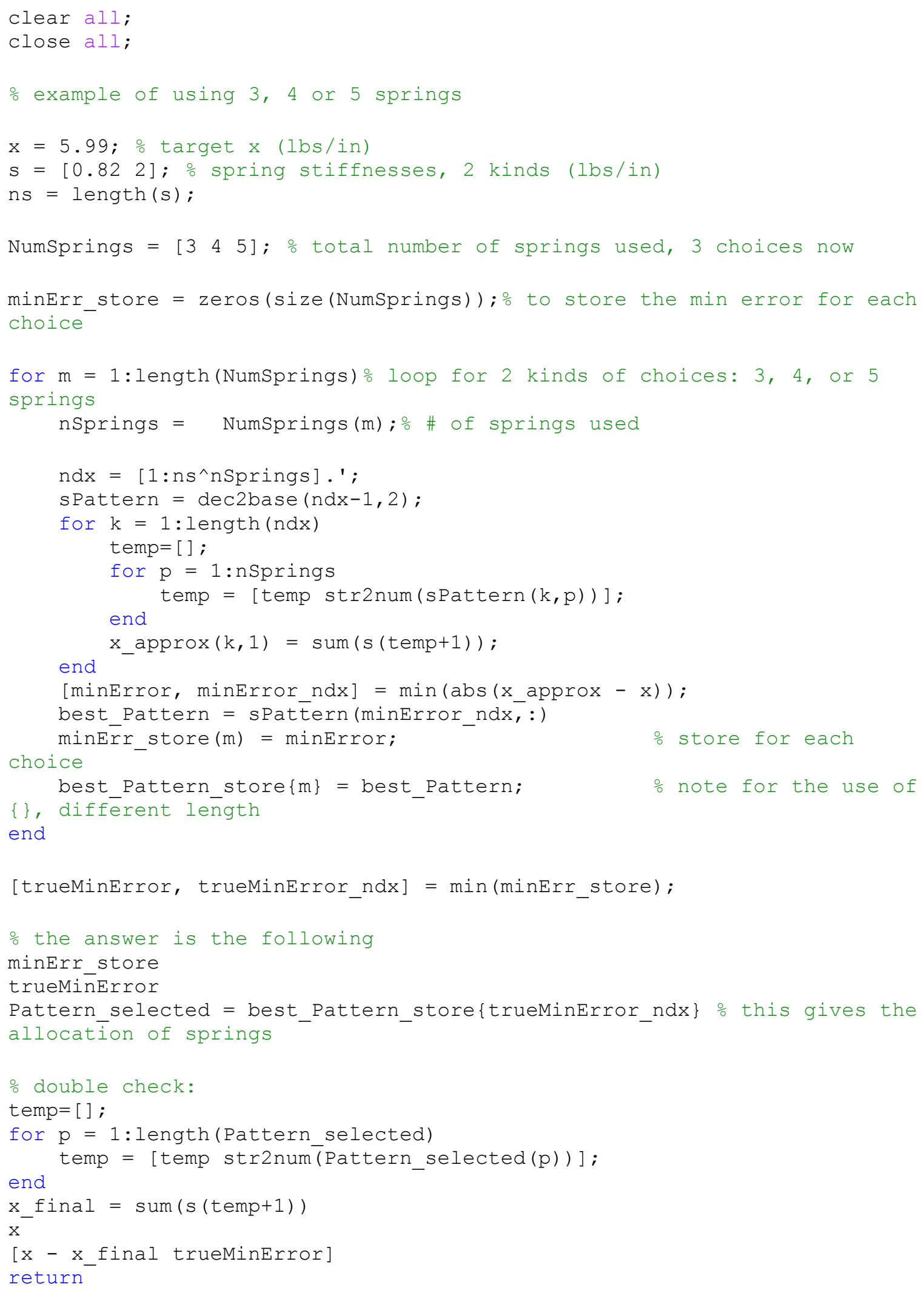


APPENDIX F

$\underline{\text { Surveys }}$ 


\section{Queen's University \\ Pre-Task PLAD Survey}

TASK:

(To be completed by Automotive Employee)

\section{Do you have any discomfort or pain? $\quad \mathrm{Y} \quad / \quad \mathrm{N}$}

(If yes please indicate locations and severities on the diagram below)

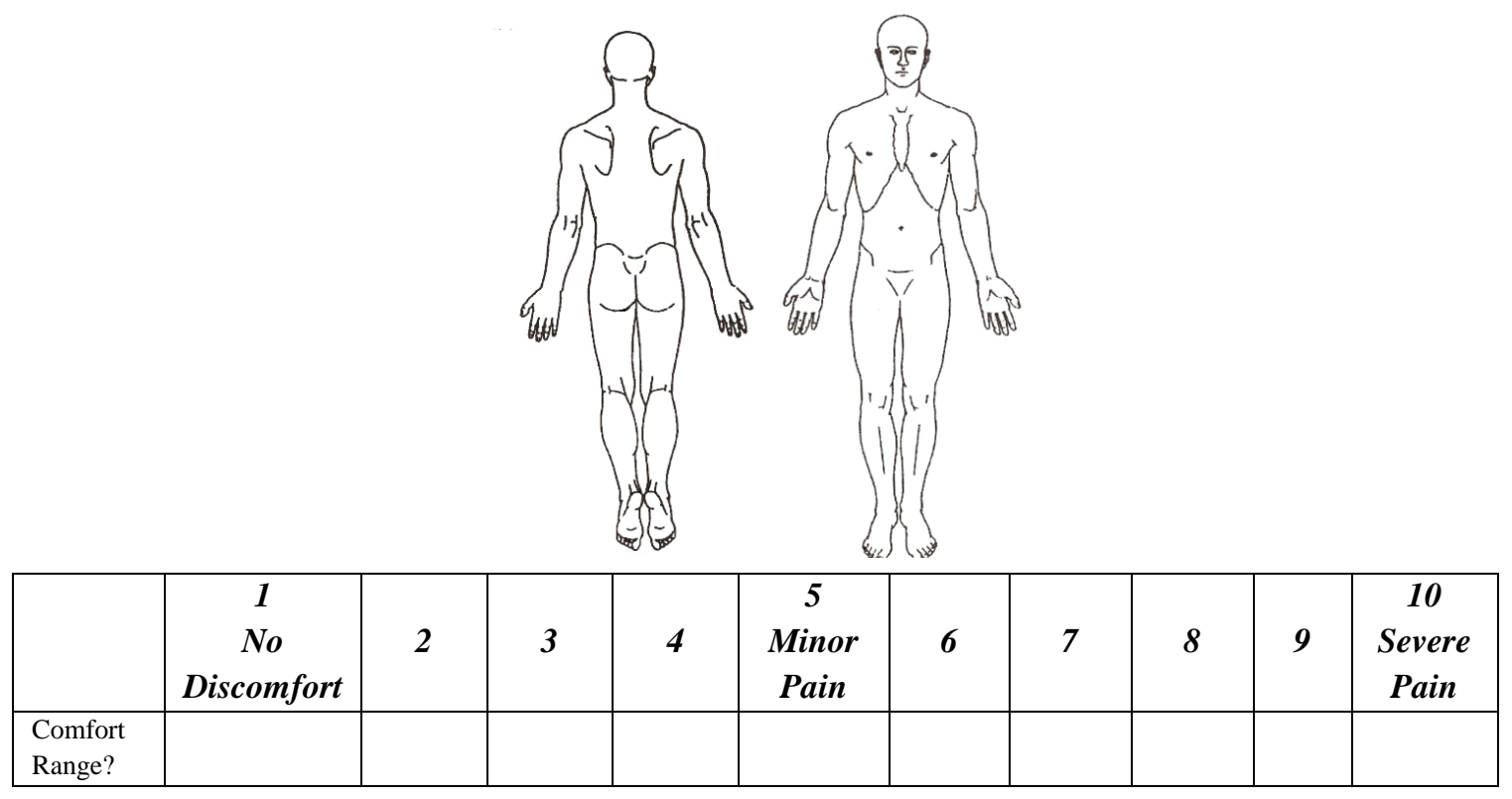

2. Do you have any flexibility/ range of motion problems? $\quad$ Y / N

(If yes please indicate locations and severities on the diagram below)

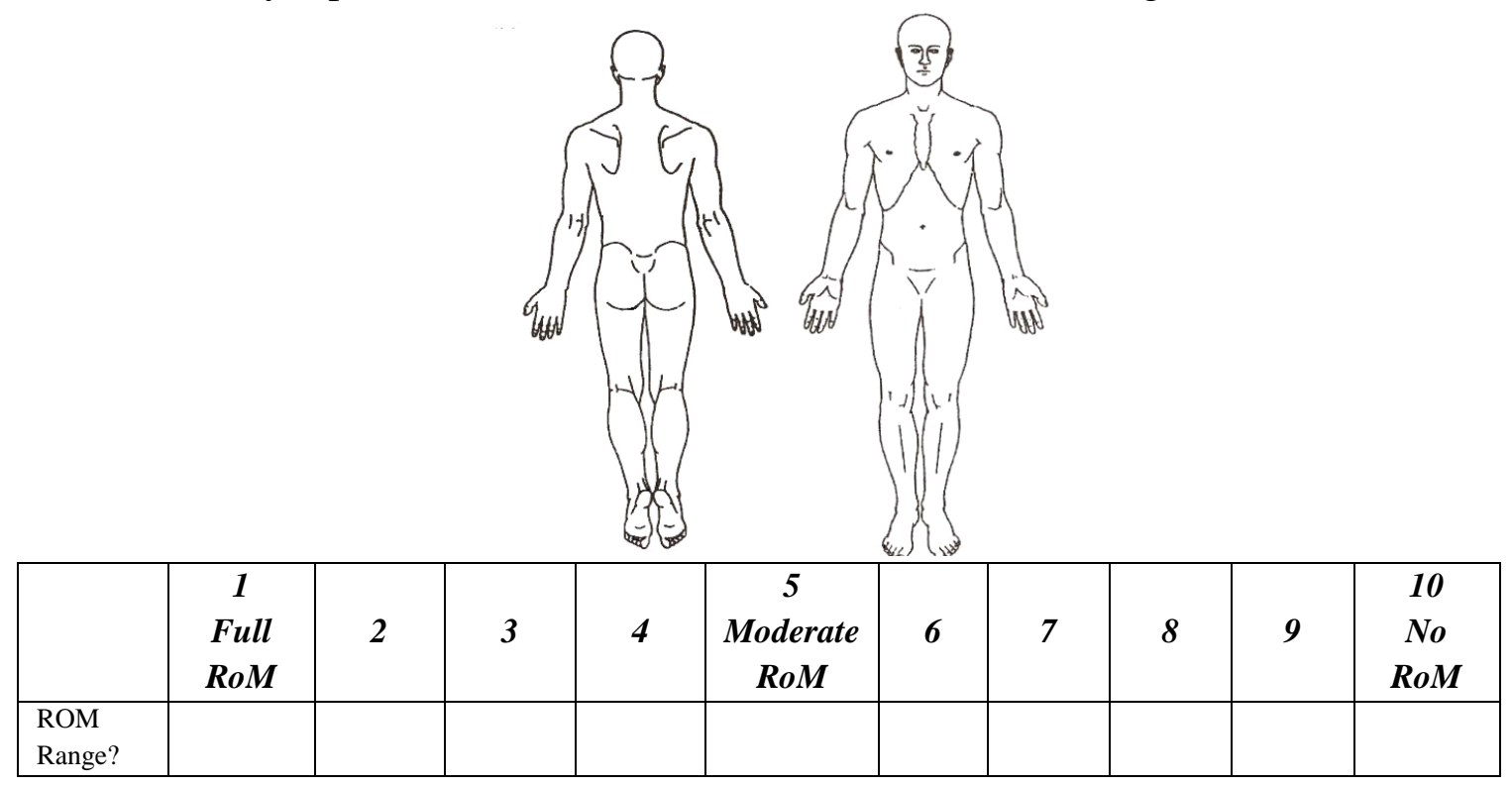


3. Have you ever done this task before? $\mathrm{Y} / \mathrm{N}$ How many years/months?

4. Do you find this task difficult? $\mathrm{Y} / \mathrm{N}$ Why?

5. Rank your perception of fatigue after a 2 hour shift on this task

\begin{tabular}{|l|c|c|c|c|c|c|c|c|c|c|}
\hline & $\begin{array}{c}1 \\
\text { No } \\
\text { Fatigue }\end{array}$ & 2 & 3 & 4 & $\begin{array}{c}5 \\
\text { Moderately } \\
\text { Fatigued }\end{array}$ & 6 & 7 & 8 & 9 & $\begin{array}{c}10 \\
\text { Exhausted }\end{array}$ \\
\hline $\begin{array}{l}\text { Fatigue } \\
\text { Range? }\end{array}$ & & & & & & & & & & \\
\hline
\end{tabular}

6. Do you think the PLAD may help with this task? (Circle One)
a. Yes definitely
b. Yes slightly
c. Maybe
d. Not really
e. Not at All
f. Unsure

7. What are your concerns about wearing the PLAD for this task? (Circle One)

a. No concerns at all

b. Does it work?

c. Will I be able to move?

d. It is uncomfortable

e. I might get injured 


\section{Queen's University During-Task PLAD Survey}

(To be completed by Researcher every 10 minutes)

1. How hard do you feel you are working (Rating of Perceived Exertion) on a scale of 6 to 20?

\begin{tabular}{|l|l|l|l|l|l|l|l|l|l|l|l|l|l|l|}
\hline 6 & 7 & 8 & 9 & 10 & 11 & 12 & 13 & 14 & 15 & 16 & 17 & 18 & 19 & 20 \\
\hline
\end{tabular}

2. Do you feel any pressure points or discomfort? Where and how severe $(/ 10) ?(1=$ none, $10=$ severe $)$

3. Do you feel any movement restrictions? Where and how severe (/10)? (1=full ROM, 10=no ROM)

4. Can you feel the PLAD working? Where and how much (\%)?

5. Any other concerns? 


\section{Queen's University \\ Post-Task PLAD Survey}

(Written: To be completed by Automotive Employee)

\begin{tabular}{|c|c|c|c|c|c|}
\hline \multirow[t]{2}{*}{ Compared to NO DEVICE, I believe PLAD affected my: } & \multicolumn{5}{|c|}{ Tick mark your most suitable answer } \\
\hline & 1 & 2 & 3 & 4 & 5 \\
\hline 1. Back Muscles' Effort & $\square$ & $\square$ & $\square$ & $\square$ & $\square$ \\
\hline 2. Leg Muscles' Effort & $\square$ & $\square$ & $\square$ & $\square$ & $\square$ \\
\hline 3. Personal Safety & $\square$ & $\square$ & $\square$ & $\square$ & $\square$ \\
\hline 4. Balance & $\square$ & $\square$ & $\square$ & $\square$ & $\square$ \\
\hline 5. Range of Motion/ Flexibility & $\square$ & $\square$ & $\square$ & $\square$ & $\square$ \\
\hline 6. Shoulder Comfort & $\square$ & $\square$ & $\square$ & $\square$ & $\square$ \\
\hline 7. Waist Comfort & $\square$ & $\square$ & $\square$ & $\square$ & $\square$ \\
\hline 8. Knee and Foot Comfort & $\square$ & $\square$ & $\square$ & $\square$ & $\square$ \\
\hline 9. Potential for Muscle Strain Injuries & $\square$ & $\square$ & $\square$ & $\square$ & $\square$ \\
\hline 10. MY OVERALL OPINION & $\square$ & $\square$ & $\square$ & $\square$ & $\square$ \\
\hline
\end{tabular}

1. Did you feel you wanted more, less or no support from the PLAD?

a) More help?

b) Less help?

c) No device?

Why?

2. Did the PLAD interfere with any aspect of completing the task?

3. Would you be comfortable wearing this device every day? Y / N Why?

4. Please point the locations where you felt the most pressure and rank them between the ranges of $1-10$ for comfort: 


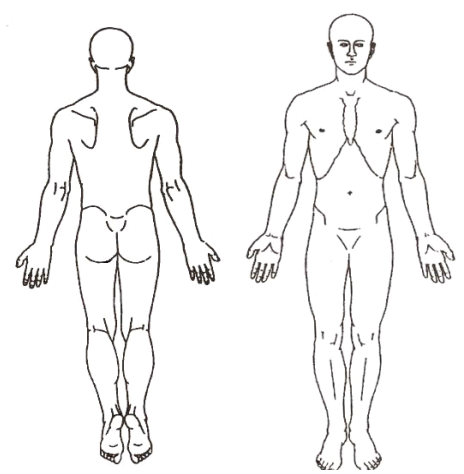

\begin{tabular}{|c|c|c|c|c|c|c|c|c|c|c|}
\hline & $\begin{array}{c}1 \\
\text { Minor } \\
\text { pressure }\end{array}$ & 2 & 3 & 4 & $\begin{array}{c}5 \\
\text { Moderate } \\
\text { pressure }\end{array}$ & 6 & 7 & 8 & 9 & $\begin{array}{c}10 \\
\text { Painful and } \\
\text { Uncomfortable }\end{array}$ \\
\hline $\begin{array}{l}\text { Comfort } \\
\text { Range? }\end{array}$ & & & & & & & & & & \\
\hline
\end{tabular}

5. Please show the locations on your body which you feel had limited range of motion due to wearing the PLAD:

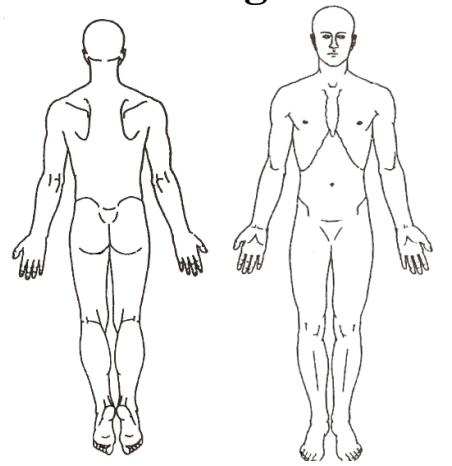

\begin{tabular}{|c|c|c|c|c|c|c|c|c|c|c|}
\hline & $\begin{array}{c}1 \\
\text { Full } \\
\text { RoM }\end{array}$ & 2 & 3 & 4 & $\begin{array}{c}5 \\
\text { Moderately } \\
\text { Hindered } \\
\text { RoM }\end{array}$ & 6 & 7 & 8 & 9 & $\begin{array}{c}10 \\
\text { No RoM }\end{array}$ \\
\hline $\begin{array}{l}\text { ROM } \\
\text { Range? }\end{array}$ & & & & & & & & & & \\
\hline
\end{tabular}

6. Additional Comments/ Concerns? 


\section{APPENDIX G}

$\underline{\text { Root Mean Squared (RMS) Difference: Filtered and Non-Filtered Data }}$

\begin{tabular}{|c|c|c|c|c|c|c|}
\hline & \multicolumn{3}{|c|}{ NO PLAD } & \multicolumn{3}{|c|}{ PLAD } \\
\hline & \multicolumn{6}{|c|}{ SUBJECT 1} \\
\hline & $\underline{\text { No Filter }}$ & $\underline{\text { Filter }}$ & \% Difference & No Filter & $\underline{\text { Filter }}$ & \% Difference \\
\hline RTES & 0.0354 & 0.0343 & 3.1993 & 0.0292 & 0.0286 & 2.3229 \\
\hline RLES & 0.0991 & 0.0971 & 2.1237 & 0.0914 & 0.0896 & 1.9837 \\
\hline RRA & 0.0200 & 0.0178 & 11.7832 & 0.0176 & 0.0168 & 4.5406 \\
\hline LRA & 0.0550 & 0.0534 & 3.0053 & 0.0214 & 0.0208 & 3.2552 \\
\hline LLES & 0.0917 & 0.0897 & 2.1307 & 0.0749 & 0.0735 & 1.8025 \\
\hline LTES & 0.0689 & 0.0676 & 1.9150 & 0.0657 & 0.0645 & 1.8144 \\
\hline \multirow[t]{3}{*}{ Average } & & & 4.0262 & & & 2.6199 \\
\hline & \multicolumn{6}{|c|}{ SUBJECT 2} \\
\hline & No Filter & $\underline{\text { Filter }}$ & \% Difference & No Filter & $\underline{\text { Filter }}$ & \% Difference \\
\hline RTES & 0.0625 & $\overline{0.0613}$ & 1.9320 & 0.0482 & $\overline{0.0475}$ & 1.6362 \\
\hline RLES & 0.1341 & 0.1308 & 2.4390 & 0.0435 & 0.0424 & 2.4187 \\
\hline RRA & 0.0232 & 0.0225 & 3.3155 & 0.0332 & 0.0325 & 2.1529 \\
\hline LRA & 0.0274 & 0.0268 & 2.2906 & 0.0643 & 0.0633 & 1.5295 \\
\hline LLES & 0.1241 & 0.1217 & 1.9712 & 0.1300 & 0.1278 & 1.6970 \\
\hline LTES & 0.0778 & 0.0763 & 1.9383 & 0.0741 & 0.0728 & 1.8366 \\
\hline \multirow[t]{3}{*}{ Average } & & & 2.3144 & & & 1.8785 \\
\hline & \multicolumn{6}{|c|}{ SUBJECT 3} \\
\hline & No Filter & $\underline{\text { Filter }}$ & \% Difference & No Filter & $\underline{\text { Filter }}$ & \% Difference \\
\hline RTES & 0.0467 & 0.0456 & 2.4828 & 0.0446 & 0.0436 & 2.3034 \\
\hline RLES & 0.0431 & 0.0421 & 2.4418 & 0.0614 & 0.0600 & 2.2438 \\
\hline RRA & 0.0701 & 0.0687 & 2.0184 & 0.0444 & 0.0437 & 1.6470 \\
\hline LRA & 0.0261 & 0.0250 & 4.2914 & 0.0482 & 0.0477 & 1.1982 \\
\hline LLES & 0.0488 & 0.0477 & 2.3095 & 0.0419 & 0.0407 & 2.8419 \\
\hline LTES & 0.0649 & 0.0638 & 1.7646 & 0.0609 & 0.0598 & 1.7876 \\
\hline \multirow[t]{3}{*}{ Average } & & & 2.5514 & & & 2.0037 \\
\hline & \multicolumn{6}{|c|}{ SUBJECT 4} \\
\hline & $\underline{\text { No Filter }}$ & $\underline{\text { Filter }}$ & \% Difference & No Filter & $\underline{\text { Filter }}$ & \% Difference \\
\hline RTES & 0.0644 & 0.0631 & 2.0920 & 0.0520 & 0.0508 & 2.2941 \\
\hline RLES & 0.1192 & 0.1164 & 2.4520 & 0.0937 & 0.0915 & 2.3254 \\
\hline RRA & 0.0279 & 0.0269 & 3.7735 & 0.0227 & 0.0220 & 3.0680 \\
\hline LRA & 0.0305 & 0.0293 & 4.0685 & 0.0334 & 0.0328 & 1.7793 \\
\hline LLES & 0.1454 & 0.1417 & 2.5859 & 0.1913 & 0.1866 & 2.4868 \\
\hline LTES & 0.1069 & 0.1045 & 2.3226 & 0.1063 & 0.1040 & 2.1740 \\
\hline \multirow[t]{3}{*}{ Average } & & & 2.8824 & & & 2.3546 \\
\hline & \multicolumn{6}{|c|}{ SUBJECT 5} \\
\hline & No Filter & $\underline{\text { Filter }}$ & \% Difference & No Filter & $\underline{\text { Filter }}$ & \% Difference \\
\hline RTES & 0.0336 & 0.0329 & 2.1588 & 0.0318 & 0.0306 & 3.8608 \\
\hline RLES & 0.0555 & 0.0542 & 2.4729 & 0.0479 & 0.0467 & 2.4642 \\
\hline RRA & 0.0203 & 0.0196 & 3.6900 & 0.0278 & 0.0270 & 3.1178 \\
\hline LRA & 0.0269 & 0.0263 & 2.2731 & 0.0249 & 0.0243 & 2.3565 \\
\hline LLES & 0.0545 & 0.0532 & 2.4324 & 0.0720 & 0.0702 & 2.5586 \\
\hline LTES & 0.0355 & 0.0348 & 2.1091 & 0.0348 & 0.0328 & 5.7636 \\
\hline \multirow[t]{3}{*}{ Average } & & & 2.5227 & & & 3.3536 \\
\hline & \multicolumn{6}{|c|}{ SUBJECT 6} \\
\hline & No Filter & $\underline{\text { Filter }}$ & \% Difference & No Filter & Filter & \% Difference \\
\hline RTES & 0.0613 & 0.0602 & 1.9059 & 0.0648 & 0.0636 & 1.8345 \\
\hline RLES & 0.0896 & 0.0883 & 1.4421 & 0.0597 & 0.0586 & 1.7907 \\
\hline RRA & 0.0266 & 0.0259 & 2.6536 & 0.0229 & 0.0222 & 2.9005 \\
\hline
\end{tabular}




\begin{tabular}{|c|c|c|c|c|c|c|}
\hline LRA & 0.0290 & 0.0285 & 1.9090 & 0.0419 & 0.0411 & 1.8437 \\
\hline LLES & 0.0851 & 0.0833 & 2.2301 & 0.0793 & 0.0777 & 2.0337 \\
\hline LTES & 0.1142 & 0.1123 & 1.6391 & 0.0703 & 0.0690 & 1.7353 \\
\hline \multirow[t]{3}{*}{ Average } & & & 1.9633 & & & 2.0231 \\
\hline & \multicolumn{6}{|c|}{ SUBJECT 7} \\
\hline & No Filter & Filter & \% Difference & No Filter & Filter & \% Difference \\
\hline RTES & 0.0440 & 0.0431 & 1.9326 & 0.0632 & 0.0618 & 2.2406 \\
\hline RLES & 0.1329 & 0.1299 & 2.3049 & 0.1145 & 0.1120 & 2.1890 \\
\hline RRA & 0.0226 & 0.0219 & 3.2153 & 0.0185 & 0.0178 & 3.5304 \\
\hline LRA & 0.0192 & 0.0185 & 3.8964 & 0.0204 & 0.0196 & 3.9785 \\
\hline LLES & 0.0986 & 0.0961 & 2.5555 & 0.0825 & 0.0805 & 2.4669 \\
\hline LTES & 0.0615 & 0.0603 & 1.8895 & 0.0538 & 0.0526 & 2.3418 \\
\hline \multirow[t]{3}{*}{ Average } & & & 2.6323 & & & 2.7912 \\
\hline & \multicolumn{6}{|c|}{ SUBJECT 8} \\
\hline & No Filter & $\underline{\text { Filter }}$ & \% Difference & No Filter & $\underline{\text { Filter }}$ & \% Difference \\
\hline RTES & 0.0257 & 0.0250 & 2.7496 & 0.0292 & 0.0285 & 2.4317 \\
\hline RLES & 0.0335 & 0.0327 & 2.4654 & 0.0413 & 0.0404 & 2.1391 \\
\hline RRA & 0.0213 & 0.0201 & 5.5433 & 0.0275 & 0.0267 & 3.0148 \\
\hline LRA & 0.0239 & 0.0231 & 3.1846 & 0.0227 & 0.0220 & 3.0285 \\
\hline LLES & 0.0482 & 0.0473 & 1.9253 & 0.0873 & 0.0855 & 2.0465 \\
\hline LTES & 0.0271 & 0.0264 & 2.5314 & 0.0297 & 0.0291 & 2.0226 \\
\hline \multirow[t]{3}{*}{ Average } & & & 3.0666 & & & 2.4472 \\
\hline & \multicolumn{6}{|c|}{ SUBJECT 9} \\
\hline & $\underline{\text { No Filter }}$ & $\underline{\text { Filter }}$ & \% Difference & $\underline{\text { No Filter }}$ & $\underline{\text { Filter }}$ & \% Difference \\
\hline RTES & 0.0271 & 0.0259 & 4.4158 & 0.0217 & 0.0211 & 3.0105 \\
\hline RLES & 0.0582 & 0.0569 & 2.2949 & 0.0523 & 0.0510 & 2.4586 \\
\hline RRA & 0.0246 & 0.0233 & 5.4372 & 0.0222 & 0.0213 & 3.8296 \\
\hline LRA & 0.0283 & 0.0276 & 2.5055 & 0.0334 & 0.0326 & 2.3968 \\
\hline LLES & 0.0789 & 0.0772 & 2.1790 & 0.0882 & 0.0862 & 2.3123 \\
\hline LTES & 0.0713 & 0.0701 & 1.6212 & 0.0468 & 0.0460 & 1.6479 \\
\hline \multirow[t]{3}{*}{ Average } & & & 3.0756 & & & 2.6093 \\
\hline & \multicolumn{6}{|c|}{ SUBJECT 10} \\
\hline & $\underline{\text { No Filter }}$ & $\underline{\text { Filter }}$ & $\%$ Difference & No Filter & $\underline{\text { Filter }}$ & \% Difference \\
\hline RTES & 0.0439 & 0.0429 & 2.3557 & 0.0450 & 0.0440 & 2.2234 \\
\hline RLES & 0.0533 & 0.0522 & 2.1180 & 0.0451 & 0.0442 & 2.0057 \\
\hline RRA & 0.0185 & 0.0176 & 5.0011 & 0.0157 & 0.0150 & 4.7145 \\
\hline LRA & 0.0165 & 0.0158 & 3.8981 & 0.0182 & 0.0176 & 3.7497 \\
\hline LLES & 0.0475 & 0.0460 & 3.2187 & 0.0479 & 0.0464 & 3.1225 \\
\hline LTES & 0.0377 & 0.0367 & 2.5477 & 0.0396 & 0.0388 & 1.9895 \\
\hline Average & & & 3.1899 & & & 2.9676 \\
\hline $\begin{array}{c}\text { Total } \\
\text { Average }\end{array}$ & & & 2.8225 & & & 2.5049 \\
\hline
\end{tabular}




\section{APPENDIX H}

Trial 1-12 (Time) Difference: ANOVA Results for Thoracic Erector Spinae

\begin{tabular}{|c|c|c|c|c|c|c|}
\hline Source & $\begin{array}{c}\text { Type III Sum } \\
\text { of Squares }\end{array}$ & $\begin{array}{c}\text { Degrees of } \\
\text { Freedom }\end{array}$ & $\begin{array}{c}\text { Mean } \\
\text { Square }\end{array}$ & F-Statistic & P-Value \\
& $\begin{array}{c}\text { Assumed } \\
\text { Greenhouse- } \\
\text { Geisser } \\
\text { Huynh-Feldt }\end{array}$ & 0.025 & 11.000 & 0.002 & 1.070 & 0.393 \\
& 0.025 & 3.822 & 0.007 & 1.070 & 0.385 \\
& Lower-bound & 0.025 & 6.994 & 0.004 & 1.070 & 0.393 \\
\hline \multirow{3}{*}{ Error(Time) } & $\begin{array}{c}\text { Sphericity } \\
\text { Assumed }\end{array}$ & 0.210 & 99.000 & 0.002 & & \\
& Greenhouse- & & & & & \\
& Geisser & 0.210 & 34.394 & 0.006 & & \\
& Huynh-Feldt & 0.210 & 62.943 & 0.003 & & \\
& Lower-bound & 0.210 & 9.000 & 0.023 & & \\
\hline
\end{tabular}

